\title{
Working
}

Paper 


\section{External Conditions and \\ Debt Sustainability in Latin America}

Gustavo Adler and Sebastián Sosa 


\title{
IMF Working Paper
}

Western Hemisphere Department

\section{External Conditions and Debt Sustainability in Latin America* \\ Prepared by Gustavo Adler and Sebastian Sosa}

Authorized for distribution by Dora Iakova

January 2013

\section{This Working Paper should not be reported as representing the views of the IMF.}

The views expressed in this Working Paper are those of the author(s) and do not necessarily represent those of the IMF or IMF policy. Working Papers describe research in progress by the author(s) and are published to elicit comments and to further debate.

\begin{abstract}
Highly favorable external conditions have helped Latin America strengthen its economic fundamentals over the last decade. But, has the region built enough buffers to guard itself from a weakening of the external environment? This paper addresses this question by developing a simple framework that integrates econometric estimates of the effect of global factors on key domestic variables that determine public and external debt dynamics, with the IMF's standard debt sustainability framework. Results suggest that, while some countries in the region are well placed to withstand moderate or even large shocks, many would benefit from having stronger buffers to be in a position to deploy countercyclical policies, especially under tail events. External sustainability, on the other hand, does not appear to be a source of concern for most countries.
\end{abstract}

JEL Classification Numbers: C32, E62, F41, F47, H62, H63

Keywords: public debt, external debt, debt sustainability, Latin America Author's E-Mail Address: gadler@imf.org; ssosa@imf.org

\footnotetext{
* We thank Saúl Lizondo, Miguel Savastano, Charles Kramer, Dora Iakova, Gian Maria Milesi-Ferretti, Luis Cubeddu, Oya Celasun, Ulric Erickson von Allmen, Herman Kamil, Leonardo Martinez, Esteban Vesperoni, participants at the IMF's WHD seminar series, and IMF-WHD country teams for their useful comments and feedback, and Andresa Lagerborg for her excellent research assistance.
} 
I. Introduction

II. A Decade of Falling Public and External Debt, 2003-12 ……...........................................

A. Fiscal sustainability ..........................................................................................

Pre-Lehman Period: 2003-08 ……………………....................................

Post-Lehman Period: 2009-12 ..................................................................

B. External sustainability ………...............................................................

Pre-Lehman Period: 2003-08 ………………………..................................

Post-Lehman Period: 2009-12....................................................................

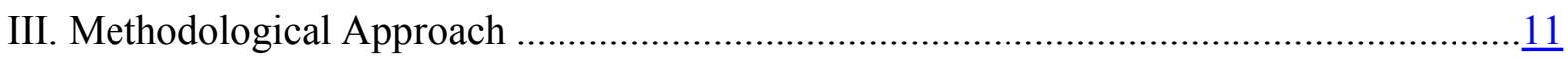

A. Public and External Debt Sustainability Analysis ...............................................11

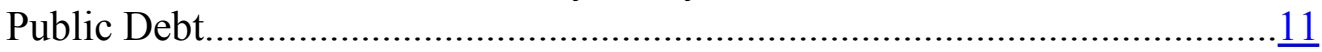

External Debt Dynamics .........................................................................13

B. Conditional Forecasting of Key Domestic Variables: a VAR approach..................14

C. Sovereign Spreads Module...................................................................................

IV. Debt Dynamics Under Alternative Global Scenarios ...................................................16

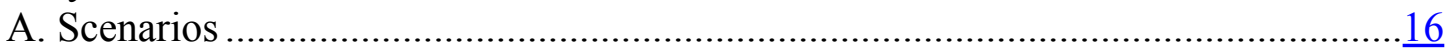

Scenario 1: Temporary Financial Shock ...................................................

Scenario 2: Temporary Real Shock ………………................................

Scenario 3: A Protracted Global Slowdown .................................................17

Scenario 4: A Tail Event...........................................................................

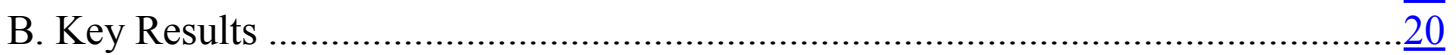

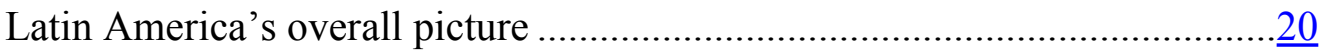

Country-specific results ............................................................................

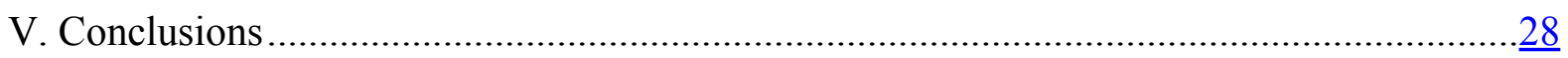

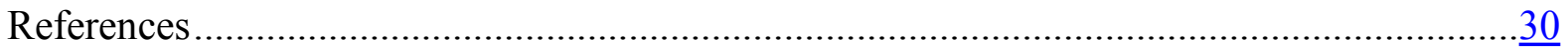

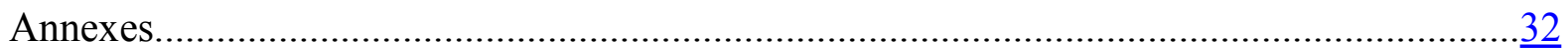

Tables

1. Key Global Assumptions under Alternative Scenarios ................................................... 18

2. Key Domestic Policy Assumptions under Alternative Scenarios ...................................... 


\section{Figures}

1. Latin America: Fey Fiscal Indicators, 2002-12 4

2. Latin America. Key External Indicators, 2002-12 …....................................................

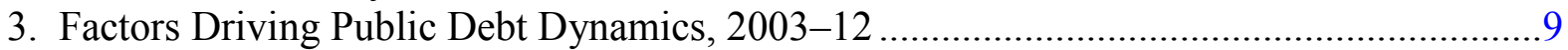

4. Components of Primary Balance Dynamics, 1995-2012 ……………..............................

5. Factors Driving External Debt Dynamics, 2003-12 …................................................. 10

6. Global Variables under Alternative Scenarios, 2003-17 ....................................................18

7. Latin America. Factors Driving Public and External Debt Dynamics under Alternative Global Scenarios, 2003-17

8. Latin America. Public and External Debt under Alternative Scenarios and Policies, 2012-17

9. Key Fiscal Indicators under Different Scenarios, 2012-17

10. Key External Indicators under Different Scenarios, 2012-17 .28 


\section{INTRODUCTION}

Over the last decade Latin America experienced an impressive strengthening of key macroeconomic fundamentals (Figures 1 and 2), especially during the period 2003-08, that ended with the global financial crisis triggered by the bankruptcy of Lehman Brothers. The region not only displayed remarkable improvements in terms of stocks - reducing public and external debt levels, and accumulating public and foreign assets — and flows - improving primary fiscal and current account balances - but also notable changes towards less vulnerable debt structures - reducing the share denominated in foreign currency and extending maturity.

Figure 1. Latin America. Key Fiscal Indicators, 2002-12 1/ (simple average and 20th and 80th percentiles)
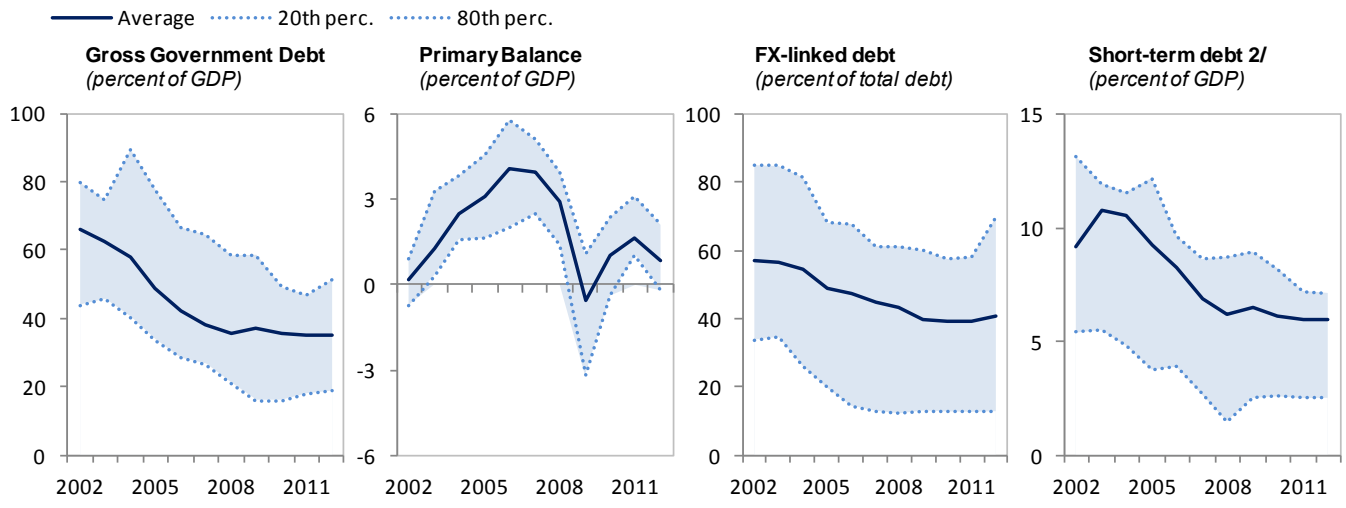

Sources: IMF International Financial Statistics, and country desks.

1/Latin America includes Argentina, Bolivia, Brazil, Chile, Colombia, Ecuador, Mexico, Paraguay, Peru, Uruguay and Venezuel a.

2/Excludes Bolivia and Paraguay.

Figure 2. Latin America. Key External Indicators, 2002-12 1/ (simple average and 20th and 80th percentiles)

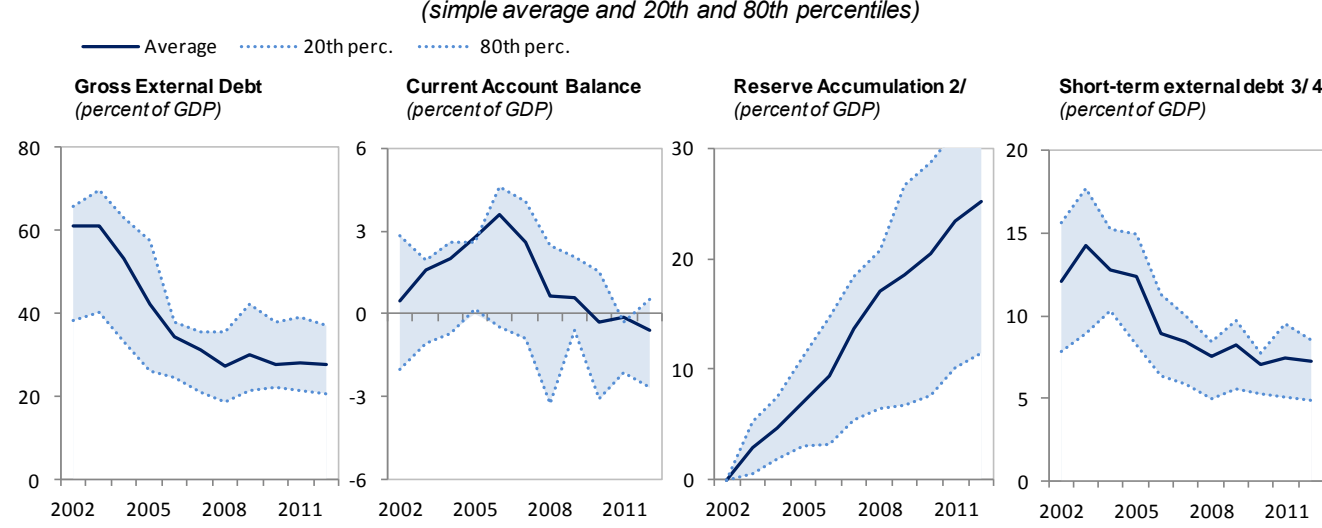

Sources: IMF International Financial Statistics, and country desks.

1/Includes Argentina, Bolivia, Brazil, Chile, Colombia, Ecuador, Mexico, Paraguay, Peru, Uruguay and Venezuela. 2/Cumulative flow of gross international reserves since 2002.

$3 /$ At residual maturity.

4/Excludes Bolivia and Paraguay.

While, undoubtedly, prudent policies played an important role, these gains reflected to a significant extent the highly favorable external environment that the region benefited from during this period - interrupted only temporarily during the 2008-09 international financial crisis and characterized by strong external demand, an unprecedented boom in commodity 
prices, and very benign global financing conditions. However, with prospects of less favorable external conditions going forward, and even the possibility of a sharp deterioration associated with looming risks - e.g., an escalation of the euro area financial crisis - the regional policy debate is focusing on whether the region has taken full advantage of the 'windfall'. In particular: Has the region built enough buffers to guard itself from external shocks? ${ }^{1,2}$

This paper sheds light on this question by studying the link between global variables - such as commodity prices, world growth, and financial market conditions - and a set of domestic variables (GDP growth, trade balance, real exchange rate, and sovereign spreads) that explain most — if not all — of the dynamics of public and external sustainability indicators. To this end, it develops a simple framework that integrates (i) econometric estimates of the effect of exogenous external variables on these key domestic variables with (ii) the IMF's standard framework for debt-sustainability analysis (DSA). This integrated framework allows us to examine the evolution of public and external debt sustainability indicators (both in terms of stocks and flows) under alternative global scenarios; and consequently assess the adequacy of current levels of 'buffers' for eleven Latin American countries. ${ }^{3}$

The study entails a methodological contribution to the existing IMF framework for public and external DSA, as the latter is currently not equipped to assess how changes in external conditions affect debt dynamics, given its lack of linkages between global and domestic variables. ${ }^{4}$ Moreover, stress tests under the traditional DSA framework consider shocks to certain variables in isolation (output growth, interest rates, etc.), without taking into account the correlation among shocks and the joint dynamic response of some of these variables.

The paper relates to a growing literature seeking to improve debt-sustainability analysis. Most of these recent contributions (Celasun et al, 2006; Cherif and Hasanov, 2012; Favero and Giavazzi, 2007 and 2009; Kawakami and Romeu, 2011; and Tanner and Samake, 2008) have focused primarily on the joint stochastic properties of shocks, aiming at developing a probabilistic approach to DSA, including by incorporating explicit fiscal reaction functions to take into account the policy response to shocks and the feedback effects of fiscal policy on macroeconomic variables. Like our paper, they rely on a methodology that combines VAR models with debt feedback to assess the impact of a set of macroeconomic shocks on public debt dynamics. These studies, however, do not examine the impact of specific external shocks on debt dynamics - which are highly relevant for Latin America, especially for those economies that are highly financially integrated with international capital markets and/or rely

\footnotetext{
${ }^{1}$ The paper focuses on debt sustainability from the perspective of potential external shocks, leaving aside other objectives or possible shocks that could shape the desirability of larger buffers (e.g., management of nonrenewable resources, buffers to deal with possible contingent liabilities arising from private sector excesses, etc.). The paper also leaves aside issues related to the appropriateness of the fiscal stance on cyclical grounds.

${ }^{2}$ For a first look into this issue see IMF (2012a).

${ }^{3}$ The sample includes all South American economies (except Guyana and Suriname) and Mexico, representing about 95 percent of the region's GDP.

${ }^{4}$ For details on the IMF's debt sustainability framework, see IMF (2002, 2003. 2005, 2011, and 2012b).
} 
heavily on commodity exports. ${ }^{5}$ In addition, most of these papers focus on a limited set of countries, and solely on public debt—without looking into external debt. Our paper contributes to the literature by filling this gap.

Our main results suggest that current fiscal positions in the region are, on average, adequate to deal with temporary and even moderate protracted external shocks, although fiscal space to face more severe protracted shocks could be limited. At the same time, there are important differences across countries especially with respect to their ability to deal with protracted shocks, with countries broadly falling into three groups: (i) a group (Argentina and Venezuela) that would face considerable fiscal sustainability issues under large shocks, and varying constraints even under moderate ones; (ii) a second group (Brazil, Ecuador, Mexico and Uruguay) that could manage moderate shocks but would benefit from building additional buffers to be in a position to deploy countercyclical policies under adverse scenarios, without reaching debt levels that could raise concerns about fiscal sustainability; and (iii) a third group (Bolivia, Chile, Paraguay, Peru and to a lesser extent Colombia) with a relatively solid position to withstand sizeable shocks - even responding with expansionary policies - without putting fiscal solvency at risk. Overall, these results suggest that many countries in the region would benefit from building further fiscal space while favorable conditions last, in order to be in a position to actively use fiscal policy should the external environment deteriorate markedly. In terms of the external position, our results indicate that, despite evidence of a recent widening in current account deficits, external sustainability does not appear to be a source of concern for Latin America in general.

The paper proceeds as follows: the next section presents key stylized facts about the factors behind the declining debt ratios in the region over the last decade. Section III describes the methodological approach used to examine how fiscal and external sustainability indicators would be affected under alternative (downside) scenarios. Section IV describes the scenarios under consideration and presents the main results, deriving an assessment of the adequacy of current buffers. Section V concludes with the key takeaways.

\section{A Decade of Falling Public and External Debt, 2003-12}

\section{A. Fiscal sustainability}

We first take a historical view at the drivers of public debt dynamics over the last decade, relying on the (accounting) decomposition offered by the IMF's public DSA framework. ${ }^{6}$ For consistency across countries, we focus on general government gross debt, as reported by the World Economic Outlook. In most cases, this level of consolidation appropriately reflects the

\footnotetext{
${ }^{5}$ The role of external conditions in driving macroeconomic outcomes in Latin America has been studied extensively in the literature (see, for instance, Osterholm and Zettelmeyer, 2008, and Izquierdo, Romero, and Talvi, 2007) but without exploring the implications for either fiscal or external sustainability.

${ }^{6}$ It is important to highlight that the contributions of different factors to the changes in debt-to-GDP ratios, as presented in the IMF's DSA framework, entail a simplification, as there are multiple interactions (nonlinearities) among the different factors, as described in section III.
} 
level of public indebtedness. ${ }^{7}$ In addition, while the focus on gross rather than net debt implies overlooking the recent accumulation of assets by the public sector in certain countries, this is unlikely to distort the results as the asset accumulation, when sizeable, has tended to coincide with low levels of gross debt, thus not changing the general conclusions of the sustainability assessment.

\section{Pre-Lehman Period: 2003-08}

Between 2003 and 2008, Latin America witnessed a steep improvement of its fiscal sustainability indicators, most notably bringing public debt-to-GDP ratios down, on average, by about 30 percentage points of GDP (Figure 3 ). The decline was primarily driven by a combination of the direct effect of rapid economic growth and sizeable primary surpluses. Negative real interest rates also appeared to have played a role in the downward debt dynamics in some countries. ${ }^{8}$ Interestingly, the marked real exchange rate appreciation observed during this period contributed only marginally to reduce debt levels. ${ }^{9}$

There are, however, visible differences across countries in the region, particularly regarding how they managed the rapidly raising revenues during this period. Indeed, the observed contribution of primary surpluses is not necessarily a reflection of fiscal discipline in all countries, as this was a period of economic bonanza characterized by strong growth and markedly higher commodity prices, and therefore a substantial increase in fiscal revenues. ${ }^{10}$

In the LA7 group (encompassing Brazil, Chile, Colombia, Mexico, Paraguay, Peru, and Uruguay $^{11}$, a drop of 20 percentage points of GDP in public debt ratios reflected mainly the contributions of primary surpluses and rapid real GDP growth, with the former being the result of real public expenditures growing at a slower pace than booming revenues - and generally slower than potential GDP growth-(Figure 4). Chile, Colombia, Paraguay, and Peru displayed particularly restrained expenditure policies. ${ }^{12} \mathrm{~A}$ decomposition between

\footnotetext{
${ }^{7}$ In the case of Argentina, intra-public sector claims (between the central government and public agencies like the Central Bank, ANSeS, etc) have grown in recent years.

${ }^{8}$ The accumulation of (gross) foreign assets in different types of sovereign funds was a key (partially) offsetting factor.

${ }^{9}$ This reflects several factors: (i) some countries with relatively high foreign currency denominated debt (Bolivia and Peru) allowed for limited exchange rate movements during this period; (ii) in others (Brazil), most of the appreciation occurred only after public debt had shifted markedly towards local currency instruments; (iii) in others (Chile and Mexico) foreign currency debt represents a very low share of total public debt; and (iv) in Uruguay, the fact that the cumulative contributions are computed from 2002 onwards, implies including the sharp depreciation of 2002-03.
}

${ }^{10}$ See IDB (2008) for an interesting discussion on this issue, Cespedes and Velasco (2011) for a comparison of fiscal behavior during the recent boom relative to previous commodity price booms, and Frankel et al (2011) for a broader analysis of emerging markets' 'graduation' from fiscal procyclicality.

${ }^{11}$ Countries are grouped based on similarities in terms of the role played by the different factors in driving the debt dynamics.

${ }^{12}$ See country-by-country Annex Figures A1-A4. 
commodity and non-commodity related revenues suggests that the extraordinary increase in revenues arose primarily from the commodity sector, as non-commodity revenues in these economies increased in line with real GDP at rates that, while higher than those observed in the previous decade, were broadly in line with long-term potential. ${ }^{13}$

The rest of Latin America also experienced a remarkable fall in indebtedness during this period (averaging about 45 percentage points of GDP), although starting from much higher debt levels. ${ }^{14}$ In these cases, the decline was mostly driven by the direct effect of the economic boom on output (with GDP growth considerably above long-term potential, except in Bolivia) and by negative real interest rates. ${ }^{15}$ While primary balances also played an important role in reducing debt ratios, the extent of savings of the booming revenues (derived both from direct taxation on the commodity sector and from taxes on broad economic activity) was limited. Indeed, real public expenditure grew at a faster pace than potential GDP growth and even faster than observed output growth. As a result, and in contrast to the LA7 group, these countries spent a substantial fraction of the revenue boom. ${ }^{16}$

\section{Post-Lehman Period: 2009-12}

Public debt trends changed markedly in 2009, reflecting the effects of the global crisis. Since then, Latin America's debt ratios have remained broadly stable on average, at around 35 percent of GDP, mostly on account of no further contributions from primary balances. Again, there is a stark difference between LA7 and the rest of Latin America during this period.

After implementing significant fiscal stimulus during 2009-10, LA7 countries have been making efforts to consolidate their fiscal positions and recompose primary surpluses (most noticeably Chile and Peru), although the recent improvements in primary balances partly reflect the rebound in commodity-related revenues in some cases. The result has been a (modest) resumption of the declining trend in debt ratios in most countries of this group.

The rest of Latin America, in contrast, has shown a sustained deterioration in primary balances since 2009, turning primary surpluses into deficits and thus contributing to push debt ratios upwards. ${ }^{17}$ This deterioration has taken place despite the recovery of commodityrelated revenues, as expenditure has continued to grow rapidly (significantly faster than potential GDP and even current GDP growth). In some of these economies, negative real interest rates on public debt have continued to play an important role supporting debt reduction (Argentina and Bolivia) or containing its increase (Venezuela).

\footnotetext{
${ }^{13}$ For a discussion on the importance of commodity revenues in resource rich countries, see IMF (2012).

${ }^{14}$ This group of countries includes Argentina, Bolivia, Ecuador, and Venezuela.

${ }^{15}$ Argentina's debt restructuring in 2005 was a major factor driving debt ratios down. Bolivia also benefitted from a debt relief program, of roughly 25 percent of GDP, in 2006.

${ }^{16}$ The analysis of the composition of spending of the revenue windfall, or whether different levels of spending were optimal from a social point of view, are beyond the scope of this paper, as our interest lies primarily on the macro implications for debt sustainability.
}

${ }^{17}$ Bolivia, which maintained primary surpluses in this period, is an exception. 
Figure 3. Factors Driving Public Debt Dynamics, 2003-12 1/

(cumulative contributions since 2002, in percent of GDP, simple averages)

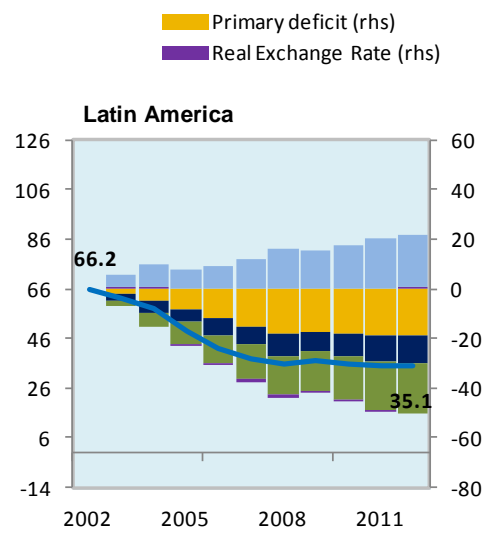

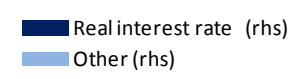

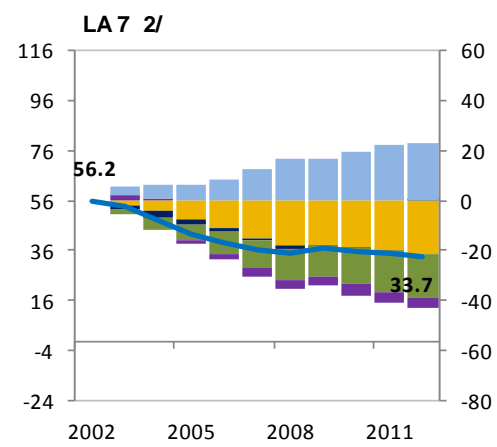

Real GDP growth (rhs)

Public Debt

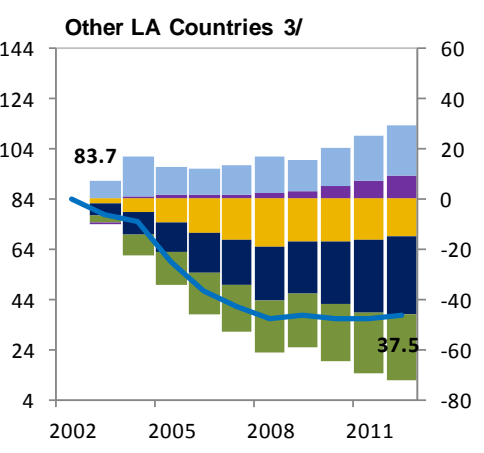

Sources: IMF International Financial Statistics, and authors' calculations.

1/Main factors driving public debt dynamics as identified in IMF's DSA framework.

2/Includes Brazil, Chile, Colombia, Mexico, Paraguay, Peru, and Uruguay.

3 / Includes Argentina, Bolivia, Ecuador, and Venezuela.

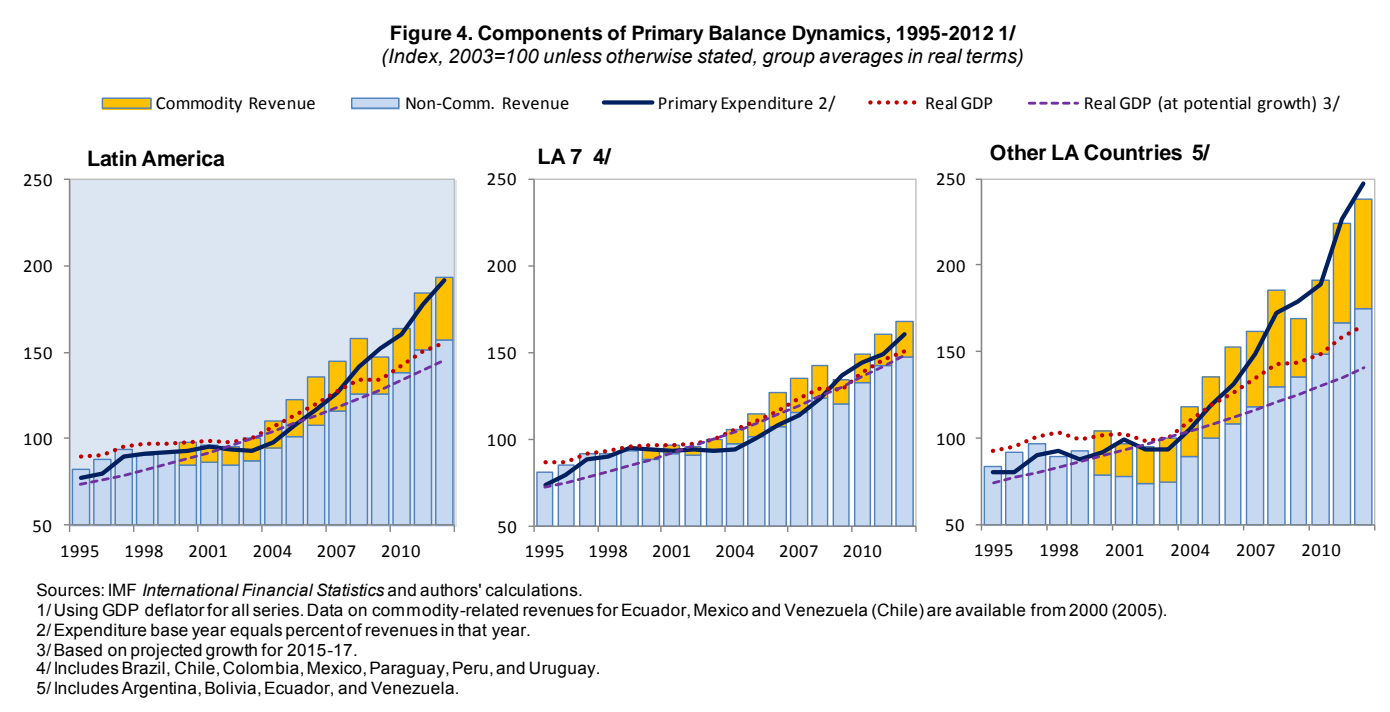

\section{B. External sustainability}

\section{Pre-Lehman Period: 2003-08}

The dynamics of external debt during this period shares some of the trends observed for public debt. The region as a whole made significant progress in bringing down external debtto-GDP ratios in this period, reducing them by more than 30 percentage points of GDP on average (Figure 5). Moreover, this sharp improvement was accompanied by a sizeable accumulation of foreign assets (reaching nearly 70 percent of GDP on a cumulative basis). ${ }^{18}$ However, once again, there are visible differences between the two groups of countries mentioned above.

\footnotetext{
${ }^{18}$ This reflected both public policies oriented to the accumulation of international reserves and assets under sovereign funds as well as private sector portfolio allocations (e.g., pension funds accumulating assets abroad).
} 
In the $L A 7$ group, external debt declined by 25 percent of GDP, primarily on account of the significant real appreciation and external financing in the form of non-debt flows (especially FDI), combined with moderate current account surpluses.

The rest of Latin America (all of which are heavy commodity exporters) witnessed an even more remarkable drop in external indebtedness (reaching about 50 percentage points of GDP), although starting from much higher levels. This reduction was mainly explained by large current account surpluses - reflecting highly favorable terms of trade - as well as sizeable real exchange rate appreciation. Unlike for the LA7 group, the role of non-debt flows was quite limited. These economies accumulated large amounts of foreign assets (largely by the public sector in Bolivia and Ecuador, while mostly by the private sector in Argentina and Venezuela).

\section{Post-Lehman Period: 2009-12}

In 2009, however, the previous downward trend came to a halt - mainly reflecting a slowdown in real appreciation and a weakening of current account balances-leaving debt ratios at about 28-30 percent of GDP for both groups of countries.

In sum, despite the evident deterioration in debt trends after the Lehman event, the improvement in terms of both public and external debt sustainability over the last decade has been remarkable. At the same time, current debt levels are still, in some cases, relatively high and close to thresholds that are typically considered risky. In this context, and being many of these economies highly sensitive to external conditions, it is not obvious the extent to which countries across Latin America are well placed to withstand a significant deterioration in the external environment.

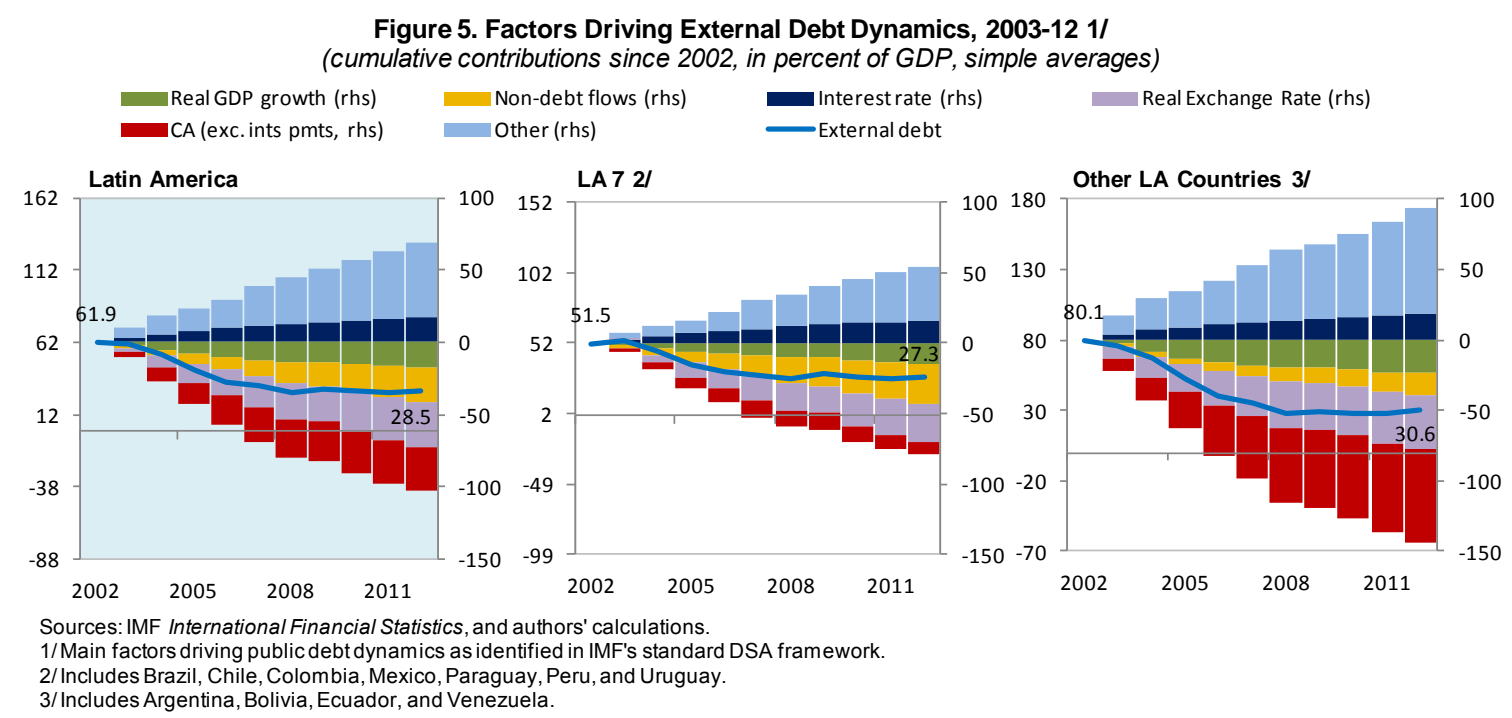




\section{Methodological ApProach}

\section{A. Public and External Debt Sustainability Analysis}

This section describes the framework to examine how external conditions affect, through their impact on key domestic variables, the dynamics of public and external debt ratios. ${ }^{19}$ The framework entails mapping, by means or econometric estimates, how shocks to key global variables - commodity prices, world growth, and financial market conditions - affect a set of domestic variables - GDP growth, trade balance, real exchange rate, and sovereign spreadsthat enter into the laws of motion of public and external debt.

Illustration of Integrated Public and External Debt Sustainability Approach ${ }^{1}$

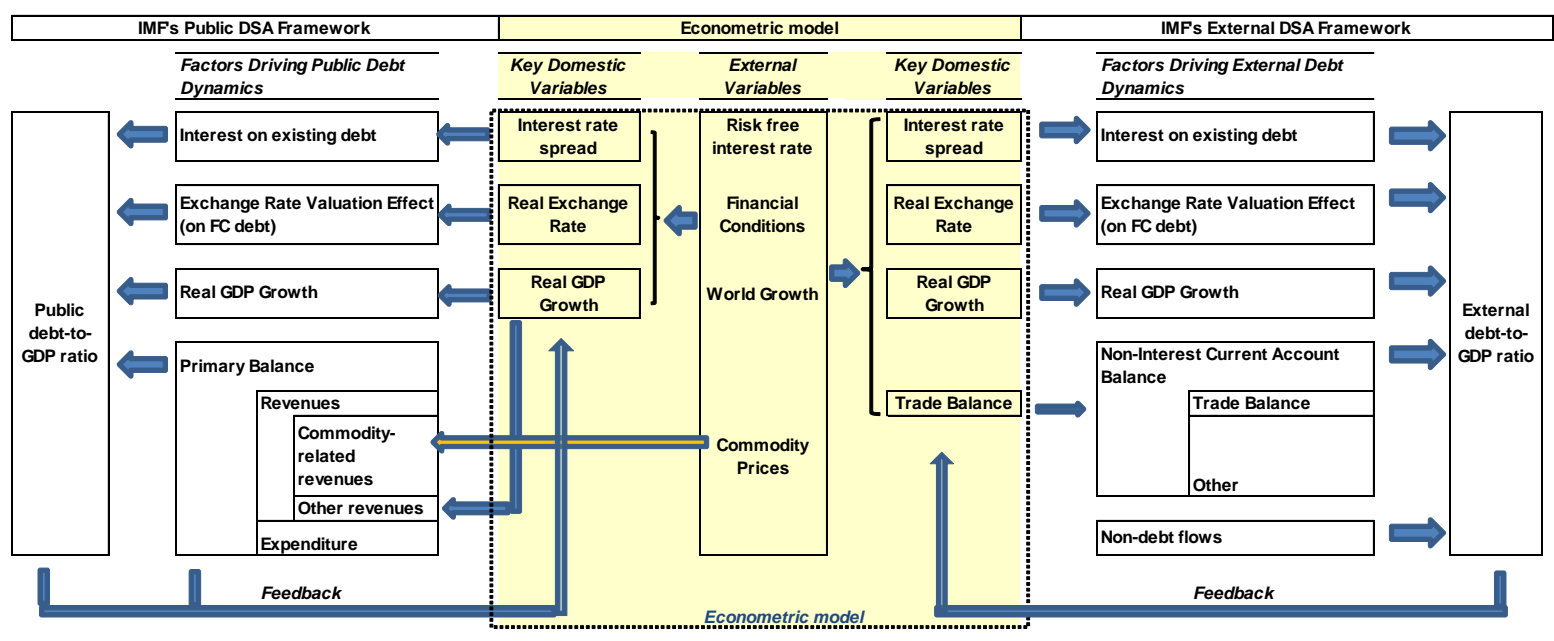

${ }^{1}$ The diagram presents a simplified illustration of the integrated framew ork for public and external debt sustainability. Details and underlying assumptions are discussed in section Ill.

Once the econometric model is estimated and integrated with the DSA framework, one can undertake scenario analysis to evaluate the adequacy of the current fiscal or external position, by generating conditional forecasts of the endogenous domestic variables.

To start, we show how the law of motion of debt ratios can be expressed as a function of the small set of domestic variables mentioned above.

\section{Public Debt}

Consider the following equation that governs the path of public debt (in nominal, local currency, terms):

$$
D_{j, t}=E_{j, t} D_{j, t-1}^{F C}\left(1+r_{j, t-1}\right)+D_{j, t-1}^{L C}\left(1+i_{j, t-1}\right)-P B_{j, t}
$$

where $D_{j, t}$ is country $j$ 's nominal stock of public debt in period $t ; D_{j, t-1}^{F C}\left(D_{j, t-1}^{L C}\right)$ is the stock of foreign (domestic) currency-denominated debt; $E_{j, t}$ is the nominal exchange rate vis-à-vis the

\footnotetext{
${ }^{19}$ As in the IMF's standard debt sustainability framework, we focus on general government gross debt.
} 
U.S. dollar; $r_{j, t-1}$ and $i_{j, t-1}$ are the average interest rates on foreign and local currency debt respectively, and $P B_{j, t}$ is the nominal primary fiscal balance.

It is evident from the non-linearity of this equation that it is not possible to fully isolate the contribution of each of the main economic variables to the change in public debt. One can, however, write this equation in a way that approximates such contributions (as done in the IMF's standard DSA).

Denote $x_{t} \equiv X_{t} / G D P_{t}$ as a nominal variable $X_{t}$ expressed in percent of GDP; $i_{j, t}^{e}=$ $\alpha_{j, t} i_{j, t}+\left(1-\alpha_{j, t}\right) r_{j, t}$, as the effective average interest rate; $\pi_{j, t}$ as domestic inflation (GDP deflator); $g_{j, t}$ as real GDP growth and $\varepsilon_{j, t}$ as the nominal depreciation of the domestic currency vis-à-vis the US dollar. Then, defining $\alpha_{j, t}=D_{j, t}^{L C} / D_{j, t}$ as the share of localcurrency denominated debt, one can reduce equation (1) to a small number of terms:

$$
\Delta d_{j, t}=\left[i_{j, t-1}^{e}-\pi_{j, t}\left(1+g_{j, t}\right)\right] \theta_{j, t}-\left(g_{j, t}\right) \theta_{j, t}+\left[(1-\alpha)\left(1+r_{j, t}\right) \varepsilon_{j, t}\right] \theta_{j, t}-p b_{j, t}
$$

where $\theta_{j, t}=\left\{\frac{d_{j, t-1}}{\left(1+g_{j, t}\right)\left(1+\pi_{j, t}\right)}\right\}$. The first term of equation (2) broadly captures the (accounting) contribution of the real interest rate; the second term captures the effect arising from real GDP growth; the third term captures the impact of exchange rate movements (through valuation effects on foreign currency-denominated debt); and the last term reflects the contribution of the primary balance.

Taking into account the share of debt falling due in the current period $\left(\gamma_{j, t-1}\right)$ and subsequent periods $\left(1-\gamma_{j, t-1}\right)$, we can model the dynamics of the average interest rate as a function of marginal interest rates:

$$
i_{j, t}^{e}=\left(1-\gamma_{j, t}\right) i_{j, t-1}^{e}+\gamma_{j, t-1}\left\{\alpha i_{j, t}+(1-\alpha) r_{j, t}\right\}
$$

Assume the following pass-through structure from (global) risk-free interest rates $\left(r_{t}^{*}\right)$ and sovereign spreads $\left(s_{j, t}\right)$ into domestic interest rates $\left(i_{j, t}\right)$. That is, $\Delta i_{j, t}=\Delta r_{t}^{*}+\Delta s_{j, t}$. Assume also that real and nominal exchange rate shocks map one-to-one: $\Delta \ln \left(\right.$ reer $\left._{j, t}\right)=-\varepsilon_{j, t} \cdot{ }^{20}$

From equations (2) and (3), this set of (relatively innocuous) assumptions and from the fact that $r_{j, t}=r_{t}^{*}+s_{j, t}$, one can show that dynamics of the public debt-to-GDP ratio is governed by the behavior of only four (endogenous) domestic variables: $\{s, g$, reer, $p b\}$.

Furthermore, one can model the primary balance in a simple fashion by decomposing it into commodity revenues, non-commodity revenues, and expenditures (all in percent of GDP):

\footnotetext{
${ }^{20}$ This implies that both $\pi_{t}$ and $\pi_{t}^{*}$ (international inflation) are invariant across the scenarios under consideration, so that movements in the real effective exchange rate mirror those of the nominal exchange rate.
} 


$$
p b=r e v^{C}+r e v^{N C}-\exp
$$

Subsequently, commodity revenues can be modeled as a function of the corresponding commodity prices:

$$
r e v_{S c e n}^{C}=\operatorname{rev}_{B L}^{C} *\left(\frac{P_{S c e n}^{C}}{P_{B L}^{C}}\right)
$$

where $r e v_{S c e n}^{C}\left(\operatorname{rev}_{B L}^{C}\right)$ are commodity-related revenues and $P_{S c e n}^{C}\left(P_{B L}^{C}\right)$ are world commodity prices under a specific scenario (under the baseline).

Finally, a constant non-commodity revenue-to-GDP ratio is assumed (i.e., an elasticity equal to one), such that: $r e v^{N C}=\eta$. Then, the dynamics of the public debt ratio is simply given by four endogenous domestic variables $\{s, g$, reer, exp $\}$ and a set of exogenous global variables.

\section{External Debt Dynamics}

Similarly, to derive the set of variables that determine the path of the external debt-to-GDP ratio, one can start from the law of motion of external debt:

$$
D_{j, t}^{E}=E_{j, t} D_{j, t-1}^{E, F C}\left(1+r_{j, t-1}\right)+D_{j, t-1}^{E, L C}\left(1+i_{j, t-1}\right)-N I C A_{j, t}-N D C F_{j, t}
$$

where $D_{j, t}^{E}$ is the nominal stock of total external debt (expressed in local currency); $D_{j, t-1}^{E, F C}$ $\left(D_{j, t-1}^{E, L C}\right)$ is the stock of foreign (local) currency-denominated debt; $r_{j, t-1}\left(i_{j, t-1}\right)$ is the average interest rate on foreign (local) currency-denominated debt; $N I C A_{j, t}$ is the current account balance excluding interest payments; and $N D C F_{j, t}$ are the non-debt-creating flows (FDI and equity portfolio).

Then, defining $\alpha_{j, t}^{E}=D_{j, t}^{E, L C} / D_{j, t}^{E}$ and $i_{j, t}^{e}=\alpha_{j, t}^{E} i_{j, t}+\left(1-\alpha_{j, t}^{E}\right) r_{j, t}$, we can derive the path of external debt in terms of a small set of factors:

$$
\Delta d_{j, t}^{E}=i_{j, t}^{e} \sigma_{j, t}-g_{j, t} \sigma_{j, t}+\left\{\left(1-\alpha_{j, t}^{E}\right)\left(1+r_{j, t}\right) \varepsilon_{j, t}\right\} \sigma_{j, t}-n i c a_{j, t}-n d c f_{j, t}
$$

where $\sigma_{j, t}=\frac{d_{j, t-1}^{E}}{\left(1+g_{j, t}\right)\left(1+\pi_{j, t}\right)}$. The first term reflects the contribution of interest payments; the second term captures the contribution of real GDP growth; the third component measures the valuation effect arising from movements in the real exchange rate; and the last two terms reflect the contributions of the current account balance (excluding interest payments) and non-debt financing flows respectively.

Modeling the non-interest current account as $N I C A_{j, t}=t b_{t}+\theta$ (where $t b_{t}$ is the trade balance in period $t$ ) and using our previous assumption on the behavior of the real exchange 
rate $\left(\Delta \ln \left(\right.\right.$ reer $\left.\left._{j, t}\right)=-\varepsilon_{j, t}\right)$, the external debt dynamics can be fully characterized by the path of a set of few domestic variables: $\{s, g$, reer, $t b, n d c f\} .^{21}$

Treating $n d c f_{\mathrm{j}}$ as exogenous (as we are primarily interested in externally-triggered shocks), and putting together the systems of equations derived for public and external debt, one can show that both debt ratios are ultimately driven by five domestic variables, $\{s, g, r e e r, t b, \exp \}$, and a set of exogenous global variables. The next section discusses how to estimate the impact of external variables on the first four variables in this set, while the behavior of the last variable (exp) is evaluated under different policy rules.

\section{B. Conditional Forecasting of Key Domestic Variables: a VAR approach}

We estimate country-specific VAR models in order to quantify the sensitivity of the variables (specified above) that characterize debt dynamics to external conditions. Specifically, the VARs are used to obtain forecasts of these domestic variables, conditional on a set of assumed global variables (global scenarios). A key feature of our framework is that primary balances and debt levels are included in the VAR in order to allow feedback effects from these variables to the other domestic variables that determine debt dynamics.

Each (reduced form) country-specific VAR model can be written as:

$$
y_{t}=B(L) y_{t-1}+H(L) z_{t}+u_{t}
$$

where $y_{t}=\left(g_{t} d T B_{t} d \ln \left(\text { reer }_{t}\right)\right)^{\prime}$ is a vector of endogenous variables and $z_{t}=$ $\left(1 g_{t}^{W} \text { vix } P_{t}^{A} P_{t}^{E} P_{t}^{M} p b_{t-1} d_{t-1}^{P}\right)^{\prime}$ is a vector of exogenous variables. The vector $y_{t}$ includes real GDP growth $\left(g_{t}\right)$, the change in the trade balance in percent of GDP $\left(d T B_{t}\right)$, and the (log difference of) the real effective exchange rate $\left(\ln \left(\right.\right.$ reer $\left.\left._{t}\right)\right) .{ }^{22}$ The vector $z_{t}$, in turn, includes global real GDP growth $\left(g^{W}\right)$, the S\&P 500 Chicago Board Options Exchange Market Volatility Index (vix) as a proxy for international financial conditions, ${ }^{23}$ the (log differences of agriculture, energy, and metals prices $\left(P_{t}^{A}, P_{t}^{E}\right.$, and $P_{t}^{M}$ respectively) ${ }^{24}$ the

\footnotetext{
${ }^{21} \mathrm{We}$ focus on the trade balance, rather than the non-interest current account, as the former is if the main driver of the latter and is likely to have more stable relationships with the other key endogenous variables (real exchange rate, real GDP growth, etc).

${ }^{22}$ In the case of countries with a significant fraction of debt denominated in foreign currency (e.g., Bolivia, Ecuador, Paraguay, Peru, and Uruguay), the use of the real effective exchange rate could result in some underestimation of potential valuation effects. At the same time, while the bilateral exchange rate vis-à-vis the U.S. dollar would better capture these effects, their inclusion would significantly complicate the VAR specification.

${ }^{23}$ The VIX index has recently been used as a measure of global uncertainty or financial stress. Bloom (2009), for instance, shows that this volatility index is highly correlated with measures of micro and macro-level uncertainty, including from financial variables. More recently, IMF (2012), Adler and Tovar (2012), and Carrière-Swallow and Céspedes (2011) also used the VIX to measure global uncertainty shocks.

${ }^{24}$ International commodity prices are measured in real terms and stripped of exchange rate effects, as in Adler and Sosa (2011).
} 
primary balance, in percent of GDP $(p b)$, and the debt-to-GDP ratio $\left(d^{p}\right) . B(L)$ and $H(L)$ are lag polynomial matrices, which include up to four lags. ${ }^{25}$

The VAR models are estimated using quarterly data from 1990:Q1 through 2012:Q1. The data sources are primarily the IMF's International Financial Statistics (IFS) and World Economic Outlook (WEO), and Haver Analytics.

It is worth noting that since our main interest resides in obtaining conditional forecasts and not standard VAR tools such as impulse response functions and variance decompositions, there is no need for identification restrictions to recover the structural parameters of the model. Similarly, as our interest is on the conditional forecasting performance of the model during bad external scenarios, specifications are selected based on their out-of-sample forecast power during the Lehman event (Figure A5 in the Annex). ${ }^{26}$

Unlike that of other papers in the literature, our approach does not entail estimating a fiscal reaction function, (i.e., there is no equation for the primary balance). This is deliberate, as our objective is not to obtain alternative debt paths under the assumption that fiscal responses to the negative shocks mirror those of the past-which may have been constrained (or suboptimal) in many cases - but rather under broadly unconstrained (either neutral or countercyclical). ${ }^{27}$ This does not mean that the VAR does not control for the fiscal stance but instead that the primary balance is treated as exogenous for the purpose of estimation only. For projections, the primary balance under alternative scenarios is constructed as follows: revenues are projected based on the forecast for output (conditional on the exogenous path of the foreign variables) and on standard assumptions about the output elasticity of noncommodity revenues. Commodity-related revenues, in turn, are projected based on the exogenously determined path of the relevant commodity prices. On the expenditure side, we consider alternative responses - both neutral and countercyclical (explained in detail later)to the negative shock. This approach allows us to better assess the impact of different components of the primary balance (commodity revenues, revenues linked to economic activity, and expenditure). Finally, as stated before, the primary balance enters the growth equation, so our approach incorporates the feedback effects of different fiscal responses on output.

\footnotetext{
${ }^{25}$ As the global variables included in vector $\boldsymbol{z}$ are exogenous to the model, this approach does not allow to capture correlations among shocks to these variables. However, the assumptions about the path of the global variables under each scenario, discussed in the next section, are based on broad patterns observed in previous episodes of external shocks.

${ }^{26}$ Table A1 in the Annex presents the estimation output of the VARs.

${ }^{27}$ Whether past fiscal policies were socially optimal or not is still a matter of debate. While there is a vast literature trying to explain the sub-optimality of procyclical policies with political economy and capital market frictions, (e.g., Talvi and Vegh, 2005; or Tornell and Lane, 1999) some authors have recently argued that procyclical responses were optimal in the context of countercyclical sovereign spreads (e.g. Cuadra et al., 2010; and Hatchondo et al., 2012).
} 


\section{Sovereign Spreads Module}

A sovereign spread equation — one of the variables that determine debt dynamics - is estimated separately since data availability is significantly more limited (starting only after 1998 , and varying by country $)^{28}$ than in the case of other variables included in the model. The spread equation includes key macroeconomic fundamentals and exogenous global variables:

$$
\Delta s_{i, t}=\beta_{i, 0}+\sum \boldsymbol{\beta}^{\prime} \Delta \boldsymbol{z}_{i, \boldsymbol{t}-\mathbf{1}}+\sum \boldsymbol{\gamma}_{\boldsymbol{i}}^{\prime} \Delta \boldsymbol{x}_{\boldsymbol{i}, \boldsymbol{t}-\mathbf{1}}+\varepsilon_{i, t}
$$

where $\boldsymbol{z}_{\boldsymbol{i}, \boldsymbol{t}}=\left(p d_{i, t} p b_{i, t} p d_{i, t}^{2} e d_{i, t}\right.$ ca $_{i, t}$ fxres $_{i, t}$ lnreer $\left._{i, t}\right)$ is a vector of potential predetermined and exogenous variables, which are expected to have similar impact across countries, and $\boldsymbol{x}_{\boldsymbol{i}, \boldsymbol{t}}=\left(v i x_{t} i_{t}^{*} \boldsymbol{\operatorname { l n }} \boldsymbol{P}_{\boldsymbol{t}}^{W}\right)$ is a vector of predetermined and exogenous variables with different effects across countries. We consider three different estimation methods: OLS (without constant), panel with fixed effects and panel with random effects.

Of the country fundamentals considered only the level of public debt, international reserves and the real exchange rate appear to have a statistically significant role. Of the exogenous variables considered, only the VIX produces statistically significant and robust results, with important differences across idiosyncratic coefficients. Surprisingly, commodity prices do not appear to be important, perhaps because of their close correlation with the VIX and the fact that the real exchange rate captures much of the impact of changes in trade prices.

As before, our interest resides primarily in the forecast properties of the model, especially during bad external scenarios. Thus, we choose a specification that displays good forecasting performance both for crisis periods as well as subsequent normal times. We do this by evaluating the out-of-sample forecasting accuracy of the different specifications and estimation methods for the period 2008:M6 to 2012:M12. Specification 6 with OLS estimation (Table A2 in the Annex) displays the best properties in this regard.

\section{Debt Dynamics Under Alternative Global Scenarios}

\section{A. Scenarios}

We first focus on debt dynamics under "baseline" global assumptions (i.e. IMF's World Economic Outlook latest projections). ${ }^{29}$ Then, we study how debt sustainability in the region would change under four alternative (adverse) global scenarios, each defined by exogenously determined paths for the exogenous variables. We explore two scenarios of temporary shocks

\footnotetext{
${ }^{28}$ Sufficiently long series of EMBI spreads are not available for Bolivia and Paraguay. In these cases, sovereign spreads are modeled using the average coefficients of the other countries of the region.

${ }^{29}$ The analysis leaves aside any issue related to possible changes in the (currency or maturity) composition of public and external debt following a shock, as these would require a much stronger set of behavioral assumptions.
} 
and two others where shocks have more permanent effects. A brief characterization of each scenario is as follows: ${ }^{30}$

\section{Scenario 1: Temporary Financial Shock}

This scenario entails a temporary 'pure' financial shock, reflected in a spike of the VIX in 2013 of similar magnitude than the one observed after the Lehman event, with the VIX returning to baseline levels in 2014. Real variables, such as global growth and commodity prices are assumed to remain unchanged at baseline levels. While the latter is a strong assumption, it is meant to allow the scenario to capture the effect of a shock that is mostly financial.

\section{Scenario 2: Temporary Real Shock}

This scenario assumes a temporary global recession, with lower growth and commodity prices during 2013-14, returning to the baseline path afterwards. This scenario can be characterized as a backdrop where global uncertainties remain somewhat elevated for some time-leading to a global economic slowdown, but no crisis - and are eventually resolved.

\section{Scenario 3: A Protracted Global Slowdown}

This scenario entails a relatively high level of uncertainty (as reflected by current levels of the VIX), lower commodity prices and lower global growth (all relative to the baseline). The scenario does not assume abrupt changes, but rather protracted weakness in real global variables.

\section{Scenario 4: A Tail Event}

In contrast to scenario 3, this is an extreme event meant to study the implications of a crisis with an impact on global variables (VIX, global GDP growth, and commodity prices) of magnitudes similar to those observed after the Lehman event. Unlike that episode-which displayed a quick rebound of commodity prices, and, to a lesser extent, global growth - this scenario assumes that a new Lehman-like event would have more protracted effects on the global economy, as fiscal and monetary space in advanced economies is today much more limited than in 2008.

For each of these scenarios, a path of global exogenous variables is assumed (Table 1 and Figure 6). These variables include: global growth, the VIX index, the 10-year U.S. T-bill interest rate, commodity prices (food, energy and metals). Some general assumptions on the

\footnotetext{
${ }^{30}$ A detailed description and the path of external variables, both under the baseline and the alternative scenarios, are presented in Table 1 and Figure 6. It is worth noting that the analysis does not consider adverse scenarios that are country-specific in nature. For example, shocks stemming from large neighbors (e.g., Brazil) could be an additional relevant shock, not studied here, for several Mercosur members (Argentina, Uruguay, and Paraguay_see Adler and Sosa, 2012).
} 
extent of non-debt creating capital inflows and on reserve accumulation are also made in order to fully specify the set of exogenous variables.

Table 1. Key Global Assumptions under Alternative Scenarios

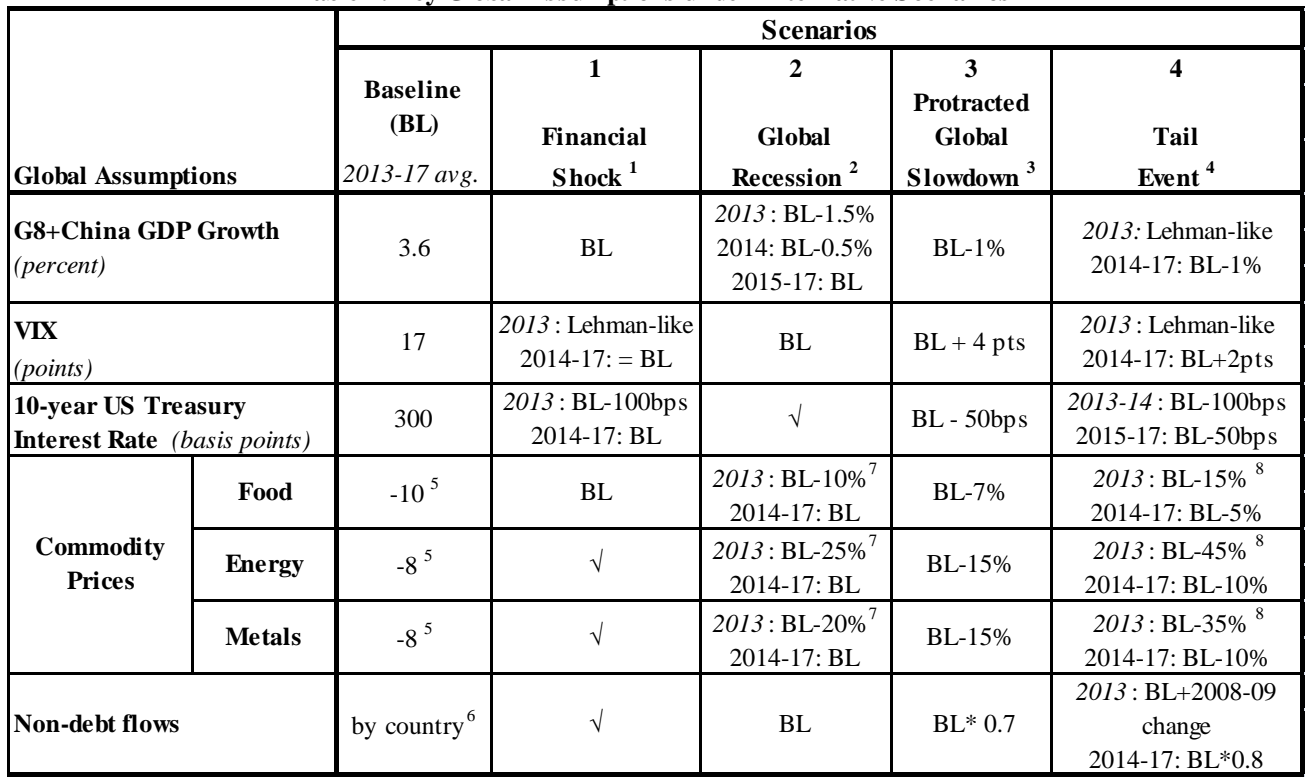

1/ Tempo rary financial s hock affecting 2013 only. Financial variables return to pro jected path under the bas eline in 2014

2/ Temporary real shock (commodity prices and world gro wth) in 2013-14. Variables return to projected path under the bas eline in 2015.

3/ Glo bals lo wdo wn over the whole forecast horizon.

4/ Lehman-like event in 2013-14, with protracted impact on glo bal gro wth, co mmodity prices and the VIX.

5/ Relative to 2012 level.

6/ As projected bycountry desks for each country.

7/ Reported gap vis-à-vis baseline is reached by end-2013. P rices recover gradually afterwards to reach bas eline by end-2014.

8/ Reported gap vis-à-vis baseline is reached by 2013-Q2. P rices recover gradually afterwards to reach new path by end-2014.

Figure 6. Global Variables under Alternative Scenarios, 2003-17

Baseline

Commodity Prices

(Index, in real terms)

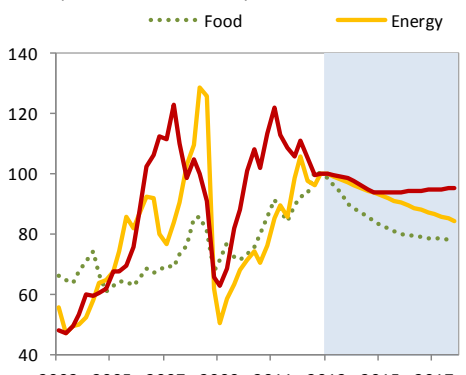

20032005200720092011201320152017
Scenario 1

Scenario 2

Scenario 3

Scenario 4

Growth and Financial Variables (percent and points)

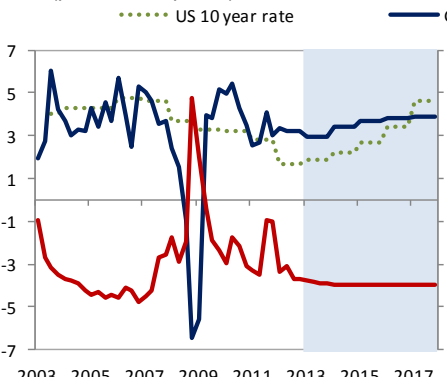

$200320052007 \quad 200920112013 \quad 20152017$

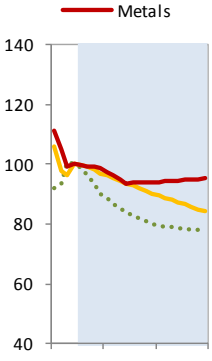

201220142016

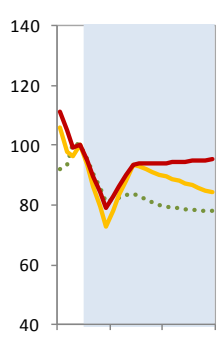

201220142016

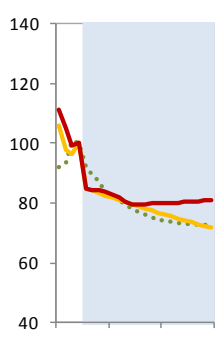

201220142016

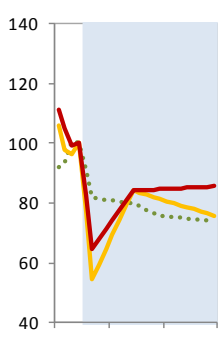

201220142016

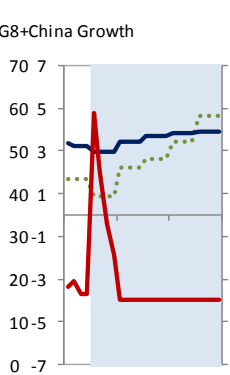

201220142016

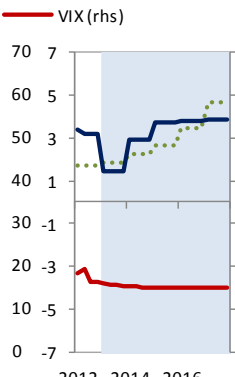

201220142016

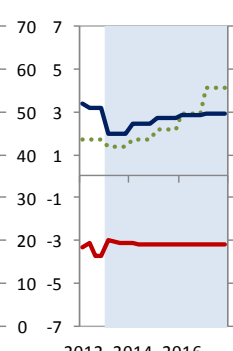

201220142016

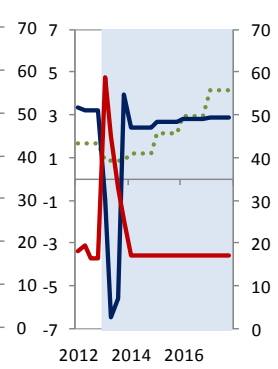


The VAR model (together with the spread equation) and the debt motion equations capture the key linkages between domestic and external variables. To fully determine the dynamics of debt ratios, however, a few assumptions on domestic policy are also necessary, as noted in section III. These include: (i) the output elasticity of non-commodity fiscal revenue; (ii) real public expenditure policy; and (iii) the extent of reserve accumulation ${ }^{31}$. Table 2 details these key assumptions under each of the four alternative scenarios.

The assumptions on real expenditure growth deserve special attention as they determine the degree of cyclicality of the fiscal stance, given the endogeneity of the other components of the primary balance. ${ }^{32}$ For each scenario we study three different expenditure rules:

Baseline fiscal policies. In this case, real expenditure growth behaves as in the baseline projection, regardless of the scenario under consideration. The idea is to focus on the 'pure' impact of changing external conditions, maintaining policies unchanged.

Neutral fiscal policy. Fiscal policy, however, is likely to react to negative external shocks. Thus, we consider an expenditure rule that implies a broadly neutral stance-i.e., expenditure growing at potential GDP growth rates under each of the four scenarios; thus only allowing for automatic stabilizers to operate..$^{33}$

Counter-cyclical fiscal policy. Finally, we consider the possibility of counter-cyclical policies beyond the effect of automatic stabilizers. To make policies comparable across countries, we specify a simple rule such that, in each scenario, expenditure grows above potential GDP growth rate by a margin that is proportional (one-to-one) to the gap between actual GDP growth and potential GDP growth.

Exploring these alternative rules allows us to assess the extent to which, under each of the negative external scenarios, fiscal buffers are large enough to (i) respond by deploying countercyclical fiscal policy, (ii) just enough to allow automatic stabilizers to work, or (iii) there is no fiscal space for stimulus and a fiscal tightening is necessary to ensure debt sustainability. Our assessment focuses on sustainability, leaving aside risks related to possible financing (i.e., liquidity) shocks. It is important to stress that, for countries with well-established fiscal rules (e.g. Brazil, Chile, Mexico), the reported dynamics under the different scenarios should be interpreted as an illustration of how fiscal variables would

\footnotetext{
${ }^{31}$ The assumption about accumulation of reserves is needed to determine the path of sovereign spreads.

${ }^{32}$ Commodity revenues are assumed to vary primarily with commodity prices, while non-commodity revenues vary with nominal GDP, as the elasticity of non-commodity revenues to output is assumed to equal one. While this elasticity may deviate from one at times - including because of possible revenue measures - the evidence suggests that, over the last decade, on average it has indeed been close to one (Annex Figure A2).

${ }^{33}$ An exception to this rule is introduced in cases where IMF baseline projections for 2013-14 assume expenditure growth above potential GDP growth. In these cases, we assume expenditure growth equals the baseline projections, to avoid a situation where fiscal policy is more expansionary in the baseline than in the negative scenario. This exception also recognizes the fact that IMF country desks (and their projections) may have specific information about expenditure plans already in the pipeline.
} 
behave in the event of a temporary deviation from the existing rules and, as such, of the magnitude of the fiscal adjustments that would be required to return to the target under the corresponding rule after the shock.

Table 2. Key Domestic Policy Assumptions under Alternative Scenarios

\begin{tabular}{|c|c|c|c|c|c|c|}
\hline \multirow{2}{*}{\multicolumn{2}{|c|}{ Policy Assumptions }} & \multicolumn{5}{|c|}{ Scenarios } \\
\hline & & $\begin{array}{c}\text { Baseline } \\
\text { (BL) } \\
2013-17 \text { avg. }\end{array}$ & $\begin{array}{c}1 \\
\text { Financial } \\
\text { Shock }^{1}\end{array}$ & $\begin{array}{c}2 \\
\text { Global } \\
\text { Recession }\end{array}$ & $\begin{array}{c}3 \\
\text { Protracted } \\
\text { Global } \\
\text { Slowdown }^{3}\end{array}$ & Tail Event $^{4}$ \\
\hline \multicolumn{2}{|c|}{$\begin{array}{l}\text { Non-Commodity Revenue } \\
\text { Elasticity to Output }\end{array}$} & $\mathrm{BL}^{5}$ & \multicolumn{4}{|c|}{1} \\
\hline \multirow{3}{*}{$\begin{array}{l}\text { Real } \\
\text { Expenditure } \\
\text { Growth } \\
\text { (percent) }\end{array}$} & BL & $\mathrm{BL}^{5}$ & \multicolumn{4}{|c|}{$\mathrm{BL}$} \\
\hline & Neutral & $\ldots$ & \multicolumn{4}{|c|}{$\begin{array}{l}\text { 2013-14: } \max \{\text { scenario potential GDP growth; BL) } \\
\text { 2015-17: scenario potential GDP growth }\end{array}$} \\
\hline & $\begin{array}{l}\text { Counter- } \\
\text { cyclical }\end{array}$ & $\ldots$ & \multicolumn{4}{|c|}{$\begin{array}{l}\text { 2013-14: Neutral + (-1) * (current year growth - scenario } \\
\text { potential GDP growth) } \\
\text { 2015-17: scenario potential GDP growth }\end{array}$} \\
\hline \multicolumn{2}{|c|}{$\begin{array}{l}\text { Reserve Accumulation } \\
\text { (percent of } G D P \text { ) }\end{array}$} & $\mathrm{BL}^{5}$ & $\mathrm{BL}$ & $\mathrm{BL}$ & 0 & \begin{tabular}{|c|}
$2013:-2.0$ \\
$2014-17: 0.0$
\end{tabular} \\
\hline
\end{tabular}

\section{B. Key Results}

\section{Latin America's overall picture}

\section{WEO Baseline projections}

We first examine the projected trajectories of public and external debt under the baseline, with the path of global variables as in the Fall 2012 IMF's World Economic Outlook (WEO). The dynamics under the baseline sheds light on the region's debt sustainability in the absence of unexpected foreign shocks. It also plays a role in assessing debt sustainability under the alternative scenarios, as projected debt ratios are computed by adding to the WEO baseline the estimated impact of changes in external conditions. The latter is computed as the difference between the debt projection under each VAR scenario forecast and the projection under the VAR baseline forecast. ${ }^{34}$ By focusing on the 'marginal' impact of changes in global conditions on WEO's baseline projection, this approach ensures that country-specific information embedded in the latter-such as revenue measures or investment plans already in the pipeline-is incorporated in the scenario projections.

$$
\left.d_{t}\right|_{\text {Scenario } i}=\left.d_{t}\right|_{\text {WEO Baseline }}+\left(\left.d_{t}\right|_{V A R \text { Forecast } i}-\left.d_{t}\right|_{V A R \text { Forecast Baseline }}\right)
$$

Under the baseline both public and external debt ratios are, on average, expected to decline only slightly (less than 2 percentage points of GDP) through 2017, continuing with the trend

\footnotetext{
${ }^{34}$ VAR-estimated baseline projections are those resulting from the use of the VAR model under WEO baseline global assumptions. These may differ from the (IMF country desks') WEO baseline projections.
} 
observed since 2009 (Figure 7). In the case of public debt, commodity-related revenues will continue to be a major factor pushing debt down, although they will be mostly offset by the continuation of non-commodity primary deficits. With (non-interest) current accounts broadly balanced on average, Latin America's external debt dynamics will be largely determined by the offsetting forces of still large non-debt-creating capital inflows (FDI and equity portfolio flows) and further foreign asset accumulation.

\section{Alternative downside scenarios}

Next, we analyze the results across different scenarios, considering baseline policies - to identify the 'pure' impact of changes in external conditions, maintaining expenditure policy unchanged - as well as policies that entail a neutral stance or a counter-cyclical fiscal stance.

\section{(i) Baseline policies}

The results suggest that the impact of temporary negative external shocks (either financial or real, as depicted by scenarios 1 and 2) both on public and external debt would be, in general, limited (Figure 7). A temporary financial shock (scenario 1) would lead to an increase of public debt of about 7 percentage points of GDP by 2017 (relative to the baseline), with most of the impact arising from the deterioration in economic activity and the associated weakening of primary balances, reinforced by the effect of the real depreciation in countries with foreign-currency denominated debt. A temporary real shock (scenario 2) would have a much more muted impact on public debt. Transitory shocks would not have visible effects on external debt dynamics. In the case of a financial shock (scenario 1) the effects of the associated real depreciation and rise in external interest rates (due to an increase in spreads) would be non-negligible, but they would be fully offset by the projected current account adjustment that would accompany this shock. Interestingly, the sharp increase in sovereign spreads under scenario 1 (Figure 7, lower panel) would induce only a mild effect on average interest rates - and thus on debt dynamics - as a result of the relatively low levels of shortterm debt.

The impact of more persistent shocks to foreign variables (scenarios 3 and 4 ) on public debt trajectories would be, however, significantly higher. Under scenario 4, public debt would increase, on average, by 20 percentage points of GDP (to around 55 percent) by 2017, due to the combination of a sharp decline in output and the associated weakening of non-commodity primary balances, considerably lower commodity revenues, and a non-negligible effect stemming from the real depreciation. External debt, on the other hand, would remain at manageable levels under these scenarios, with increases of only 5-6 percentage points of GDP by 2017-mainly reflecting lower growth, the effects of real depreciations, and a likely drop in non-debt capital inflows, offset partially by projected current account improvements.

\section{(ii) Active (Neutral and Countercyclical) Policies}

If authorities were to respond to the negative shocks of scenarios 1 and 2 by implementing either neutral or countercyclical policies (as defined earlier) the impact on public debt levels would be more pronounced, with stocks reaching about 46-51 percent and 41-44 percent of GDP by 2017, respectively (Figure 8, upper panel). While representing a sizeable impact, these levels do not appear to be particularly worrisome, especially given that primary balances would deteriorate only marginally and would not require to be adjusted significantly 
to keep public debt on a sustainable path. These scenarios would not entail a significant impact on external debt paths even under active policies.

Interestingly, under scenario 3, the debt trajectory associated with a counter-cyclical fiscal policy response would be very similar to the one resulting from a policy reaction that is essentially neutral. This reflects the fact that this scenario would imply not only a decline in actual GDP growth but also in potential growth, and thus the output gap - measured relative to the new potential - would be rather small (Figure 7, lower panel), and so would be the scope for expansionary fiscal policy. It is also worth highlighting that, if authorities failed to recognize that under this scenario the new potential growth rate is lower than previously estimated, what may be intended as a neutral stance would, in fact, be stimulative and would lead to a worsening of the primary balance and thus public debt dynamics.

Under scenario 4, there would be more scope for expansionary countercyclical policies, as output would fall significantly below (the new lower) potential levels. Both a neutral policy response - allowing automatic stabilizers to operate - and a countercyclical one would lead to substantial increases in public debt (of more than 20 and 30 percentage points of GDP by 2017 , relative to the baseline, respectively). At those levels (65 percent of GDP in the case of countercyclical policies), concerns about fiscal sustainability may emerge, especially in countries where the required adjustment in the primary balance to stabilize debt ratios would be large.

Finally, external debt would increase to around 35 percent of GDP in the face of more persistent negative external shocks (scenarios 3 and 4), irrespective of policies. As discussed earlier, this partly reflects that current accounts in Latin America tend to improve after negative external (financial) shocks. 
Figure 7. Latin America. Factors Driving Public and External Debt Dynamics under Alternative Global Scenarios, 2003-171/ (contributions to change in debt-to-GDP ratio, in percent of GDP)

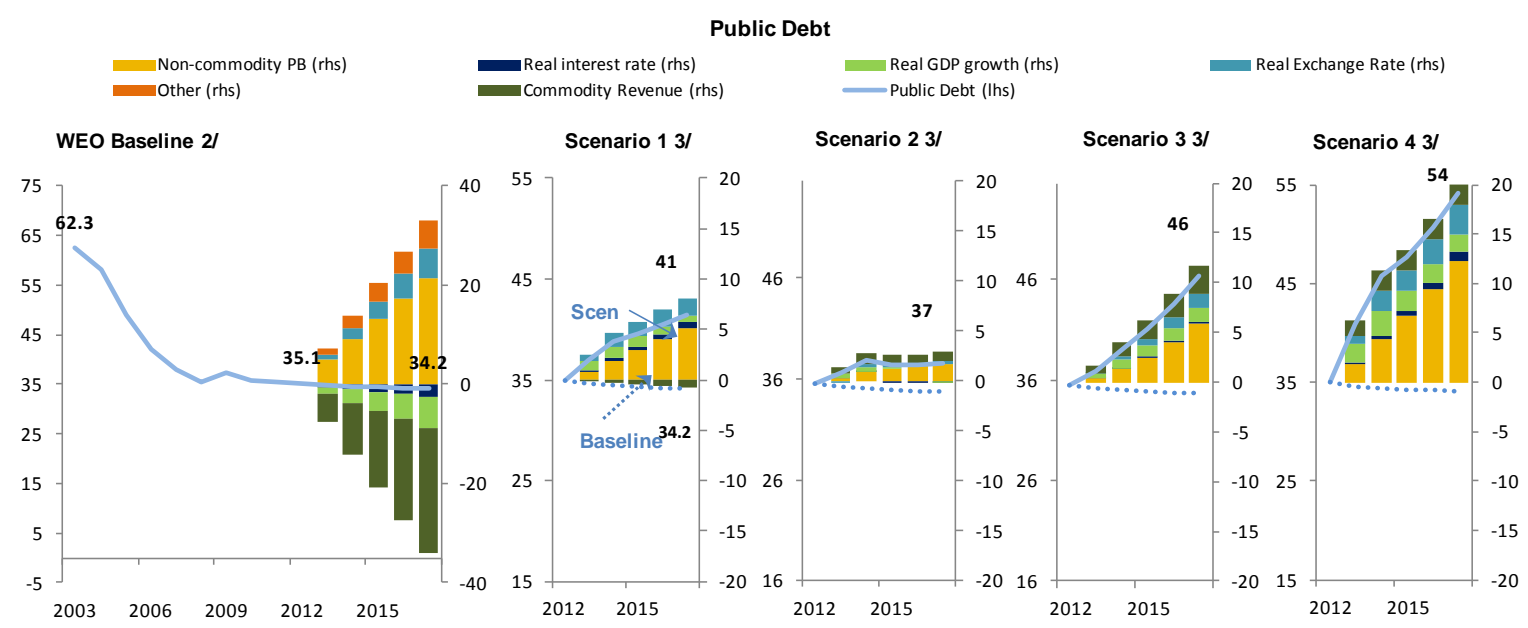

\section{External Debt}

$\begin{array}{lll}\text { Current account (exc. interests, rhs) } & \text { Interest rate (rhs) } & \text { Real GDP growth (rhs) } \\ \text { Other (rhs) } & \text { Non-debt flows (rhs) } & \text { External debt }\end{array}$

WEO Baseline 2/

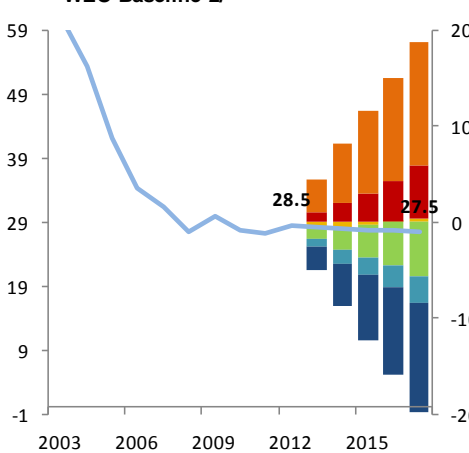

Scenario 13 /

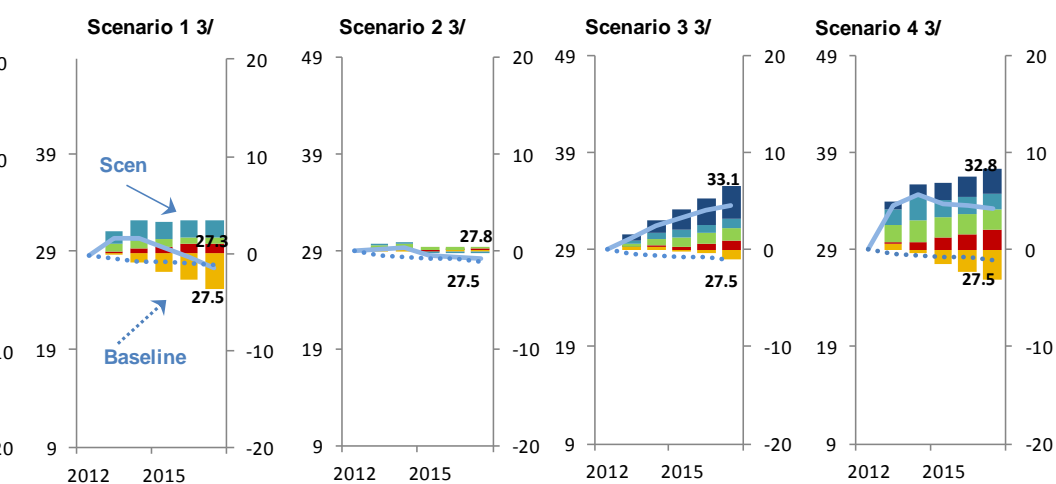

Real Exchange Rate (rhs)

Key Domestic Variables

(deviations from baseline)

..... VAR Scenario 1

VAR Scenario 2

VAR Scenario 3

VAR Scenario 4

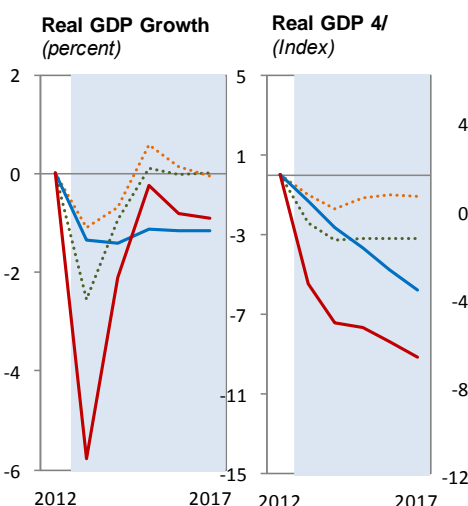

\section{Real Exchange} Rate 4/ (Index)
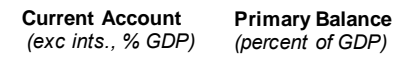

Real Interest
Rate (percent)

Sovereign Spread percent)
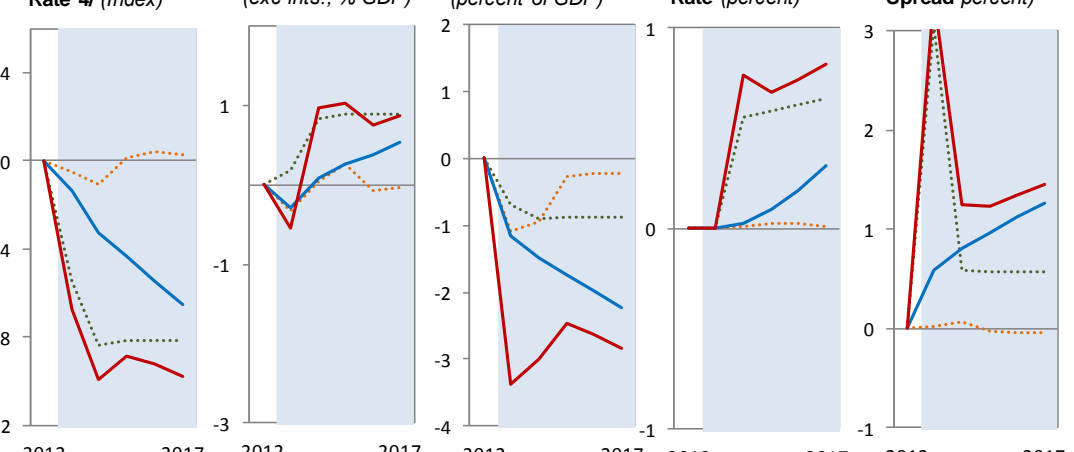

Sources: IMF International Financial Statistics and authors' estimations.

1/SImple average for Argentina, Bolivia, Brazil, Chile, Colombia, Ecuador, Mexico, Peru, Uruguay and Venezuela.

2/ Country desk projections (based on WEO baseline assumptions).

3/Based on differential between VAR forecasts and VAR baseline. Bars denote contributions of differentfactors to the deviation of the debt ratios from the baseline. $4 /$ Deviation in percent of baseline. 
Figure 8. Latin America. Public and External Debt under Alternative Scenarios and Policies, 2012-17 1/ (In percent of GDP, simple averages)
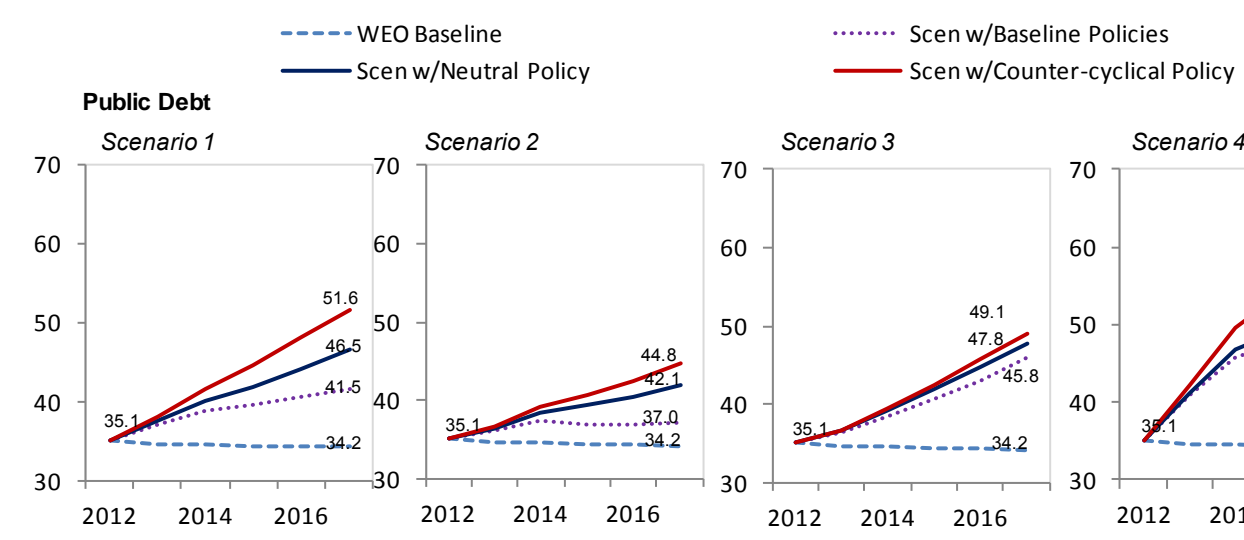

- Scen w/Counter-cyclical Policy
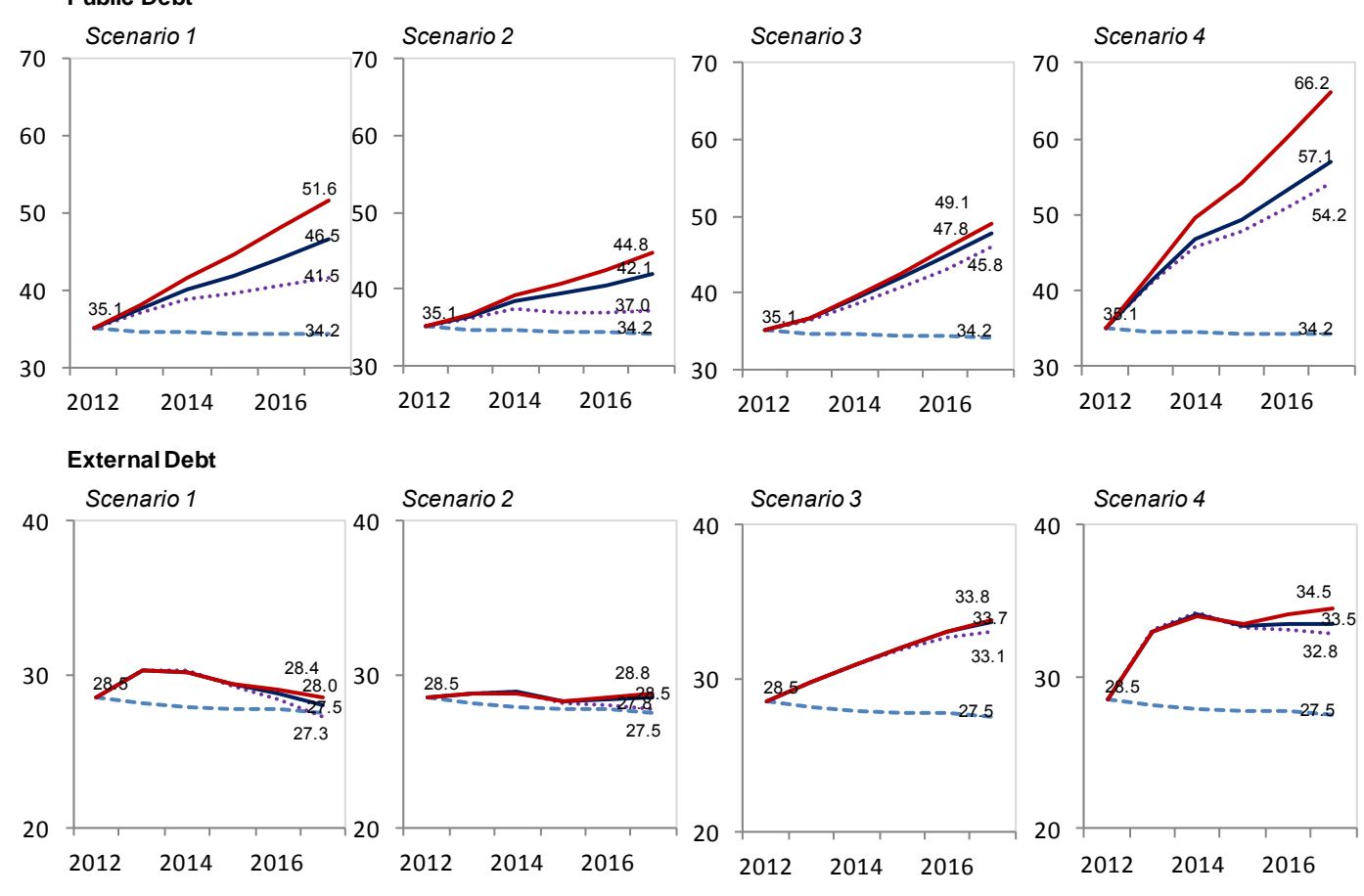

Source: authors' estimations.

\section{Country-specific results}

Averages for the region, however, mask some important differences across countries. ${ }^{35}$

\section{WEO Baseline projections}

Under baseline external conditions, public debt ratios will continue to decline moderately in most countries (Brazil and Uruguay, starting from higher initial levels, would experience the largest decreases), with primary balance gaps generally improving. A notable exception is Venezuela, where debt is projected to increase by 30 percentage points of GDP, reaching 80 percent of GDP, by $2017 .{ }^{36}$ External debt, in turn, is projected to remain broadly stable in most countries under the baseline external scenario.

\section{Alternative downside scenarios}

Most countries in the region should be in a position to undertake an expansionary countercyclical policy response in the event of temporary shocks (scenarios 1 and 2), without

\footnotetext{
${ }^{35}$ See Figures 9 and 10, and Figures A6-A16 in the Annex.

${ }^{36}$ In a few countries (mainly Argentina, Chile, Ecuador, Mexico and Venezuela), this baseline already projects fiscal consolidation to varying degrees. If such projections did not materialize, debt dynamics would worsen both under this baseline and the alternative scenarios (by construction).
} 
raising debt sustainability concerns (i.e., high debt and primary gap levels). An exception would be Venezuela, which would likely have limited or no scope for countercyclical policy, reflecting the combination of relatively weak initial positions and high sensitivity to these shocks (that could rapidly lead to large deficits).

In case of external shocks with more protracted effects (scenarios 3 and 4), countries can be classified into three different groups based on the extent of fiscal buffers to implement either neutral or countercyclical fiscal policy responses (Figure 9):

- First, a group of countries (Argentina and Venezuela) that would likely need to undertake sizeable fiscal consolidation in the face of adverse shocks, including - although to a lesser extent — moderate ones, to keep public debt on a sustainable path. ${ }^{37}$

- Second, a group (including Brazil, Mexico, Uruguay, and - to a lesser extent-Ecuador), which public debt dynamics would be less vulnerable to moderate shocks, although still significantly sensitive to tail events. In particular:

- This group should be in a position to deal with a moderate deterioration of the external environment (scenario 3), although debt ratios could reach levels (ranging from 55 to 65 percent of GDP) that - while manageable - would be relatively high for emerging market standards, and could make these economies vulnerable to possible subsequent adverse shocks. ${ }^{38}$

- Under a more severe event (scenario 4), scope for counter-cyclical policy, and to some extent even for neutral policies, would be limited without raising concerns about debt sustainability, as indicated by the sharp deterioration in debt levels and/or primary balance gaps. ${ }^{39}$

- In countries with well-established fiscal rules (Brazil, Mexico), adherence to the rule following a temporary deviation at the time of the adverse shock would, of course, ensure that public debt remains on a sustainable path. In some cases, however,

\footnotetext{
${ }^{37}$ In these two cases, results should be interpreted with caution, as important structural changes in the last decade may have affected the econometric results regarding the impact of external shocks on domestic variables. One the one hand, these countries have moved towards less international financial integration, possible making them less vulnerable to global financial shocks. At the same time, their dependence on commodity exports has increased, thus making them more vulnerable to commodity price shocks. While it is difficult to point to a specific direction of the possible estimation bias, evidence of the impact of the 2008-09 crisis on domestic output suggests that these economies are still highly sensitive to external shocks.
}

${ }^{38}$ Furthermore, in the cases of Ecuador and Mexico, the baseline already assumes a path of fiscal consolidation (with public expenditure growing below potential GDP growth). If such consolidation did not take place, debt dynamics would worsen both under the baseline and the alternative scenarios.

${ }^{39}$ For instance, countercyclical responses would lead to a sizeable jump in debt ratios to substantially high levels in Brazil, a sharp deterioration of the primary balance gap in Ecuador, or a combination of both in Mexico and Uruguay. 
returning to the fiscal targets under the rule could entail significant fiscal consolidation. ${ }^{40}$

- Finally, a group of countries (Bolivia, Chile, Colombia, Paraguay, and Peru) that, to varying degrees, appear to be in a position to weather a marked worsening of external conditions - even undertaking countercyclical policies —without jeopardizing fiscal solvency. Peru appears to exhibit the strongest position, even under the described extreme circumstances. While in Chile and Paraguay, under scenario 4 and assuming countercyclical policies, both the primary balance gap and debt ratios could increase significantly, debt would still remain at relatively moderate levels. ${ }^{41}$ Colombia, with debt levels reaching over 50 percent of GDP and the primary balance gap -4 percent of GDP, appears to exhibit a somewhat less solid fiscal position, though those figures should not raise concerns about fiscal solvency.

\footnotetext{
${ }^{40}$ As indicated before, the focus of this paper is on the sustainability impact of external shocks, leaving aside the desirability of larger buffers to guard against possible idiosyncratic shocks. The latter could be of particular importance in resource-rich economies (e.g., Bolivia and Ecuador). For a further discussion of these issues, see $\operatorname{IMF}(2012 b)$.

${ }^{41}$ The fiscal position in Chile is further strengthened by the substantial stock of foreign assets in sovereign funds (about 11 percent of GDP in 2012).
} 
Figure 9. Key Fiscal Indicators under Different Scenarios, 2012-17 1/ (percent of GDP)

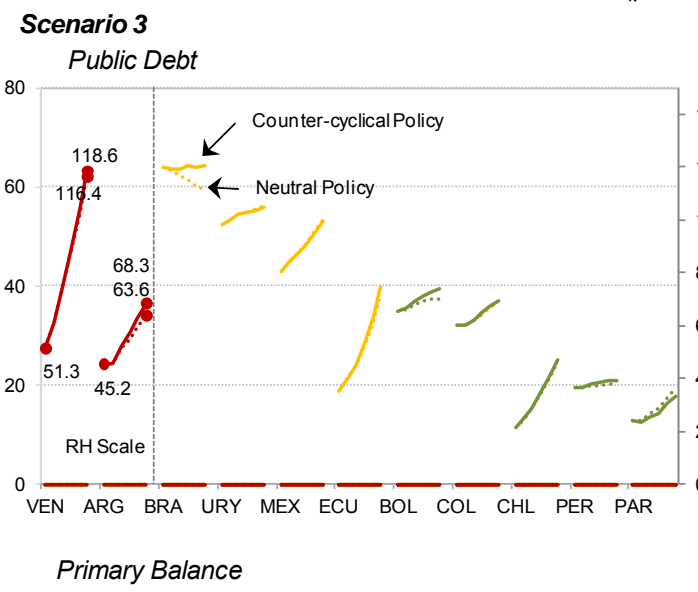

\section{Scenario 4}
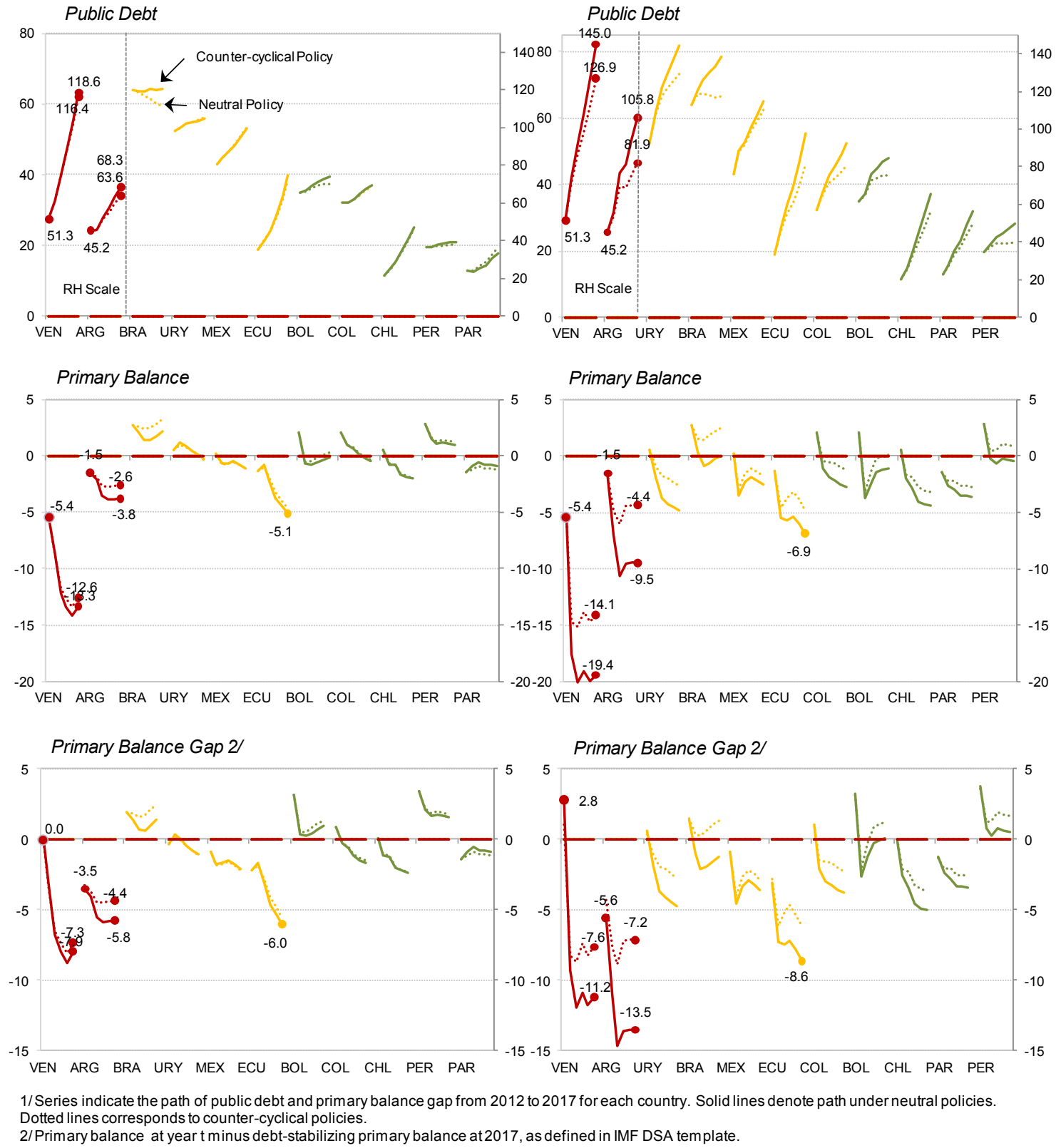

On the external front, even under the more extreme scenarios ( 3 and 4 ) countries in the region would be in a position to maintain external sustainability under check (Figure 10). ${ }^{42}$ In fact, under both scenarios (and even assuming active policy responses) debt levels would remain moderate, and current account balance gaps would be either closed or positive. A key factor driving this result is - as noted earlier - the fact that current accounts tend to improve in the face of large negative external shocks (especially financial ones).

\footnotetext{
${ }^{42}$ An exception is Venezuela, where external sustainability concerns could be raised in case of a tail event.
} 
Figure 10. Key External Indicators under Different Scenarios, 2012-17 1/ (percent of GDP)

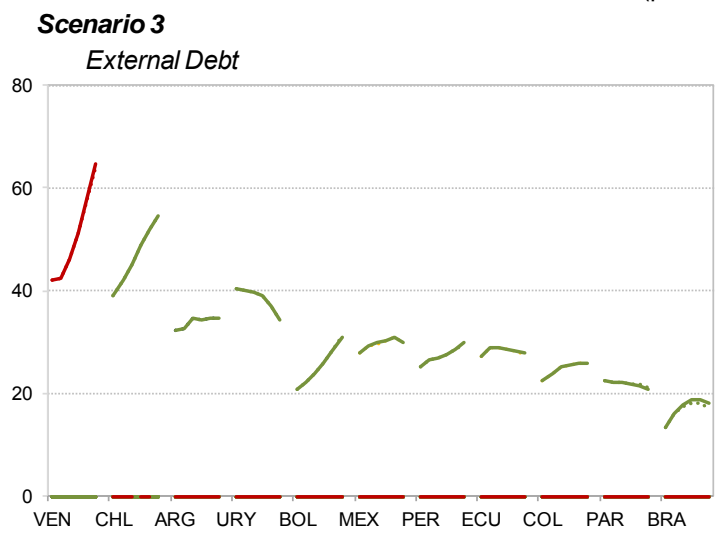

Scenario 4

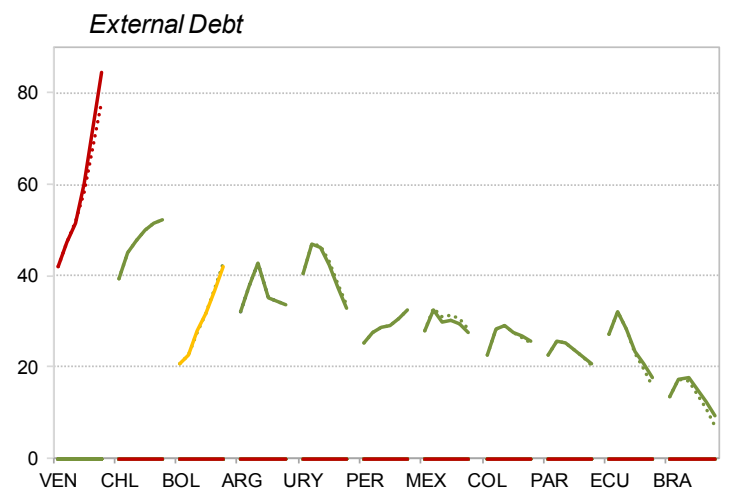

Non-Interest Current Account Balance

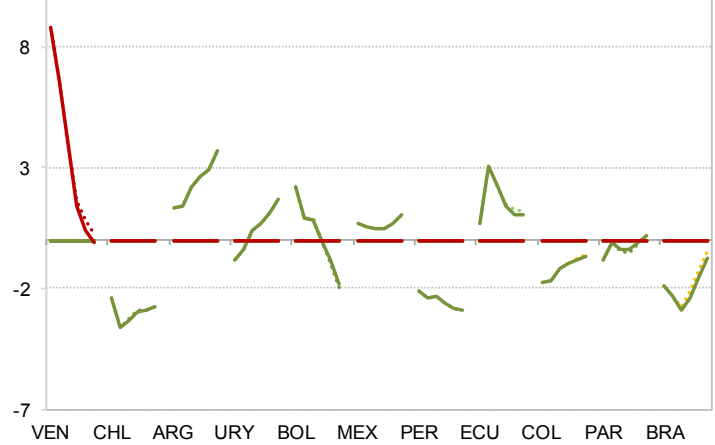

Non-Interest Current Account Balance

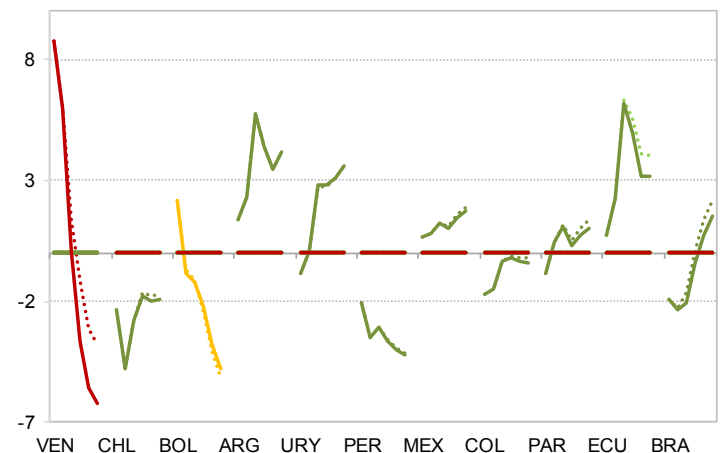

Non-Interest Current Account Balance Gap 2/
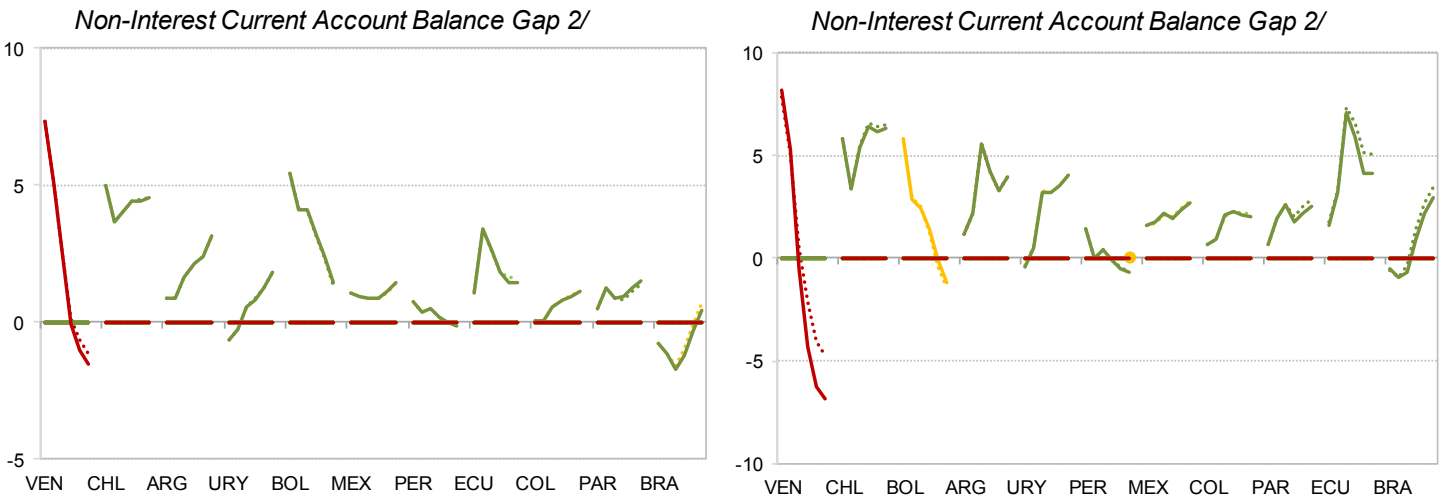

VEN CHL ARG URY BOL MEX PER ECU COL PAR BRA

VEN CHL BOL ARG URY PER MEX COL PAR ECU BRA

$1 /$ Series indicate the path of external debt and non-interest current account balance gap from 2012 to 2017 for each country. Solid lines denote path under neutral policies. Dotted lines corresponds to counter-cyclical policies.

2/Non-interest current account (NICA) balance at year $t$ minus debt-stabilizing NICA balance at 2017, as defined in the IMF DSA template.

\section{Conclusions}

Latin America experienced a sharp improvement in key macroeconomic fundamentals over the last decade, although these gains were, to some extent, the result of a highly favorable external environment. With prospects of less favorable conditions going forward, and even the possibility of a sharp deterioration (in the event of an escalation of the European financial crisis), the region's fundamentals may change drastically. This paper proposes a simple framework to undertake debt sustainability analysis focusing on the impact of changes in external variables. Using this framework, we examine how public and external debt 
sustainability indicators (both in terms of stocks and flows) would look like under alternative negative external scenarios. The results are used to assess whether current levels of policy buffers (especially fiscal) in the region are adequate to withstand a deterioration of the global environment.

The main results indicate that while external sustainability does not appear to be source of concern for Latin America in general, fiscal space to deal with a protracted deterioration of the external environment may still be limited in several countries. These results suggest that the region would benefit from further strengthening buffers, while favorable conditions last, to be in a position to actively use fiscal policy should the external environment deteriorate markedly.

There are, however, some important differences across countries and three groups can be identified according to the degrees of fiscal space to deal with negative external shocks: (i) a group (Argentina and Venezuela) that would face tight fiscal constraints even in the face of relatively moderate shocks, likely precluding the deployment of counter-cyclical policy; (ii) a group (Brazil, Mexico, Uruguay, and - to a lesser extent-Ecuador) that would have some space to run countercyclical fiscal policy but would benefit from building further space to be able to respond actively without raising concerns about fiscal sustainability or requiring large subsequent fiscal consolidations, specially under severe scenarios; and finally (iii) a group (Bolivia, Chile, Paraguay, Peru, and - to a lesser extent-Colombia) that appears to be today in a position to weather sizeable shocks with counter-cyclical policies without compromising debt sustainability. 


\section{References}

Adler, G., and C. E. Tovar, 2012, "Riding Global Financial Waves: The Economic Impact of Global Financial Shocks on Emerging Market Economies," IMF Working Paper 12/188 (Washington: International Monetary Fund).

Adler, G., and S. Sosa, 2012, "Intra-Regional Spillovers in South America: Is Brazil Systemic after All?" IMF Working Paper 12/145 (Washington: International Monetary Fund).

Adler, G., and S. Sosa, 2011, "Commodity Price Cycles: The Perils of Mismanaging the Boom,” IMF Working Paper 11/283 (Washington: International Monetary Fund).

Bloom, Nicholas; 2009; “The Impact of Uncertainty Shocks,” Econometrica, Vol. 77, No. 3, May, 2009.

Carriere-Swallow, Y., and L. F. Cespedes, 2011; "The Impact of Uncertainty Shocks in Emerging Economies," Documento de Trabajo N 646, Banco Central de Chile.

Celasun, O., X. Debrun, and J.D. Ostry, 2006, "Primary Surplus Behavior and Risks to Fiscal Sustainability in Emerging Market Countries: A 'Fan-Chart' Approach,” IMF Working Paper 06/67 (Washington: International Monetary Fund).

Cespedes, L.F., and A. Velasco, 2011, "Was this Time Different?: Fiscal Policy in Commodity Republics,” BIS Working Paper No 365 (Basel: Bank of International Settlements).

Cuadra, G., J. Sanchez, and H. Sapriza, 2010, "Fiscal Policy and Default Risk in Emerging Markets," Review of Economic Dynamics, Vol. 13 (2), April 2010.

Cherif, R., and F. Hasanov, 2012, "Public Debt Dynamics: The Effects of Austerity, Inflation, and Growth Shocks," IMF Working Paper 12/230 (Washington: International Monetary Fund).

Favero, C., and F. Giavazzi, 2007, "Debt and the Effects of Fiscal Policy," NBER Working Paper No. 12822 (Cambridge, Massachusetts: National Bureau of Economic Research).

, 2009, "How Large are the Effects of Tax Changes?," NBER Working Papers No. 15303 (Cambridge, Massachusetts: National Bureau of Economic Research).

Frankel, J.A., C.A. Végh, and G. Vuletin, 2011, "On Graduation from Fiscal Procyclicality," NBER Working Paper No. 17619 (Cambridge, Massachusetts: National Bureau of Economic Research).

Hatchondo, J. C., L. Martinez and F. Roch, 2012, "Fiscal Rules and the Sovereign Default Premium," IMF Working Paper 12/30 (Washington: International Monetary Fund). 
Inter-American Development Bank, 2008, “All that Glitters May Not be Gold. Assessing Latin America`s Recent Macroeconomic Performance,” Annual Report.

International Monetary Fund, 2002, Assessing Sustainability (Washington: International Monetary Fund). Available at: www.imf.org/external/np/pdr/sus/2002/eng/052802.pdf , 2003, Sustainability Assessments-Review of Application and Methodological Refinements (Washington: International Monetary Fund). Available at: www.imf.org/external/np/pdr/sustain/2003/061003.pdf , 2005, Information Note on Modifications to the Fund's Debt Sustainability Assessment Framework for Market Access Countries (Washington: International Monetary Fund). Available at: www.imf.org/external/np/pp/eng/2005/070105.pdf , 2011, Modernizing the Framework for Fiscal Policy and Public Debt Sustainability Analysis (Washington: International Monetary Fund). Available at: www.imf.org/external/np/pp/eng/2011/080511.pdf

,2012a, Regional Economic Outlook: Western Hemisphere—Rebuilding Strength and Flexibility (Washington: April 2012). , 2012b, "Macroeconomic Policy Frameworks for Resource-Rich Developing Countries" (Washington: International Monetary Fund). Available at: www.imf.org/external/np/pp/eng/2012/082412.pdf

Izquierdo, A., R. Romero, and E. Talvi, 2007, "Booms and Busts in Latin America: The Role of External Factors," IADB, Research Department Working Paper No. 631

(Washington: Inter-American Development Bank).

Kawakami, K., and R. Romeu, 2011, "Identifying Fiscal Policy Transmission in Stochastic Debt Forecasts," IMF Working Paper 11/107 (Washington: International Monetary Fund).

Osterholm, P.,and J. Zettelmeyer, 2008, "The Effect of External Conditions on Growth in Latin America," IMF Staff Papers, Vol. 55, Number 4.

Talvi, E. and C. Vegh, 2005, "Tax Base Variability and Procyclicality of Fiscal Policy," Journal of Development Economics, 78 (1).

Tanner, E., and I. Samake, 2008, "Probabilistic Sustainability of Public Debt: A Vector Autoregression Approach for Brazil, Mexico, and Turkey," IMF Staff Papers Vol. 55, No 1

Tornell, A., and P. Lane, 1999, “The Voracity Effect," American Economic Review, 891:2246. 
Annex Figure A1. Factors Driving Public Debt Dynamics, 2002-121/ (cumulative contributions, percent of GDP)

Primary deficit (rhs)

Real Exchange Rate (rhs)

Latin America (average)
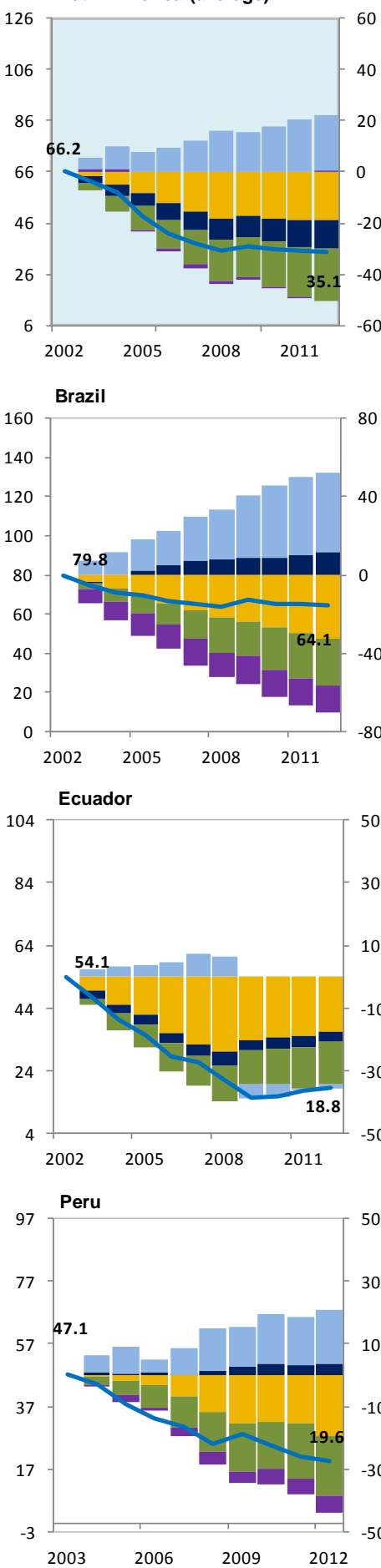

Real interest rate (rhs) Other (rhs)
Real GDP growth (rhs)

Public Debt
Argentina
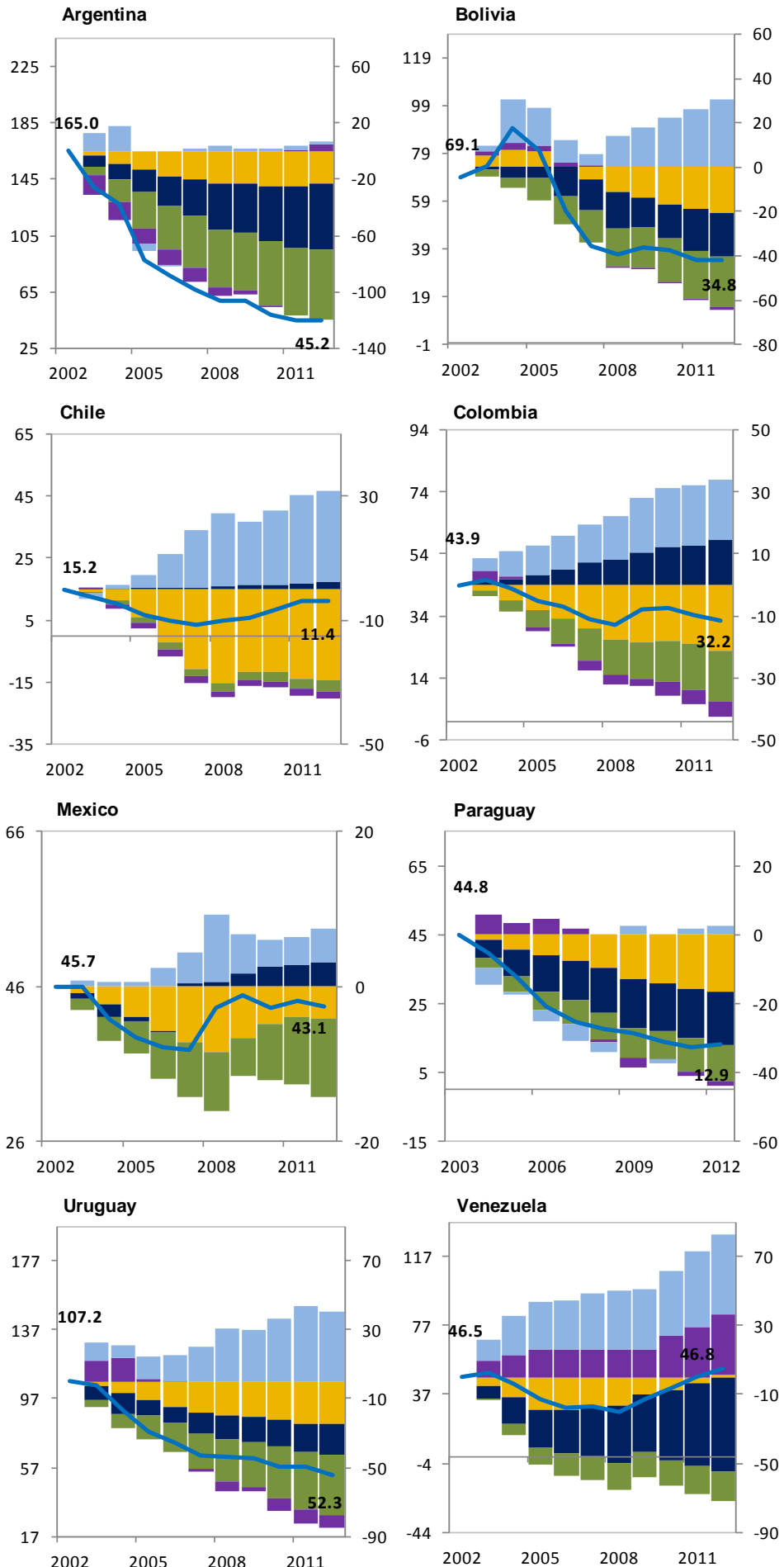

Sources: IMF International Financial Statistics, IMF country desks and authors' calculations. 
Annex Figure A2. Components of Primary Balance Dynamics, 1995-2012 1/

(Index, 2003=100 unless otherwise states, in real terms)
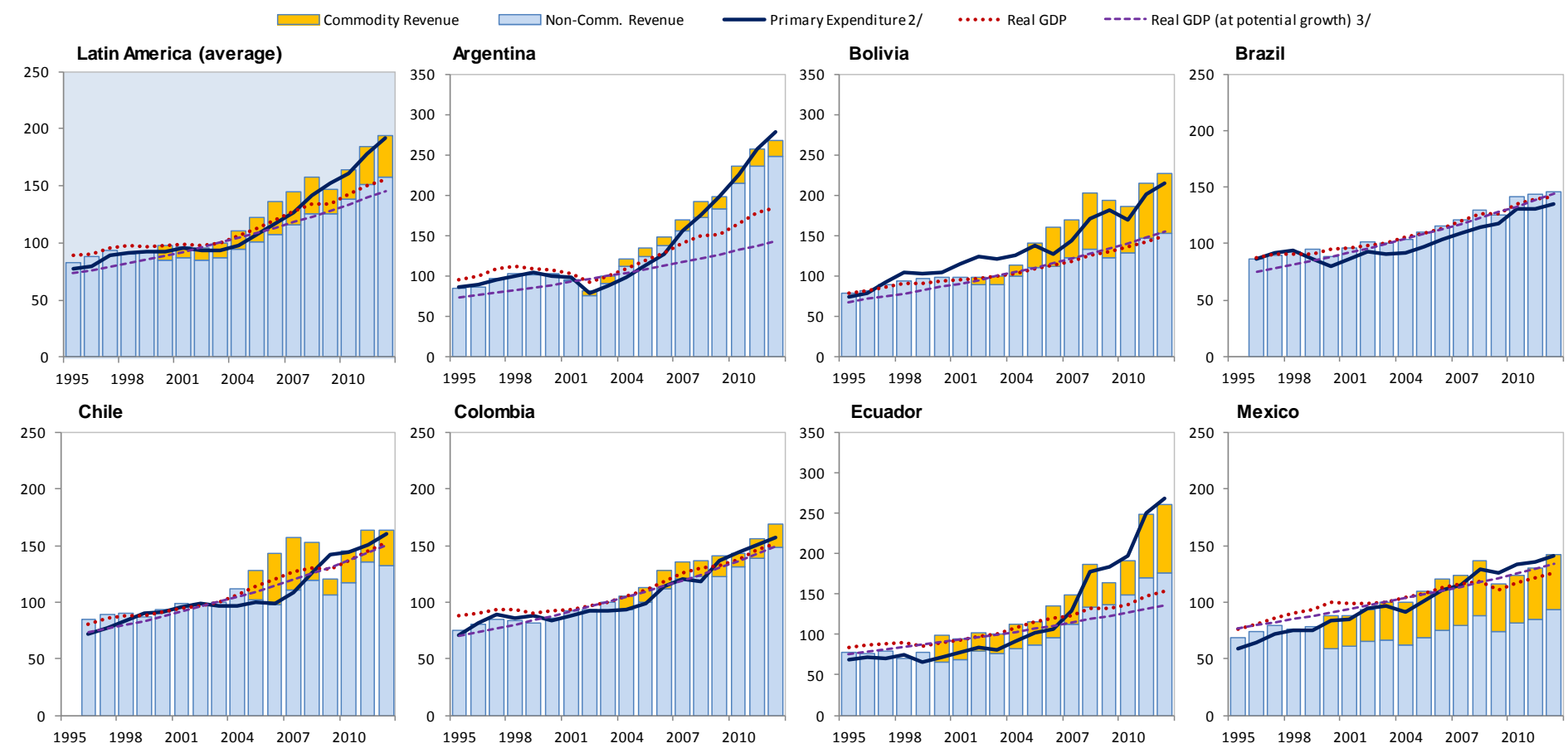

Mexico
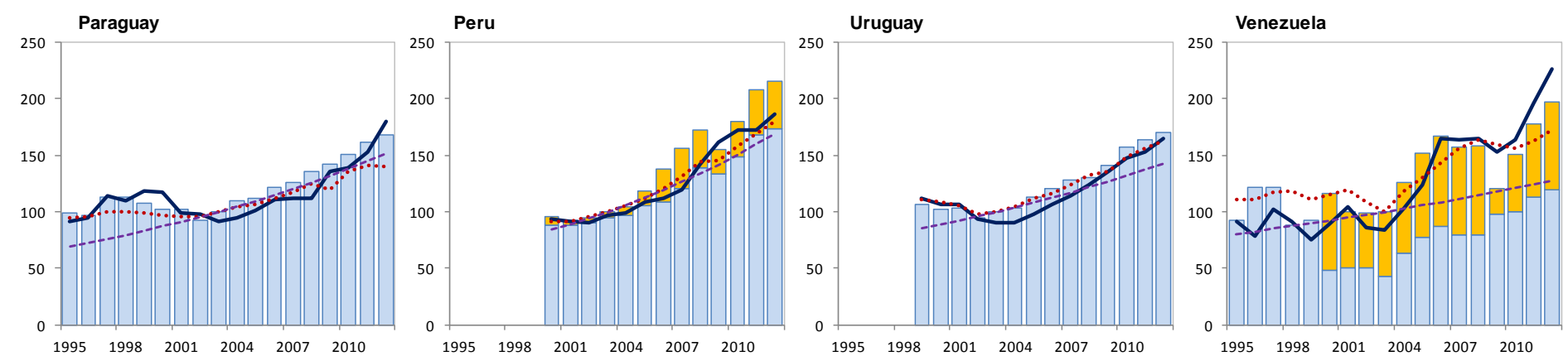

Source: IMF Intermational Financial Statistics and authors' calculations.

1/ Using GDP deflator for all series.Data on commodity-related revenues for Ecuador, Mexico and Venezuela (Chile) are avilable from 2000 (2005).

2/ Expenditure base year equals percent of revenues in that year.
$3 /$ Based on projected growth for 2015-17.

CInternational Monetary Fund. Not for Redistribution 
Annex Figure A3. Factors Driving Primary Balance Dynamics, 2002-121/ (cumulative contributions, percent of GDP)
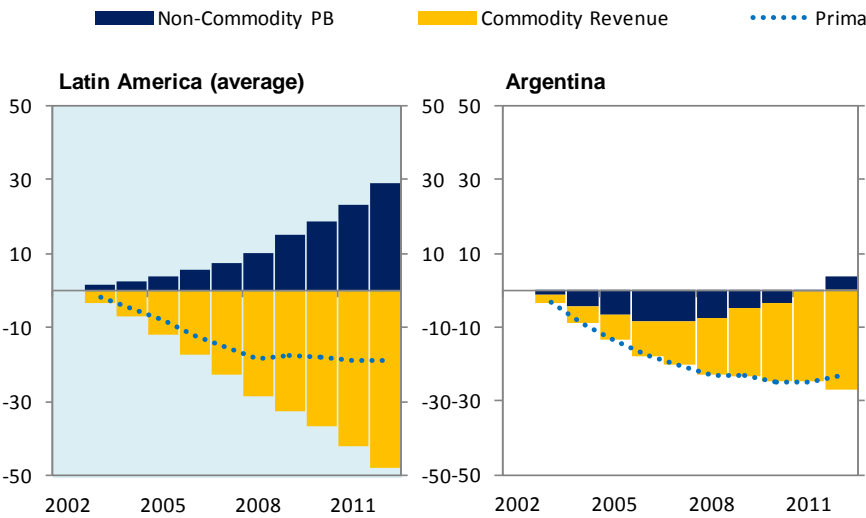

Primary deficit (rhs)
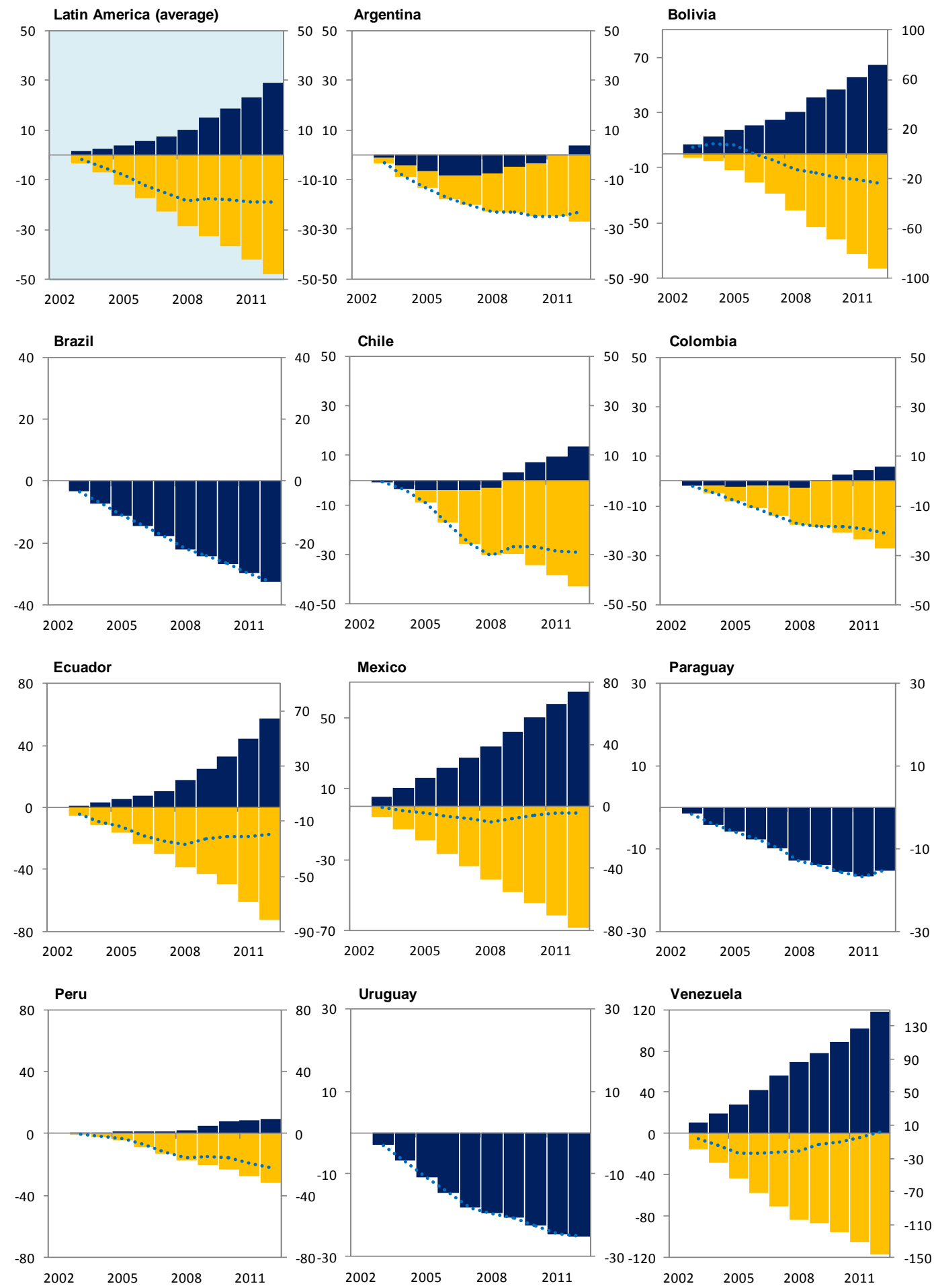

Sources: IMF International Financial Statistics, IMF country desks and authors' calculations. 
Annex Figure A4. Factors Driving External Debt Dynamics, 2002-12 1/ (cumulative contributions, percent of GDP)

Real GDP growth (rhs)

CA (exc. ints pmts, rhs)
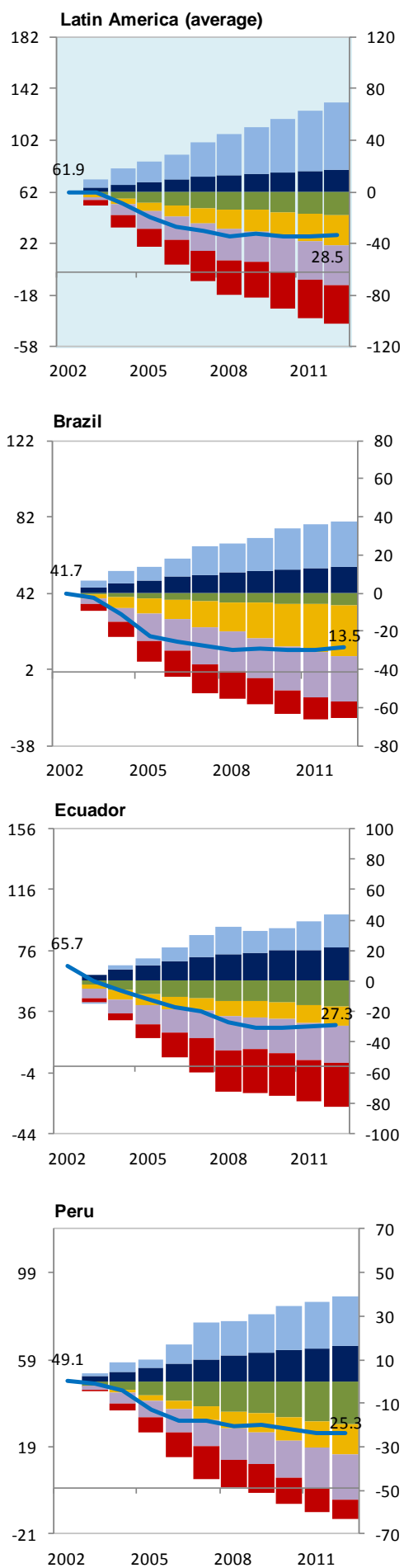

Interest rate (rhs)

External debt
Real Exchange Rate (rhs)

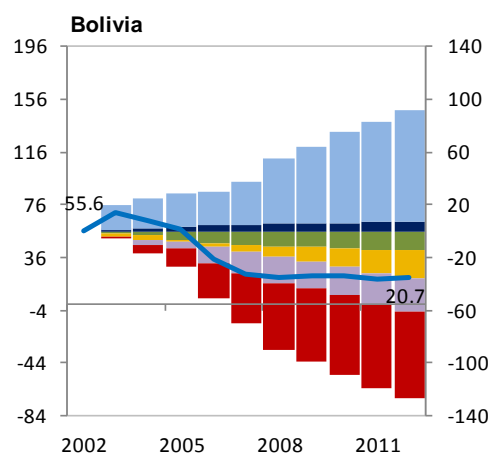

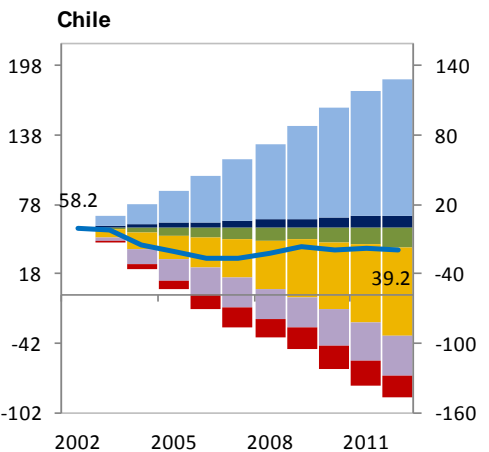
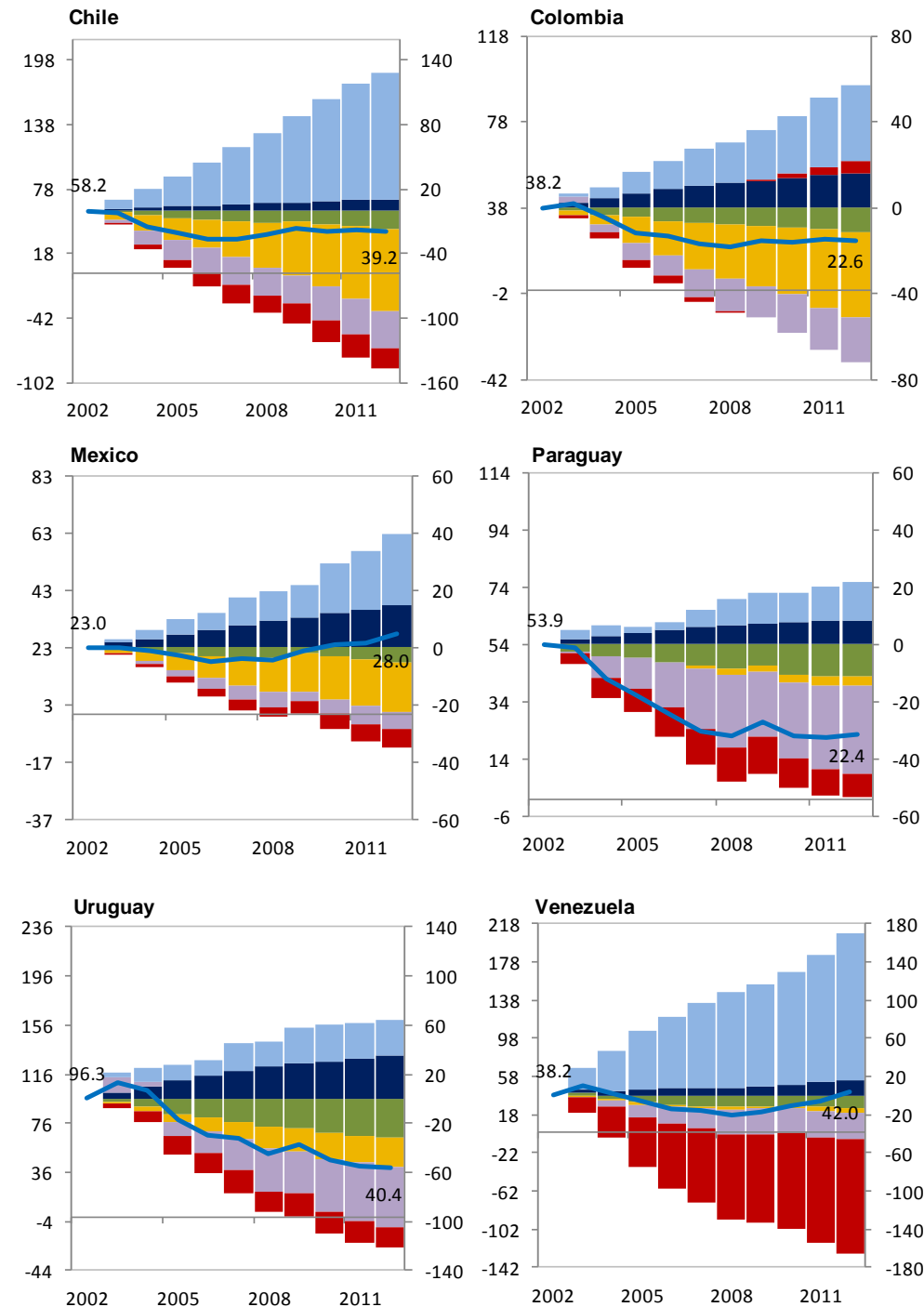

Sources: IMF International Financial Statistics, IMF country desks and authors' calculations. 
Figure A5. Forecasting Power of VAR Model During the Lehman Event
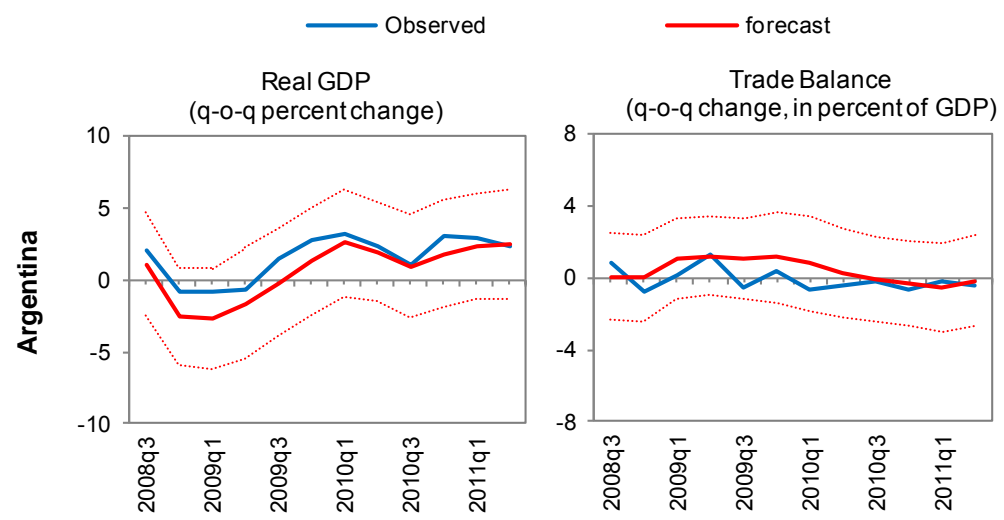

95\% C.I.
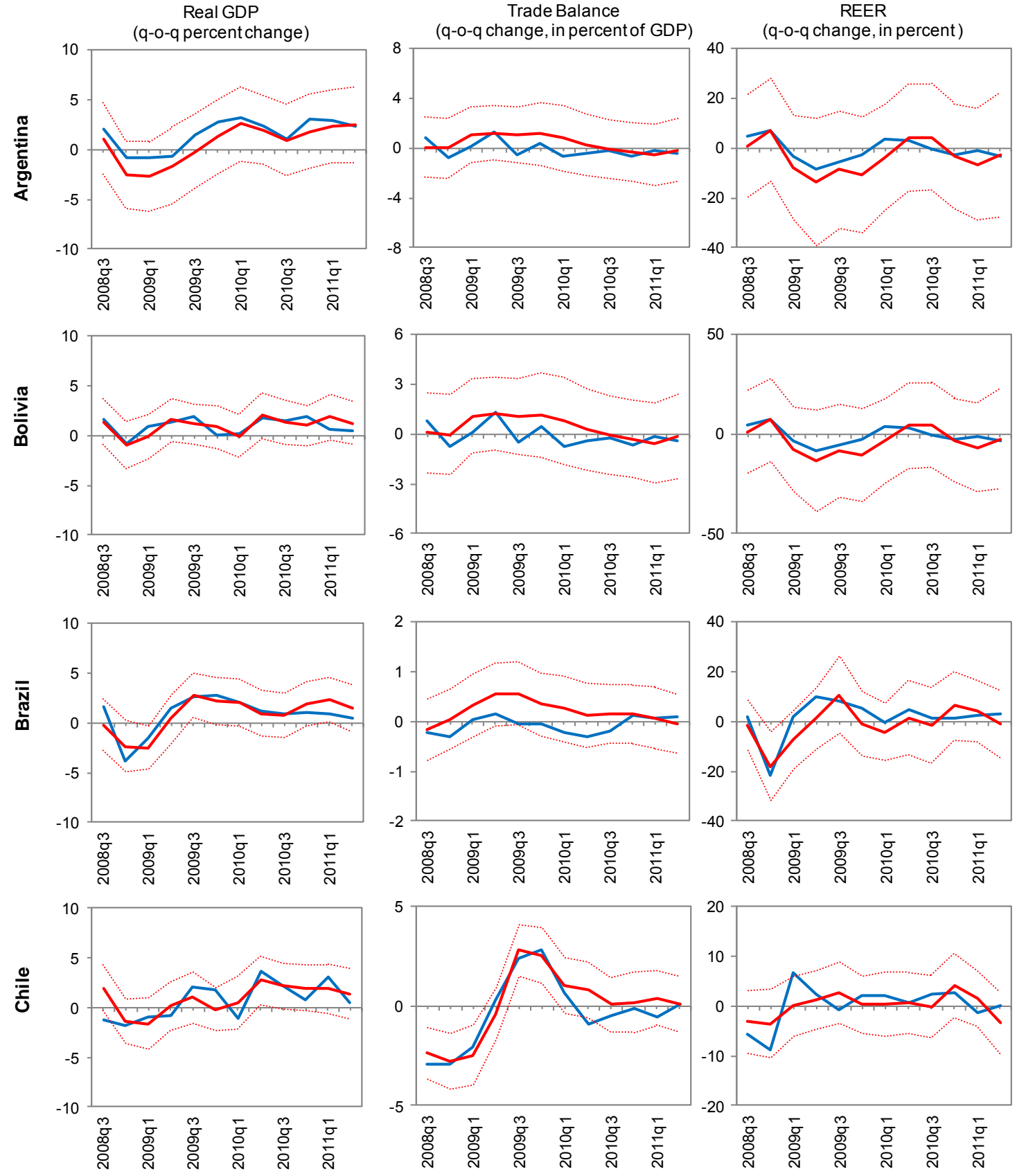
Figure A5. Forecasting Power of VAR Model During the Lehman Event (cont.)

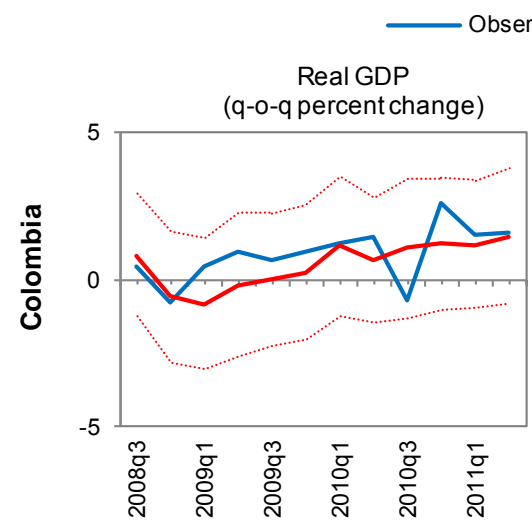

forecast

Trade Balance
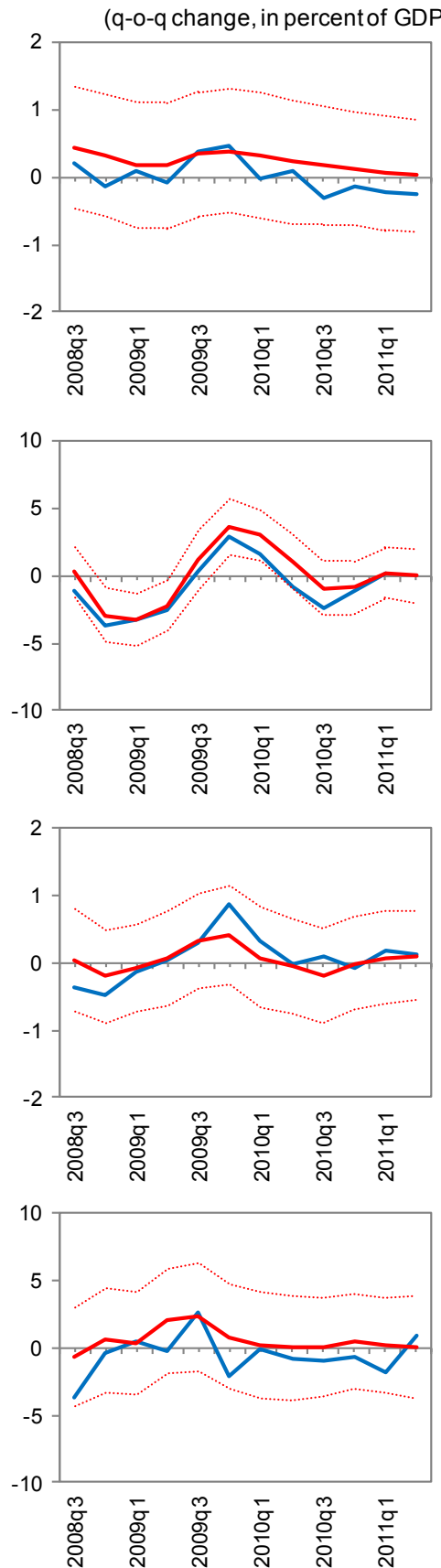

95\% C.I.

REER

(q-o-q change, in percent)
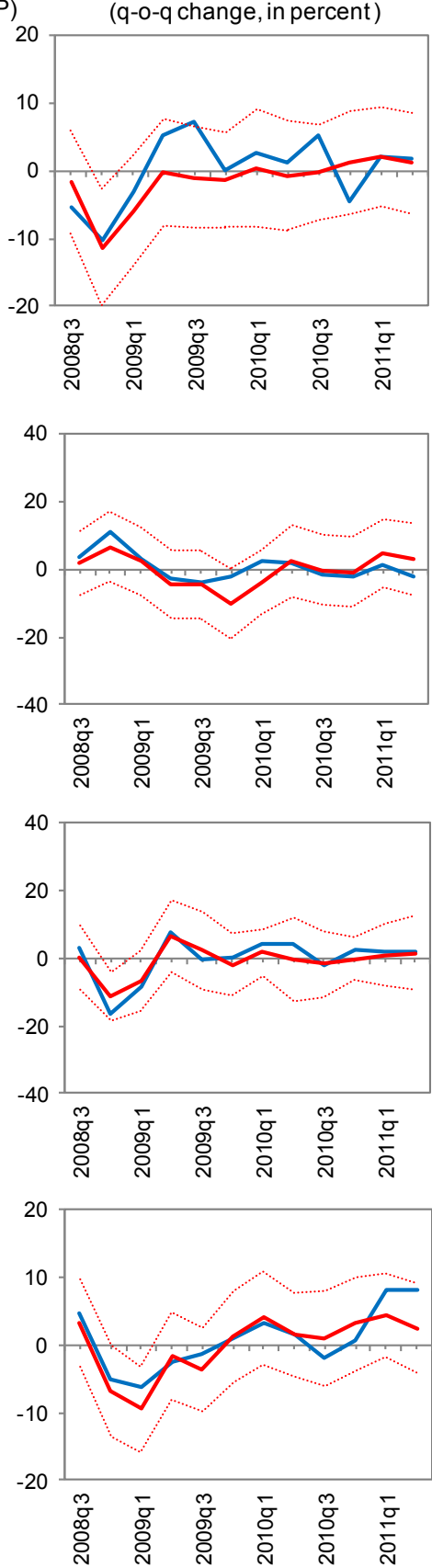
Figure A5. Forecasting Power of VAR Model During the Lehman Event (cont.)
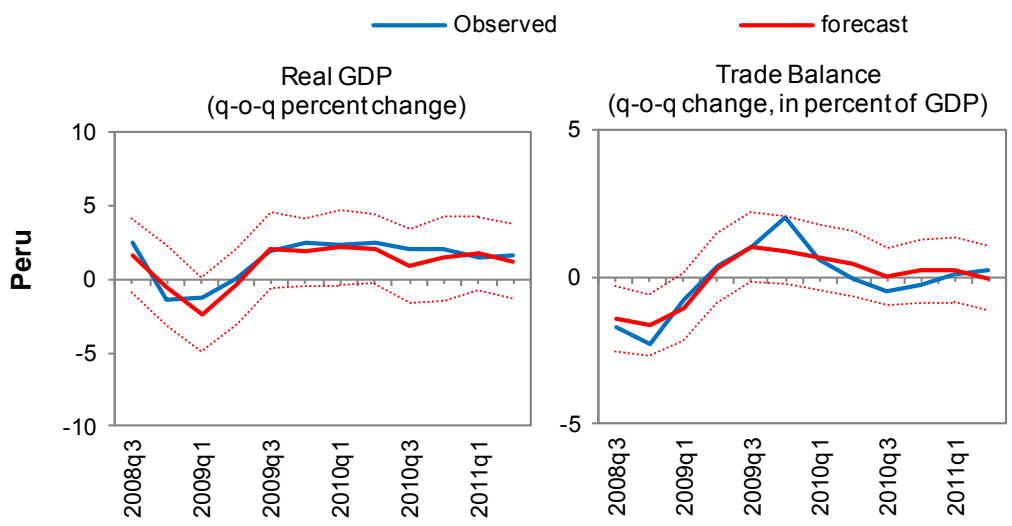

.............. 95\% C.I.
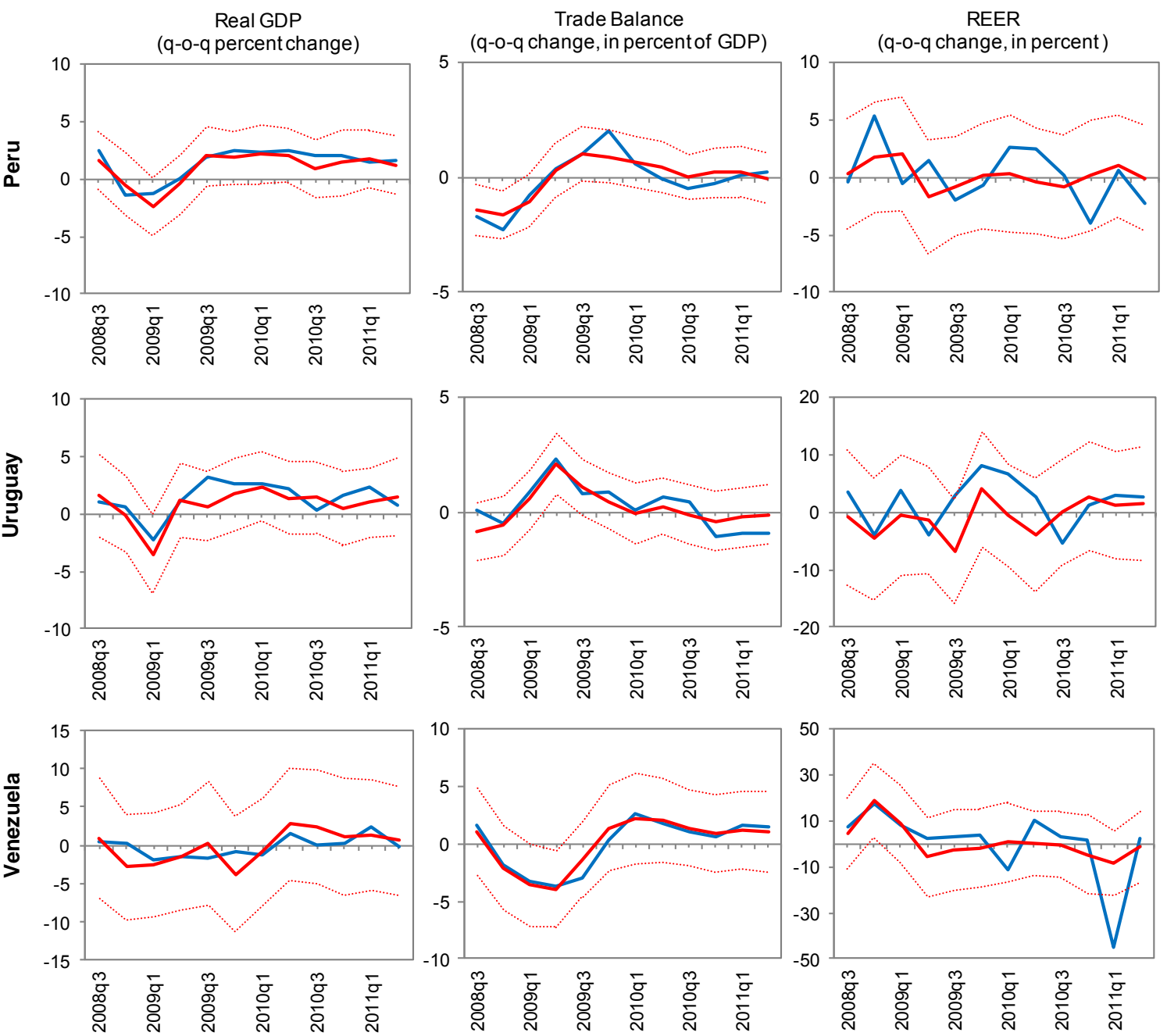


\section{Figures A6-A16}

Argentina
Factors Driving Public and External Debt Dynamics, 2003-17 1/ (percent of GDP)
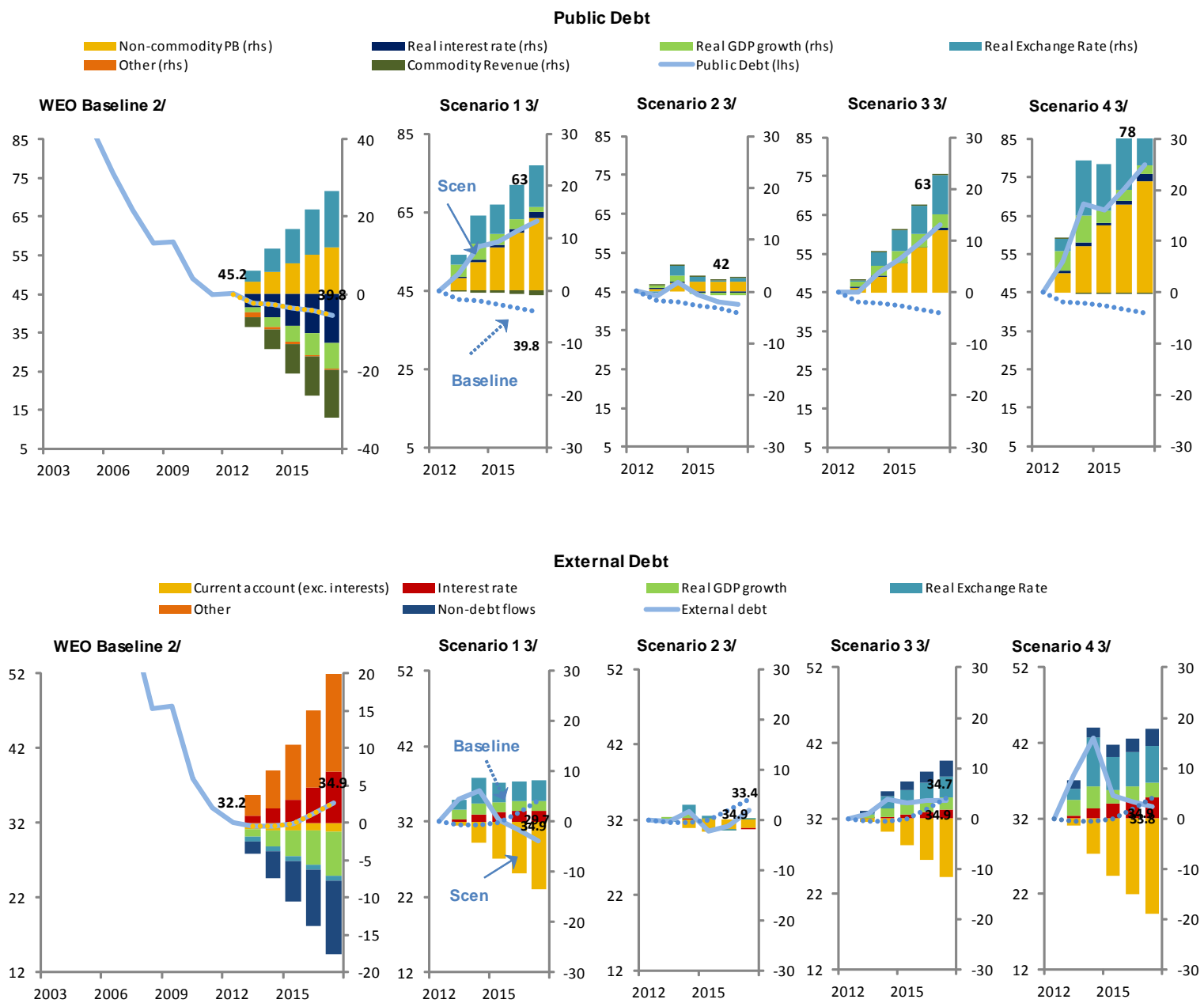

1/Public and external debt dynamics under alternative global scenarios.

2/Country desk projections (based on WEO baseline assumptions).

3/Based on differential between VAR forecasts and VAR bas eline. Bars denote contributions of differentfactors to the deviation of the debt ratios from the baseline.

Key Domestic Variables under Alternative Scenarios, 2012-17

(deviations from baseline)

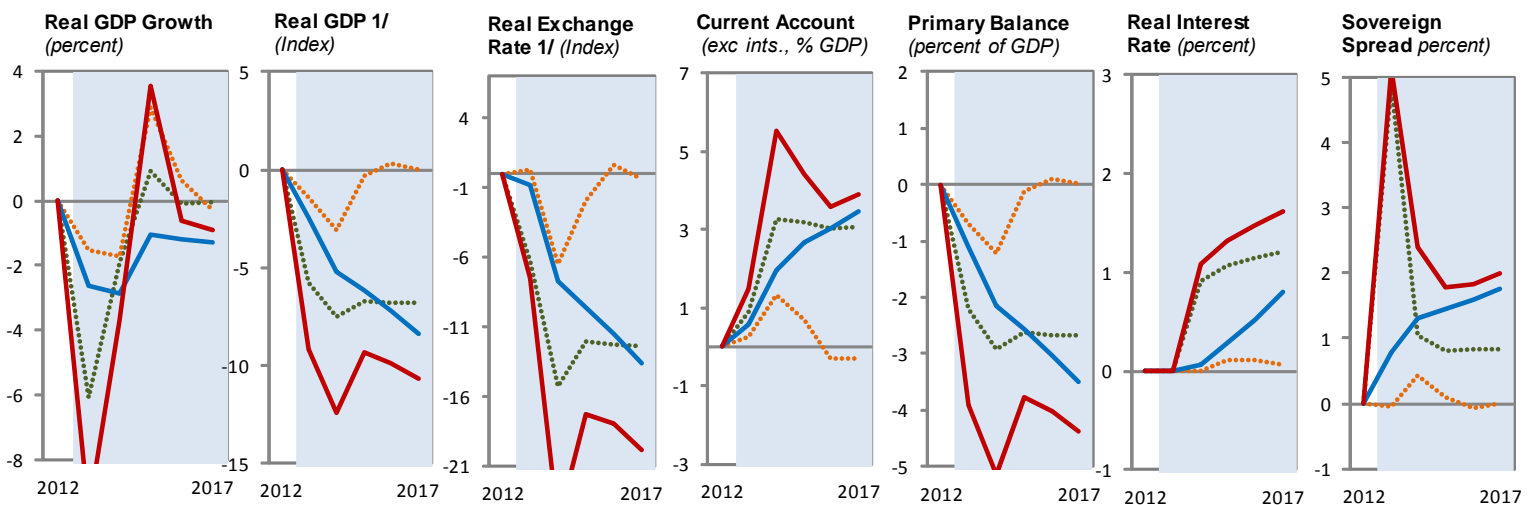

1/Deviation in percent of baseline. 
Non-commodity PB (rhs) Other (rhs)

WEO Baseline 2/
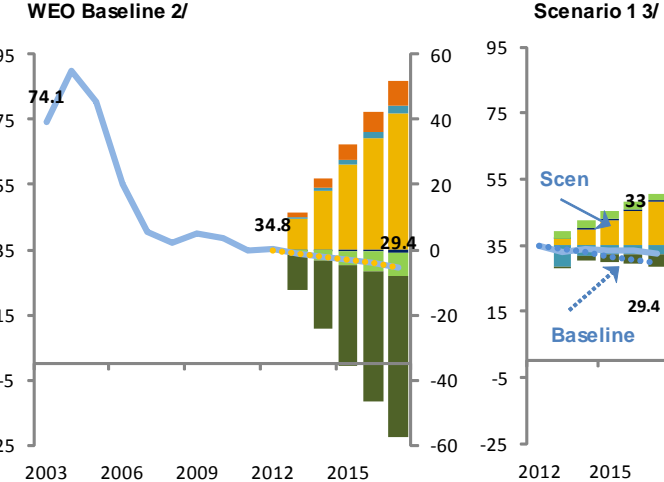

\section{Public Debt}

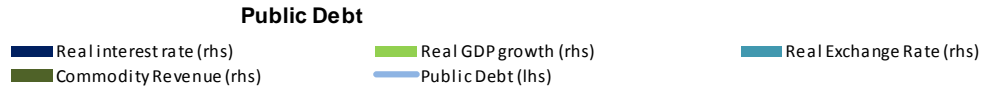

Scenario 43 /

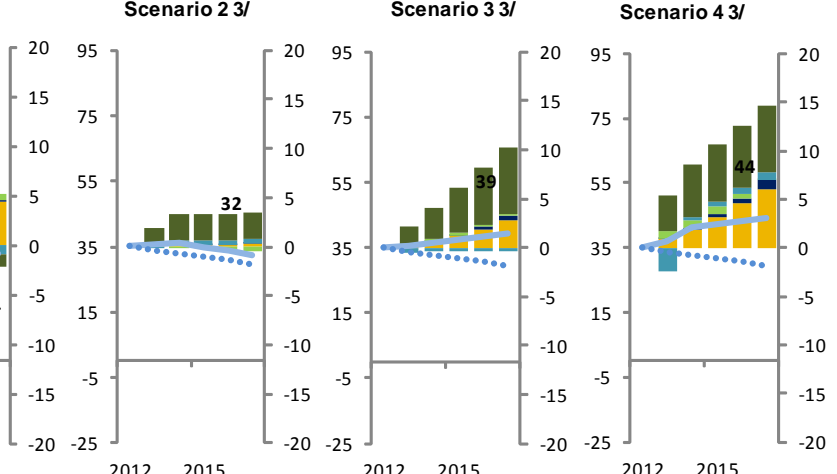

\section{External Debt}

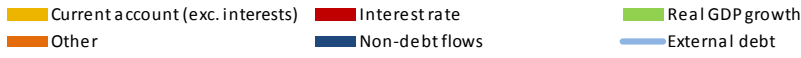

Real Exchange Rate
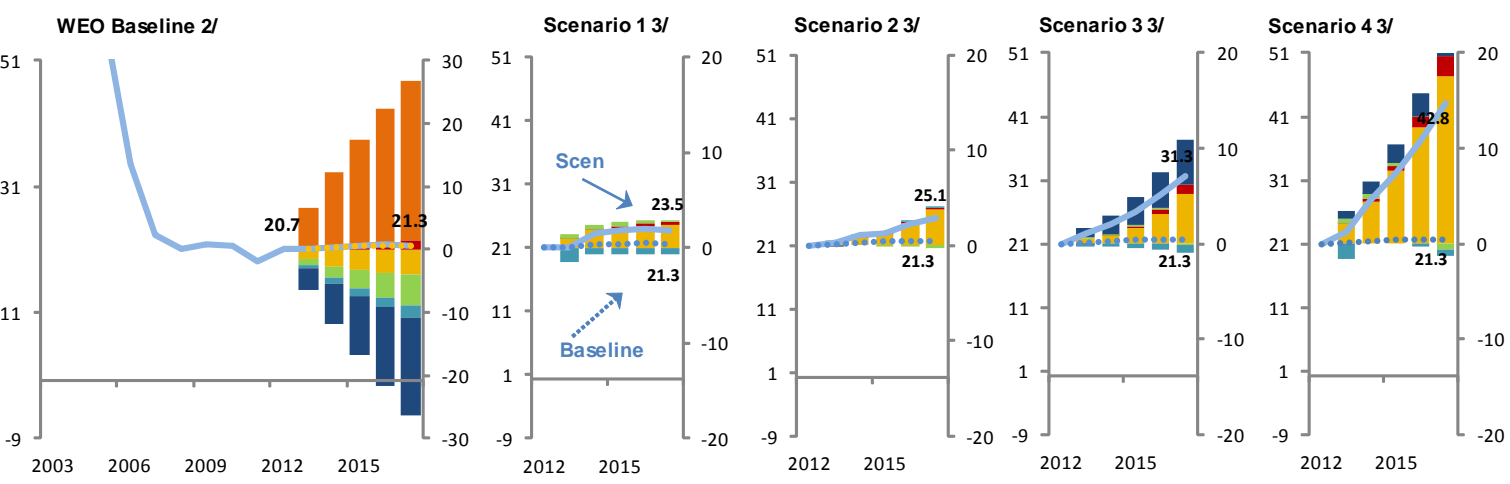

1/Public and external debt dynamics under alternative global scenarios

2/ Country desk projections (based on WEO baseline assumptions).

Key Domestic Variables under Alternative Scenarios, 2012-17 (deviations from baseline)

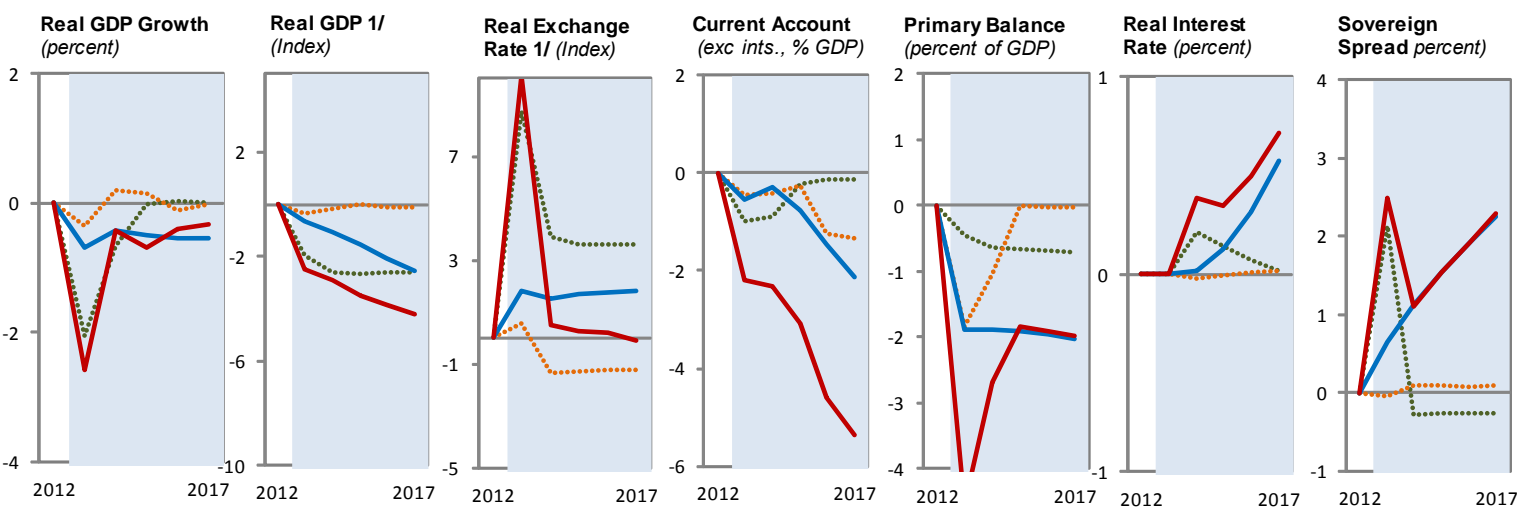

1/Deviation in percent of baseline. 
Non-commodity PB (rhs) Other (rhs)

WEO Baseline 2/
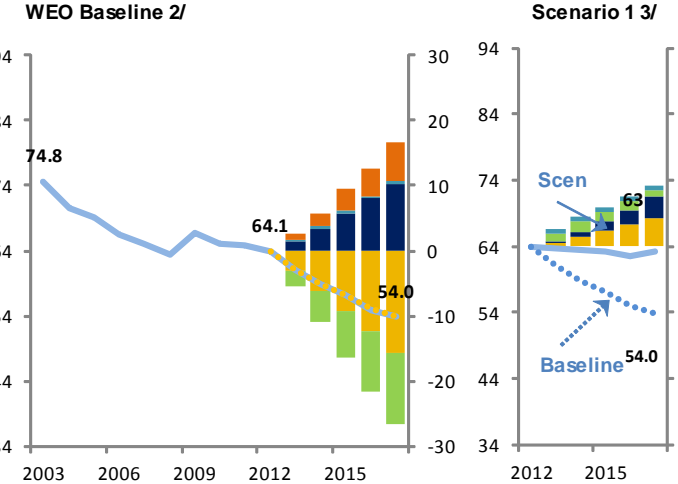

Public Debt

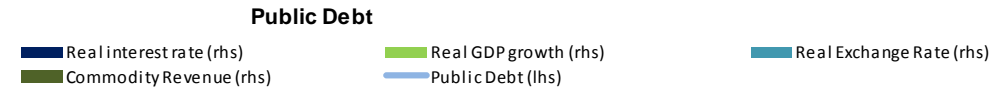

cenario 23

Scenario 33 /

Scenario $43 /$

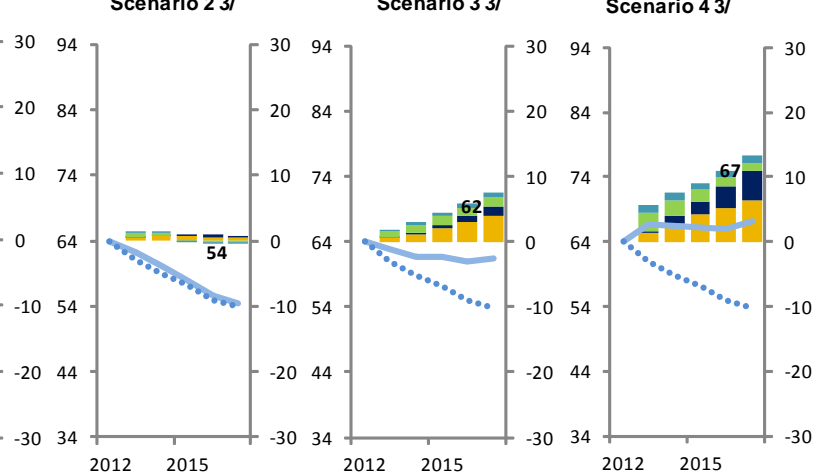

External Debt

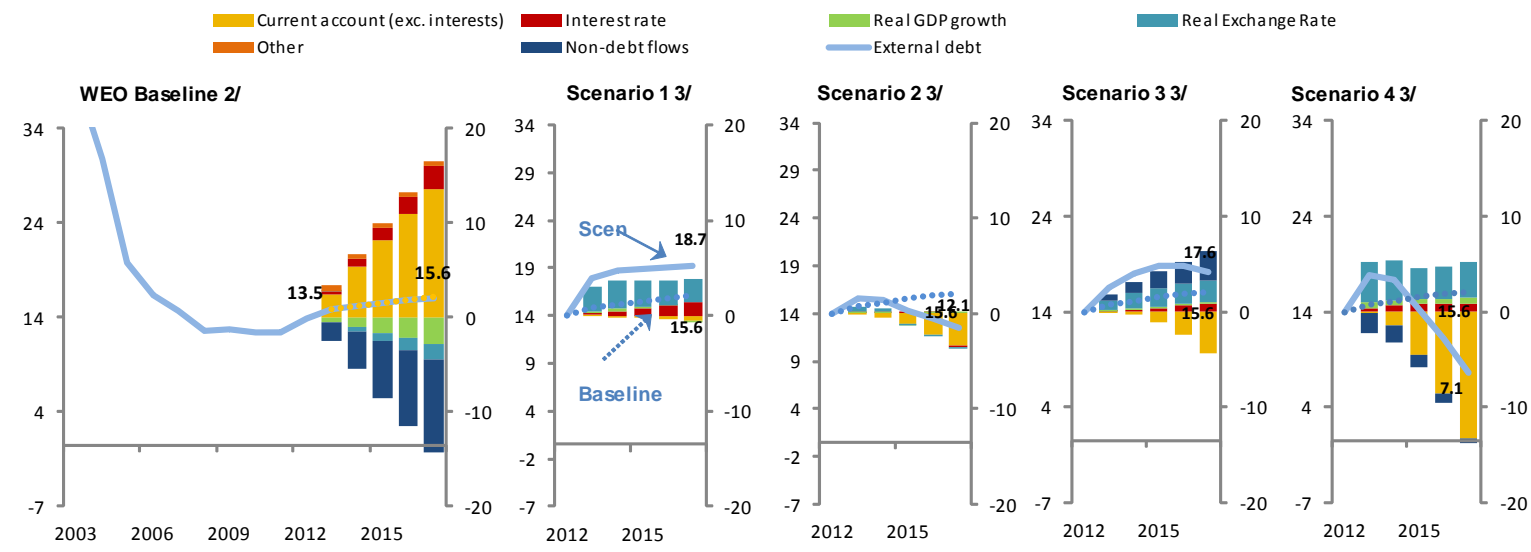

1/Public and external debt dynamics under alternative global scenarios.

2/ Country desk projections (based on WEO baseline assumptions).

$3 /$ Based on differential between VAR forecasts and VAR baseline. Bars denote contributions of differentfactors to the deviation of the debt ratios from the baseline.

Key Domestic Variables under Alternative Scenarios, 2012-17 (deviations from baseline)
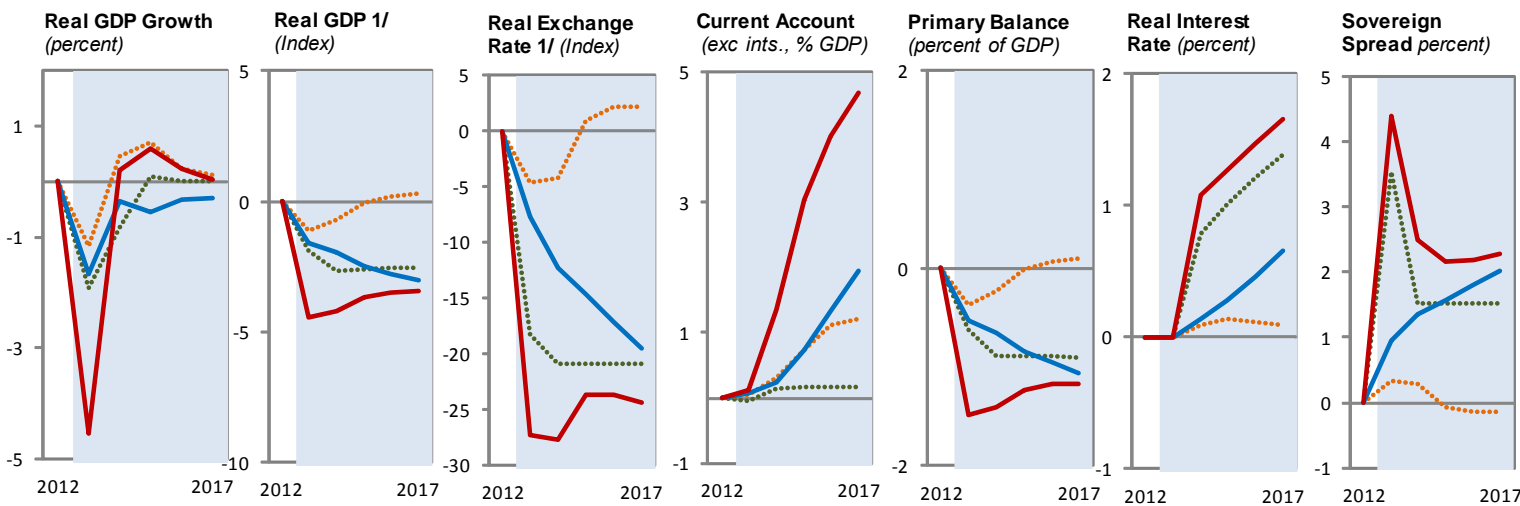

1/Deviation in percent of baseline. 
Chile

Non-commodity PB (rhs) Other (rhs)

WEO Baseline 2/

\section{Public Debt}

Real interest rate (rhs)
Commodity Revenue (rhs)

Scenario 13 / Real GDP growth (rhs)
Public Debt (Ihs)
Real Exchange Rate (rhs)

Scenario 43 /

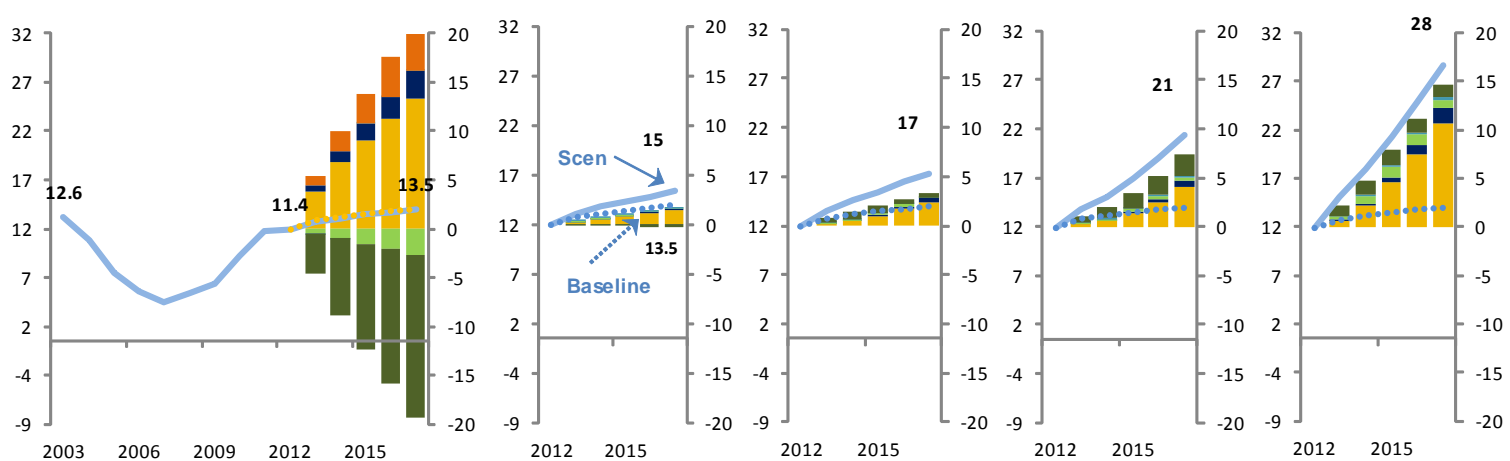

\section{External Debt}

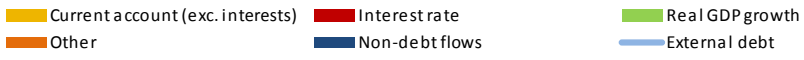

Real Exchange Rate
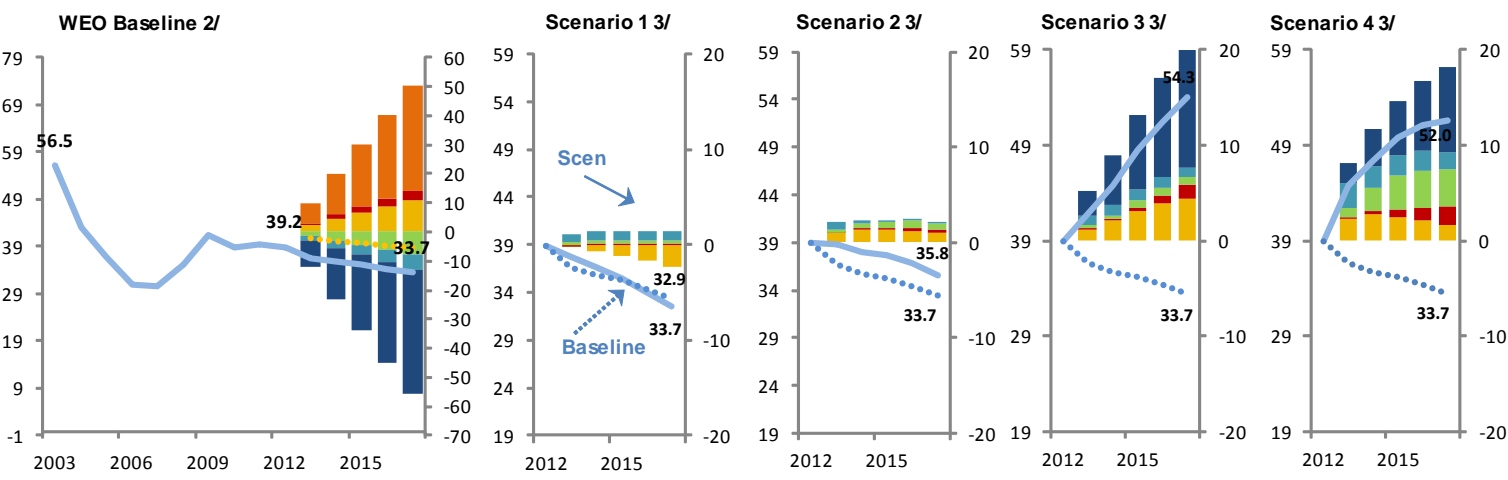

1/Public and external debtdynamics under alternative global scenarios.

2/Country desk projections (based on WEO baseline assumptions).

3 / Based on differential between VAR forecasts and VAR baseline. Bars denote contributions of differentfactors to the deviation of the debt ratios from the baseline.

Key Domestic Variables under Alternative Scenarios, 2012-17 (deviations from baseline)
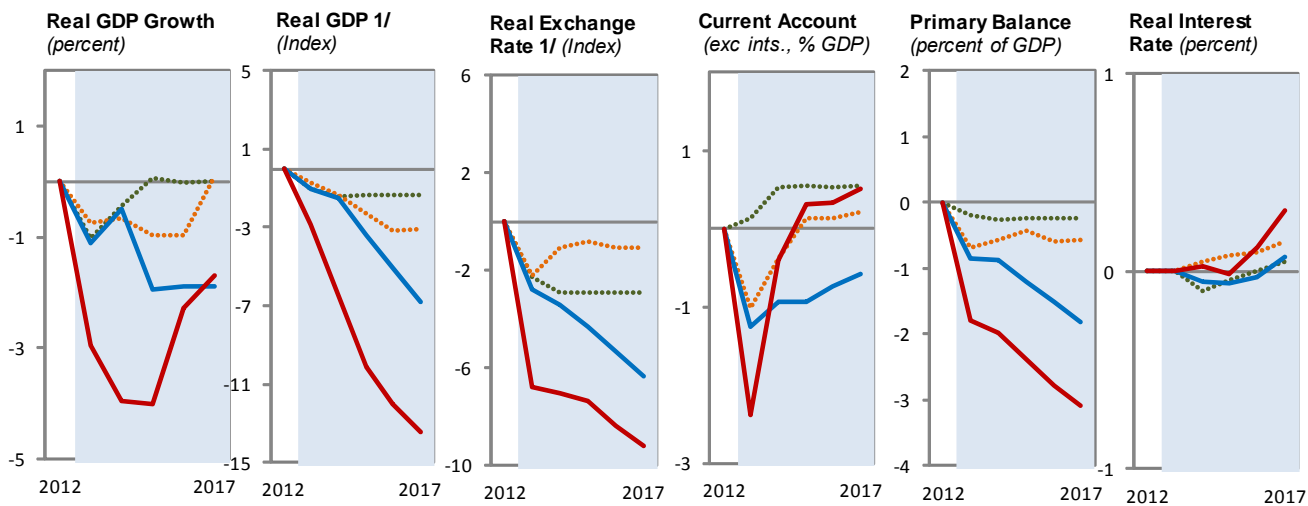

Sovereign Spread percent)

1/Deviation in percent of baseline. 
Non-commodity PB (rhs) Other (rhs)

WEO Baseline 2/

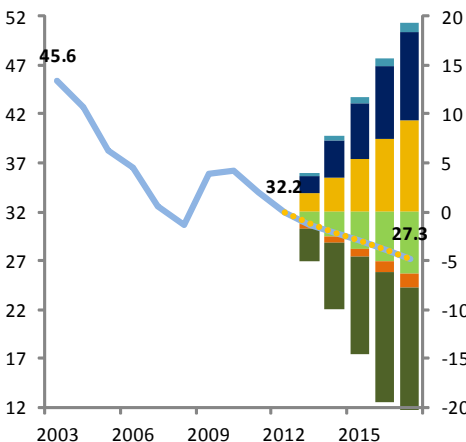

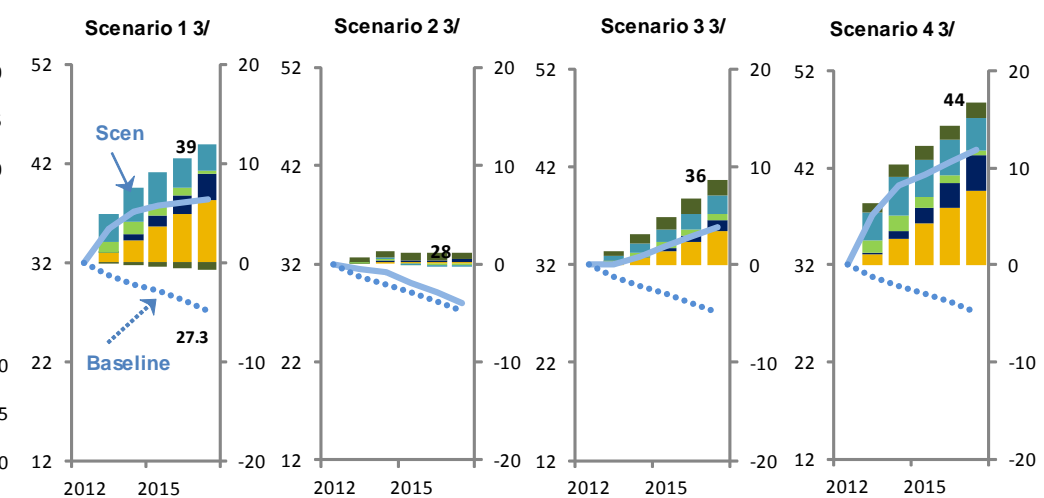

\section{Public Debt}

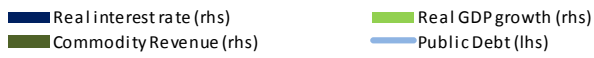

Real Exchange Rate (rhs)

\section{External Debt}

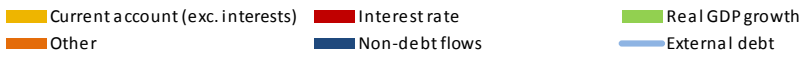

Real Exchange Rate

WEO Baseline 2/
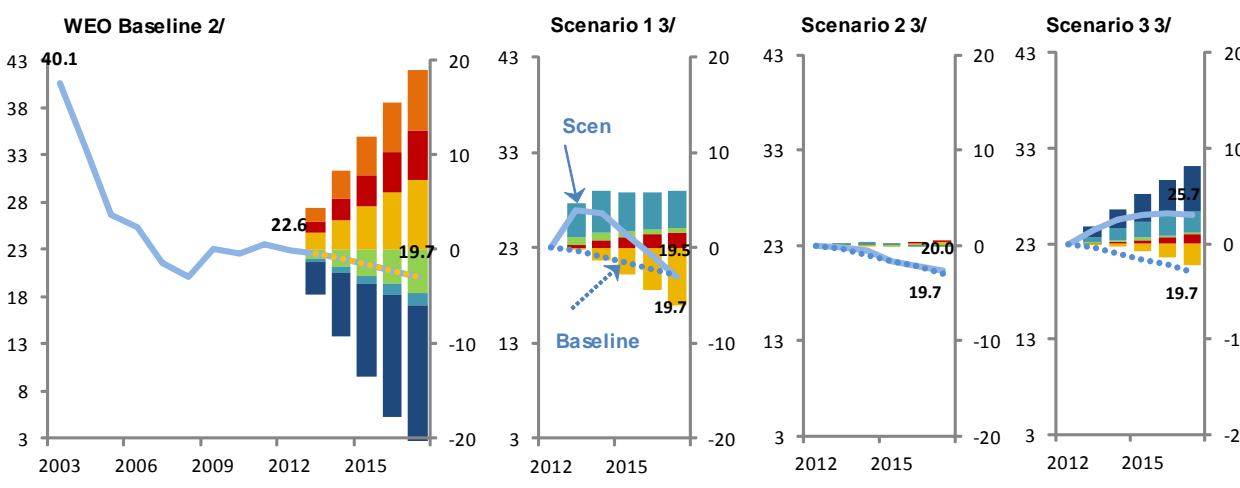

Scenario 43 /

1/Public and external debt dynamics under alternative global scenarios.

$2 /$ Country desk projections (based on WEO baseline assumptions).

3 / Based on differential between VAR forecasts and VAR baseline. Bars denote contributions of differentfactors to the deviation of the debt ratios from the baseline.

Key Domestic Variables under Alternative Scenarios, 2012-17 (deviations from baseline)

......... VAR Scenario $1 \quad \ldots . . . . .$. VAR Scenario $2 \longrightarrow$ VAR Scenario $3 \quad$ VAR Scenario 4
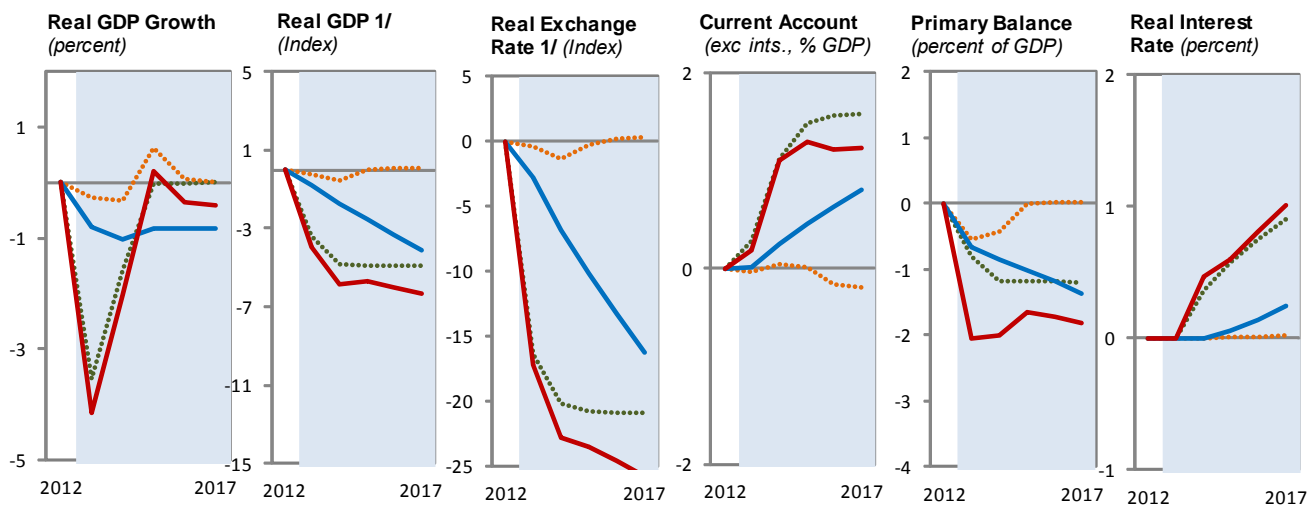

Sovereign Spread percent)

1/Deviation in percent of baseline. 
Non-commodity PB (rhs) Other(rhs)

WEO Baseline 2/

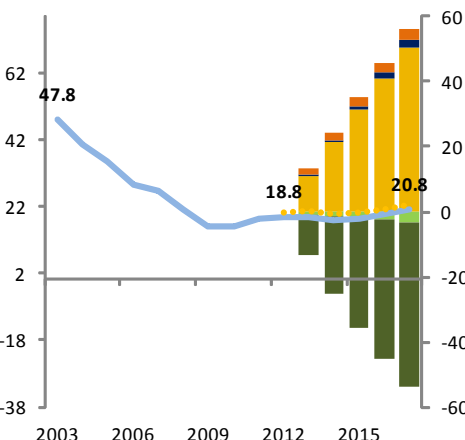

Real interest rate (rhs)
Commodity Revenue (rhs)

Scenario $13 /$ Real GDP growth (rhs)
Public Debt (Ihs)
Real Exchange Rate (rhs)

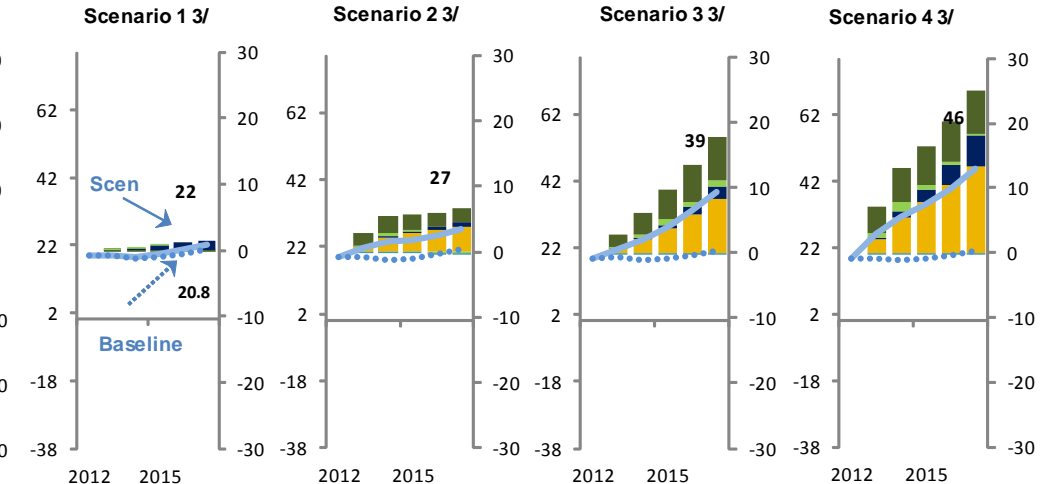

\section{External Debt}

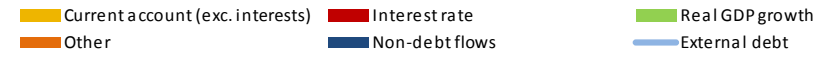

Real Exchange Rate

WEO Baseline 2/

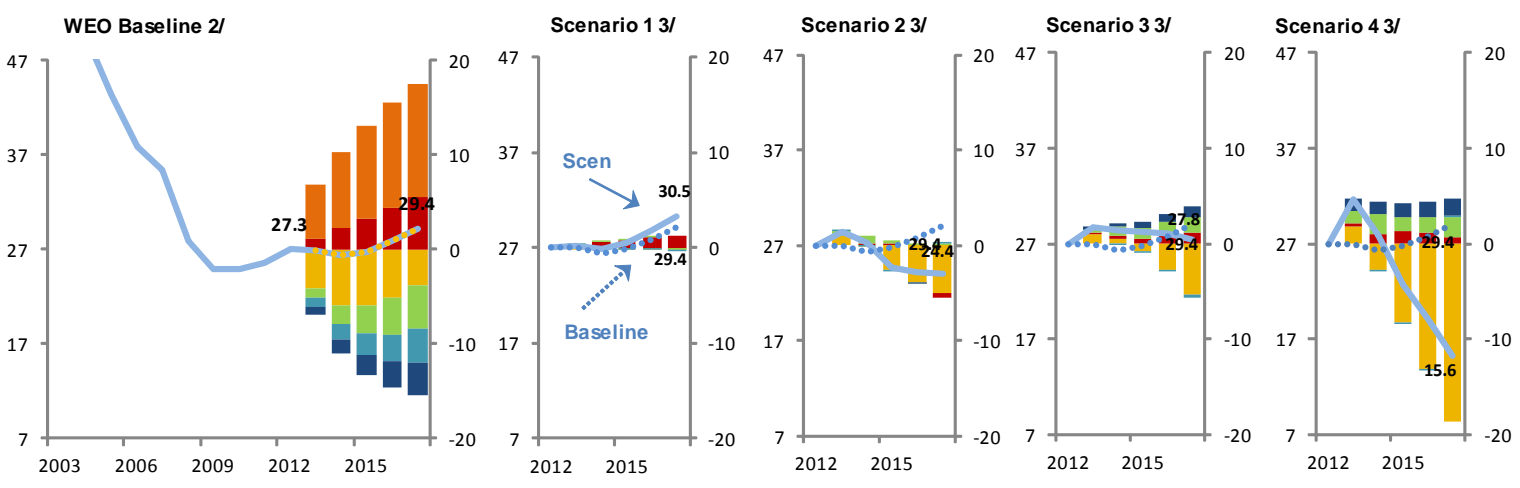

20122015

$2012 \quad 2015$

1/Public and external debt dynamics under alternative global scenarios.

2/Country desk projections (based on WEO baseline assumptions).

$3 /$ Based on differential between VAR forecasts and VAR baseline. Bars denote contributions of differentfactors to the deviation of the debt ratios from the baseline.

Key Domestic Variables under Alternative Scenarios, 2012-17 (deviations from baseline)

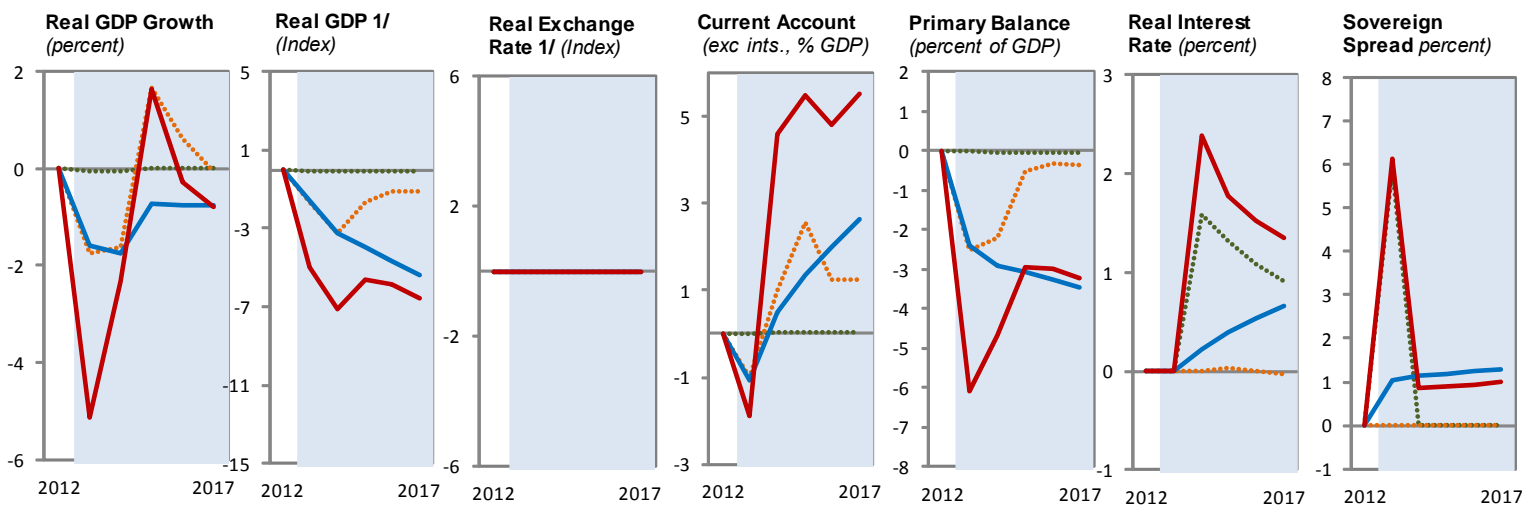

$1 /$ Deviation in percent of baseline. 
Mexico

Factors Driving Public and External Debt Dynamics, 2003-17 1/ (percent of GDP)

Non-commodity PB (rhs) Other (rhs)

WEO Baseline 2/

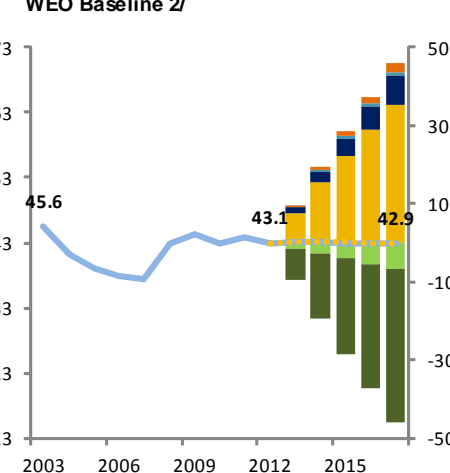

\section{Public Debt}

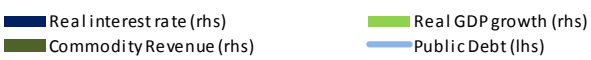

Real Exchange Rate (rhs)

Scenario $13 /$

Scenario $23 /$

Scenario $33 /$

Scenario 43 /

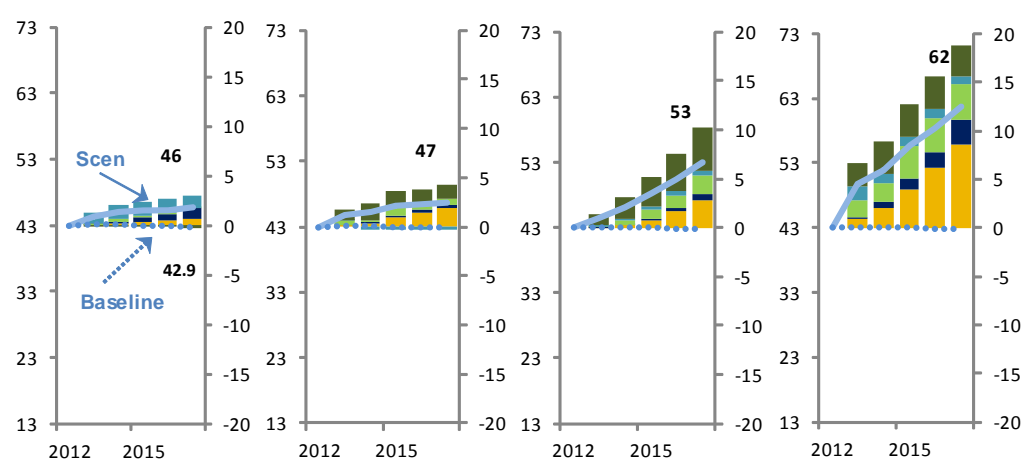

External Debt

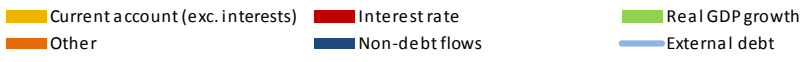

Real Exchange Rate

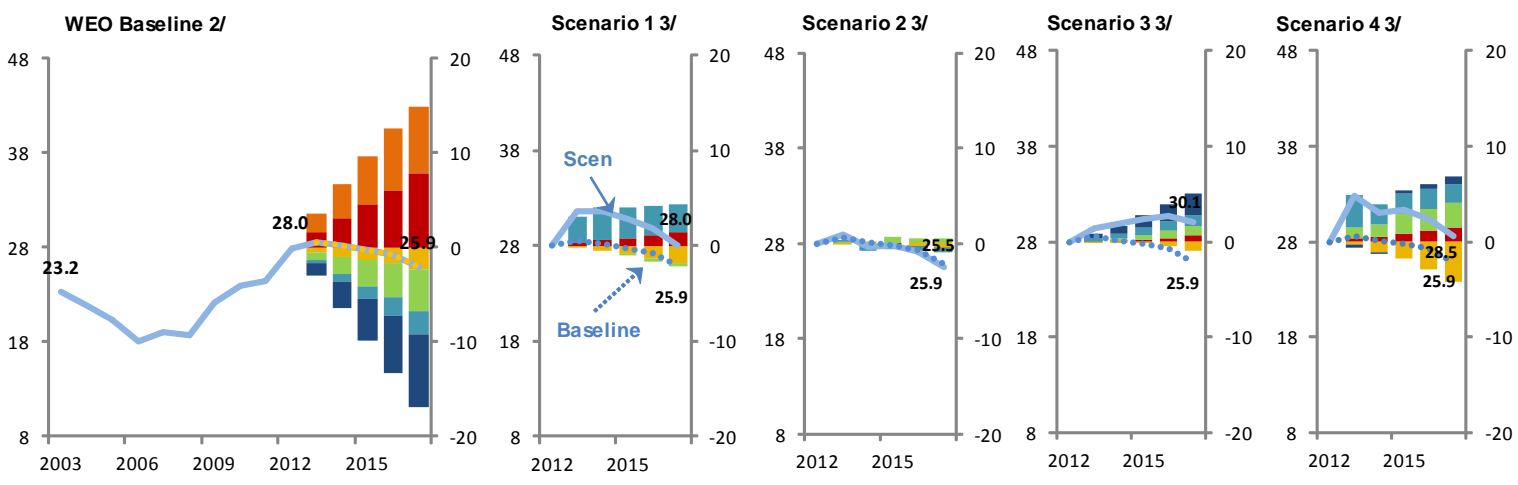

1/Public and external debt dynamics under alternative global scenarios.

$2 /$ Country desk projections (based on WEO baseline assumptions).

3/Based on differential between VAR forecasts and VAR baseline. Bars denote contributions of differentfactors to the deviation of the debt ratios from the baseline.

Key Domestic Variables under Alternative Scenarios, 2012-17 (deviations from baseline)

......... VAR Scenario $1 \quad \ldots . . . . .$. VAR Scenario $2 \longrightarrow$ VAR Scenario $3 \quad$ VAR Scenario 4
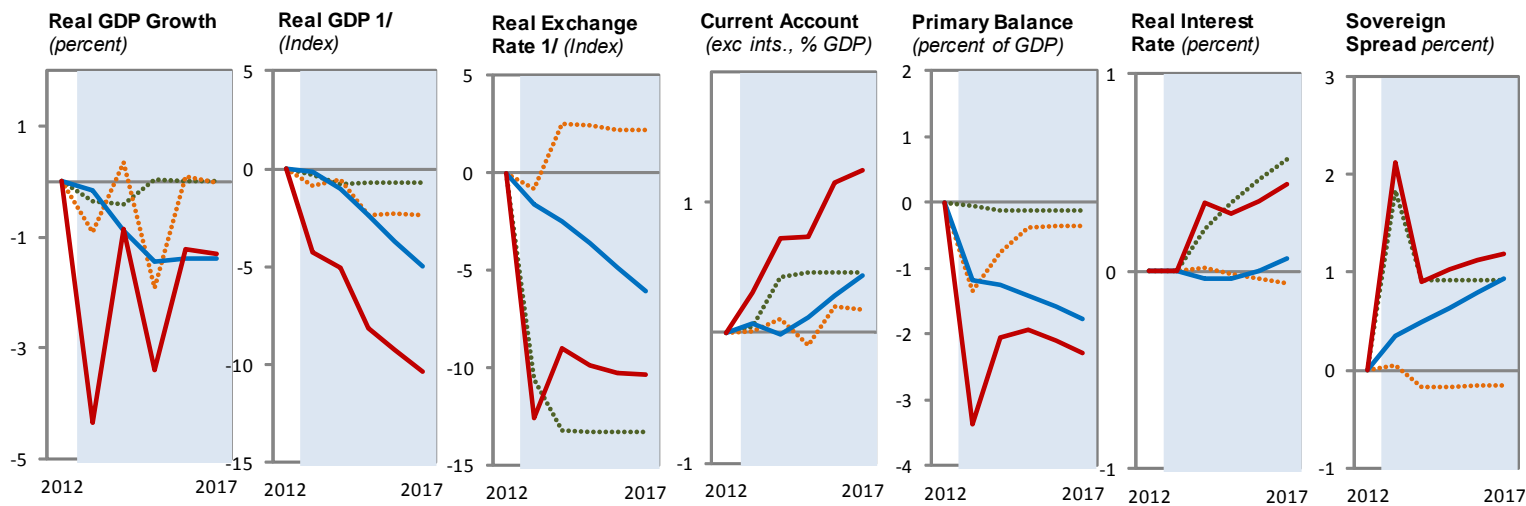

1/Deviation in percent of baseline. 
Non-commodity PB (rhs) Other (rhs)

WEO Baseline 2/

\section{Public Debt}

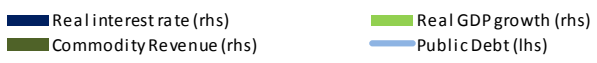

Real Exchange Rate (rhs)

Scenario $13 /$

Scenario 23

Scenario $33 /$

Scenario $43 /$

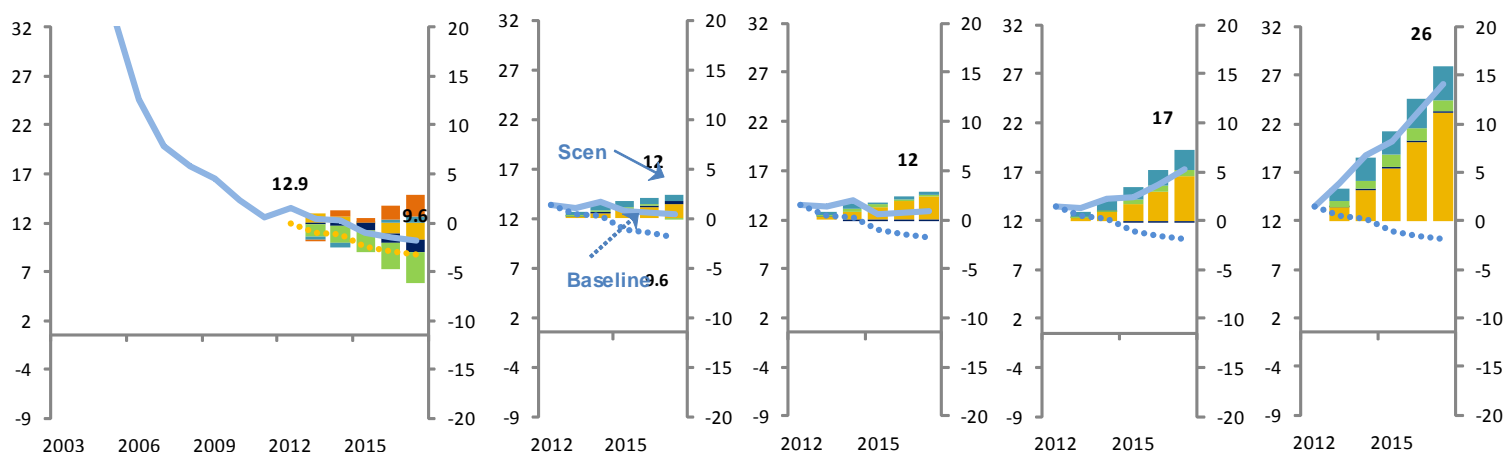

\section{External Debt}

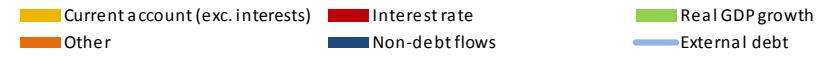

Real Exchange Rate

WEO Baseline 2/

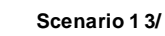

Scenario 23/ Scenario 33/

Scenario 43 /
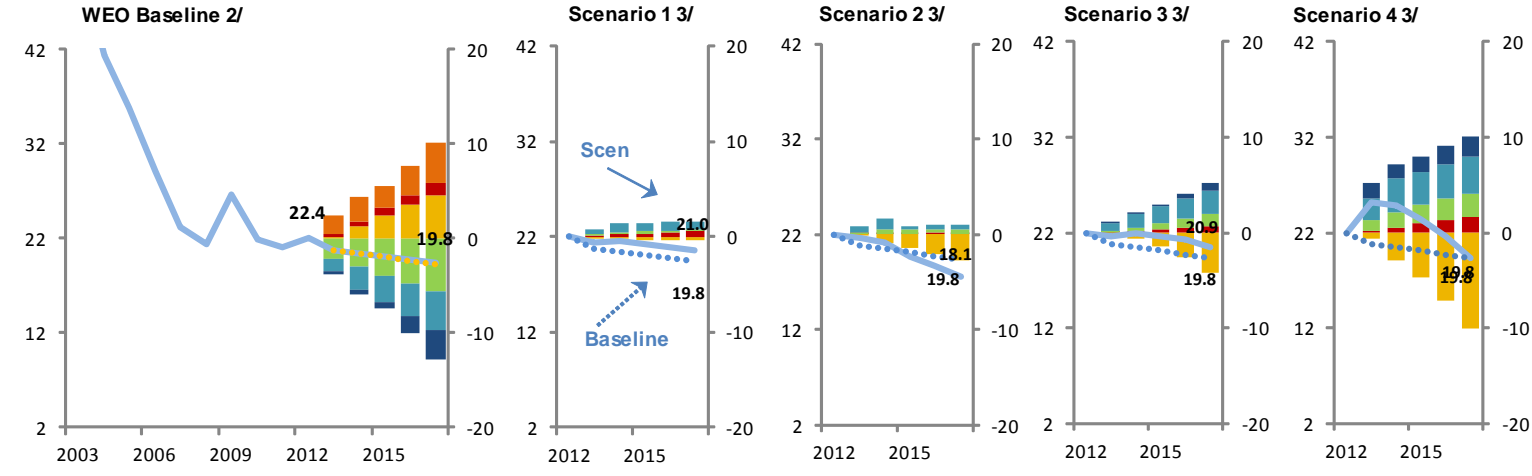

1/Public and external debtdynamics under alternative global scenarios.

2/Country desk projections (based on WEO baseline assumptions).

3 / Based on differential between VAR forecasts and VAR baseline. Bars denote contributions of differentfactors to the deviation of the debt ratios from the baseline.

Key Domestic Variables under Alternative Scenarios, 2012-17 (deviations from baseline)
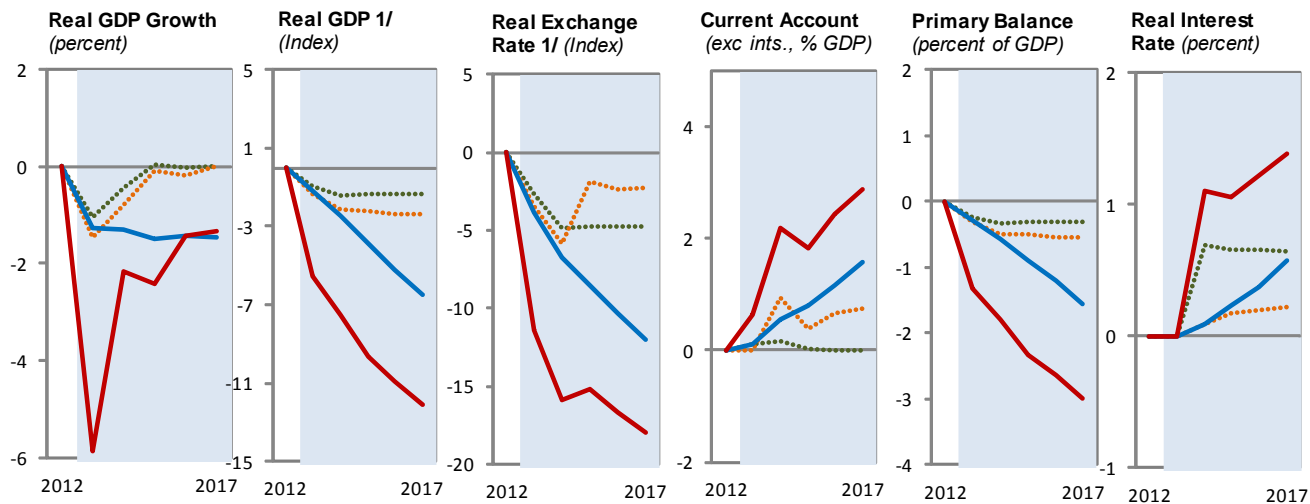

Sovereign Spread percent)

1/Deviation in percent of baseline. 
Peru

Factors Driving Public and External Debt Dynamics, 2003-17 1/ (percent of GDP)
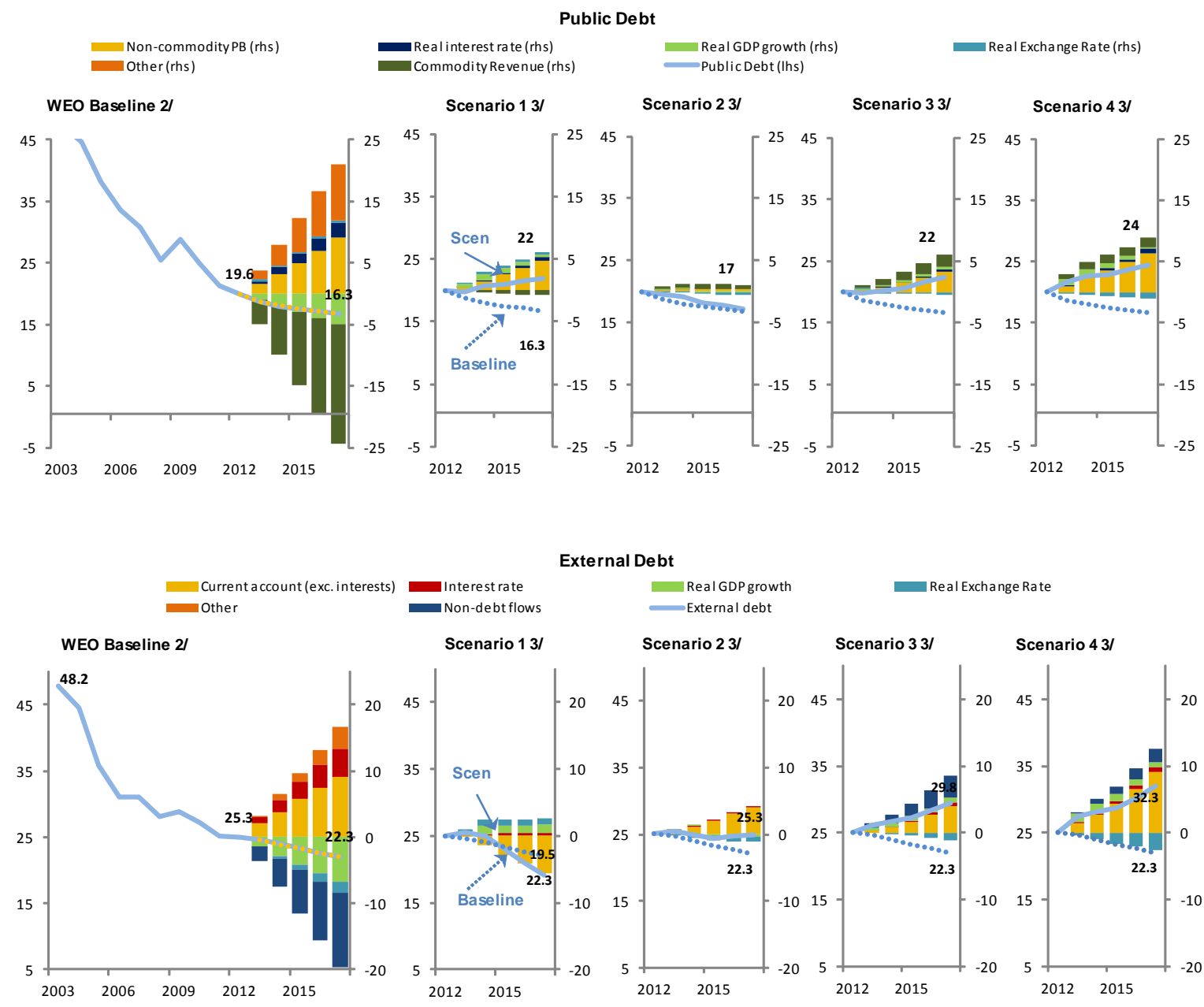

1/Public and external debt dynamics under alternative global scenarios.

2/Country desk projections (based on WEO baseline assumptions).

$3 /$ Based on differential between VAR forecasts and VAR baseline. Bars denote contributions of differentfactors to the deviation of the debt ratios from the baseline.

Key Domestic Variables under Alternative Scenarios, 2012-17 (deviations from baseline)
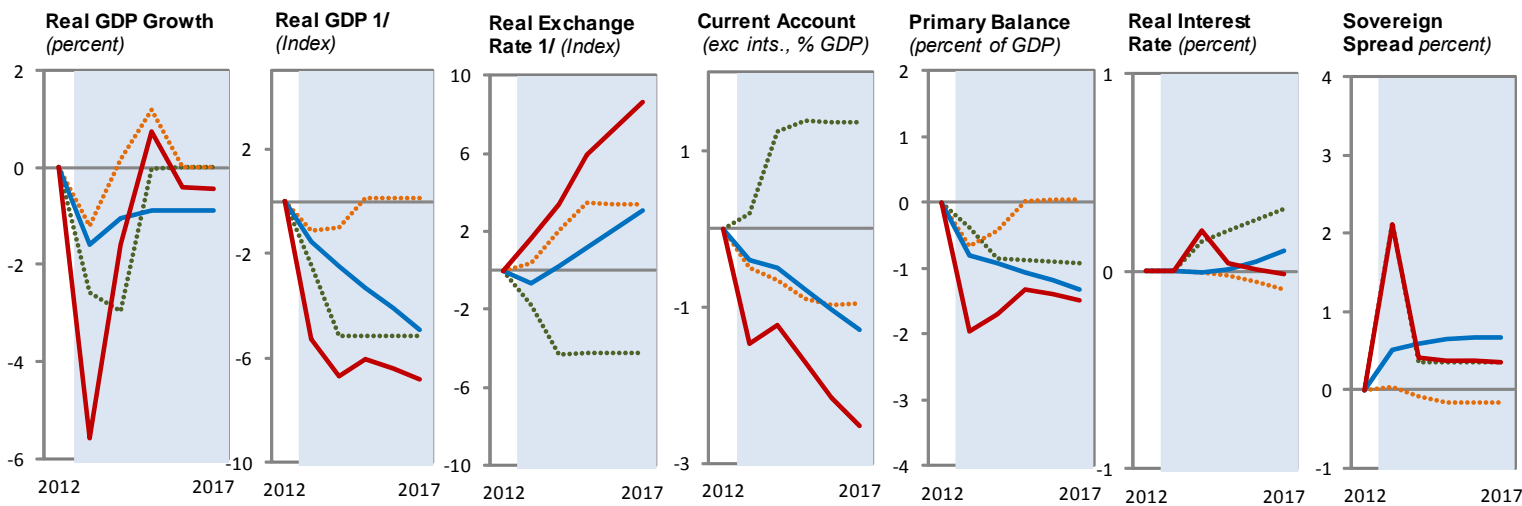

1/Deviation in percent of baseline. 

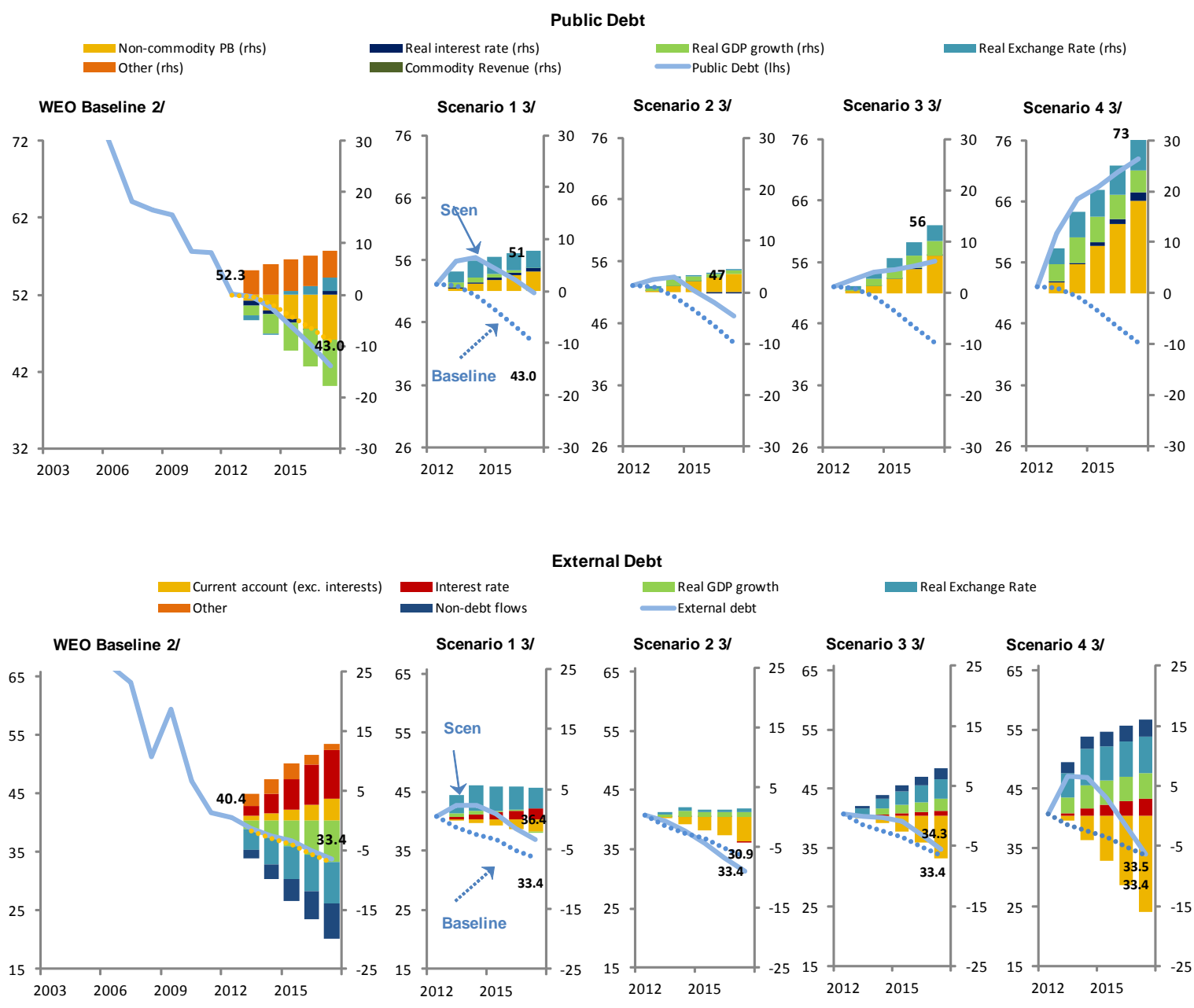

1/Public and external debt dynamics under alternative global scenarios.

$2 /$ Country desk projections (based on WEO baseline assumptions).

3/Based on differential between VAR forecasts and VAR baseline. Bars denote contributions of differentfactors to the deviation of the debt ratios from the baseline.

Key Domestic Variables under Alternative Scenarios, 2012-17 (deviations from baseline)
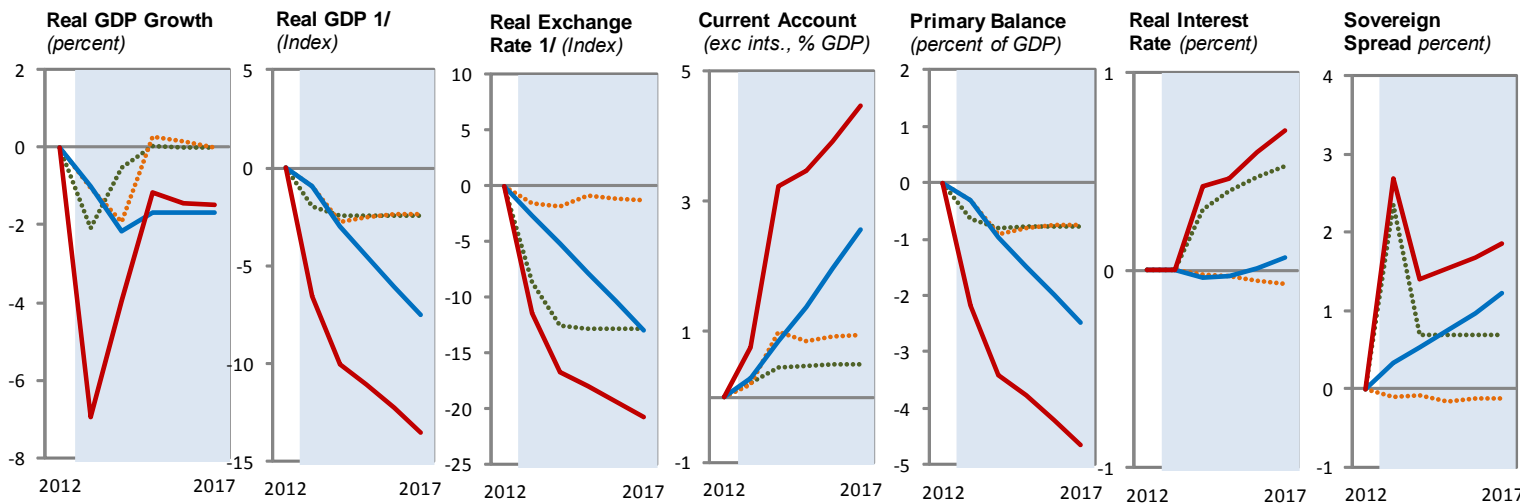

1/Deviation in percent of baseline. 
Non-commodity PB (rhs) Other (rhs)

WEO Baseline 2/

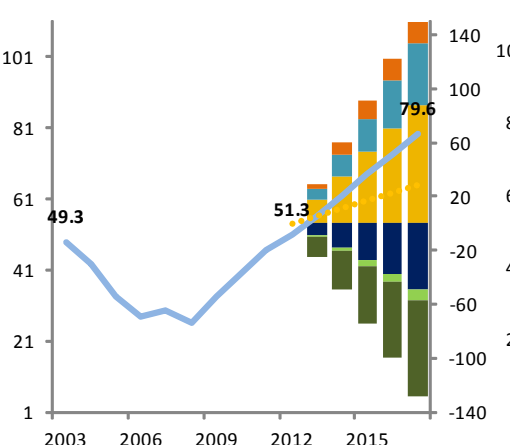

Scenario 13/
Real Exchange Rate (rhs)

\section{Public Debt}

$\begin{array}{ll}\text { Realinterest rate (rhs) } & \text { Real GDP growth (rhs) } \\ \text { Commodity Revenue (rhs) } & \text { Public Debt (lhs) }\end{array}$

Scenario 33/ Scenario 43 /

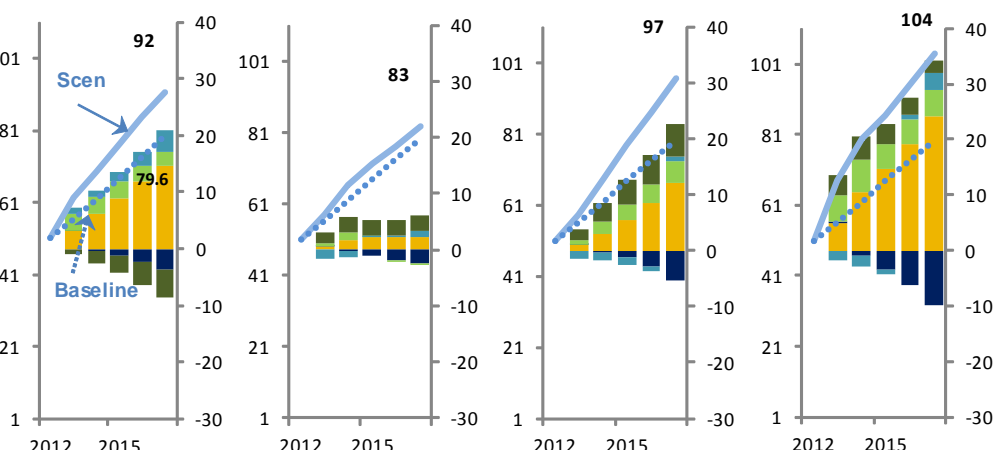

\section{External Debt}

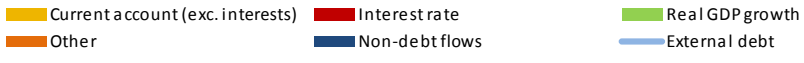

Real Exchange Rate

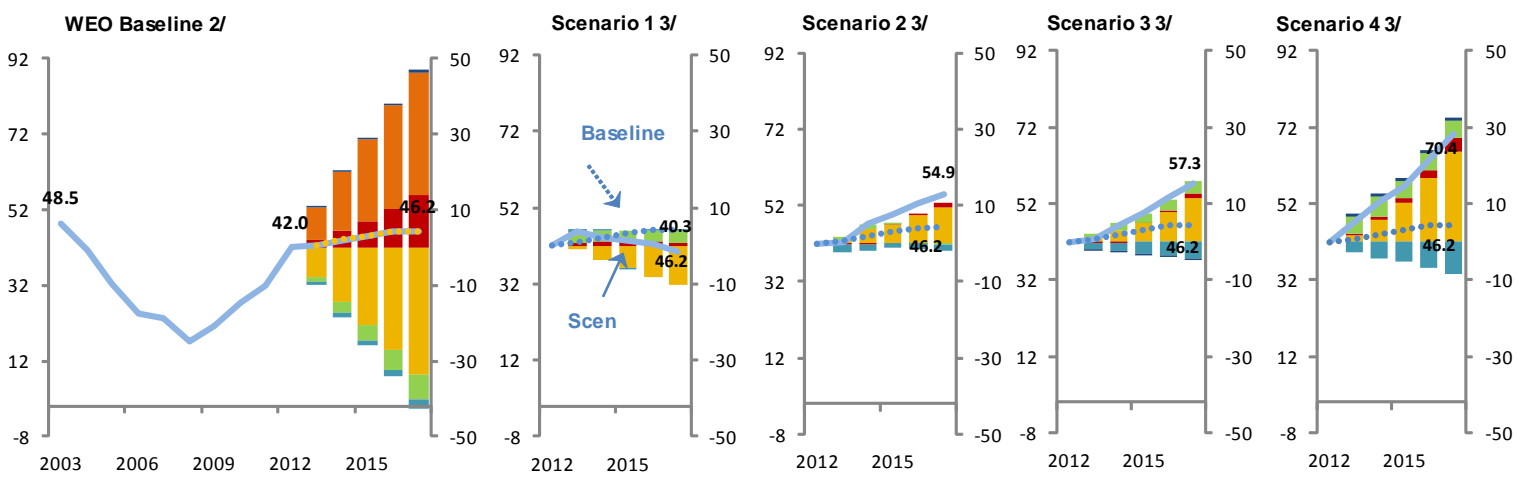

1/Public and external debtdynamics under alternative global scenarios.

2/ Country desk projections (based on WEO baseline assumptions).

Key Domestic Variables under Alternative Scenarios, 2012-17 (deviations from baseline)
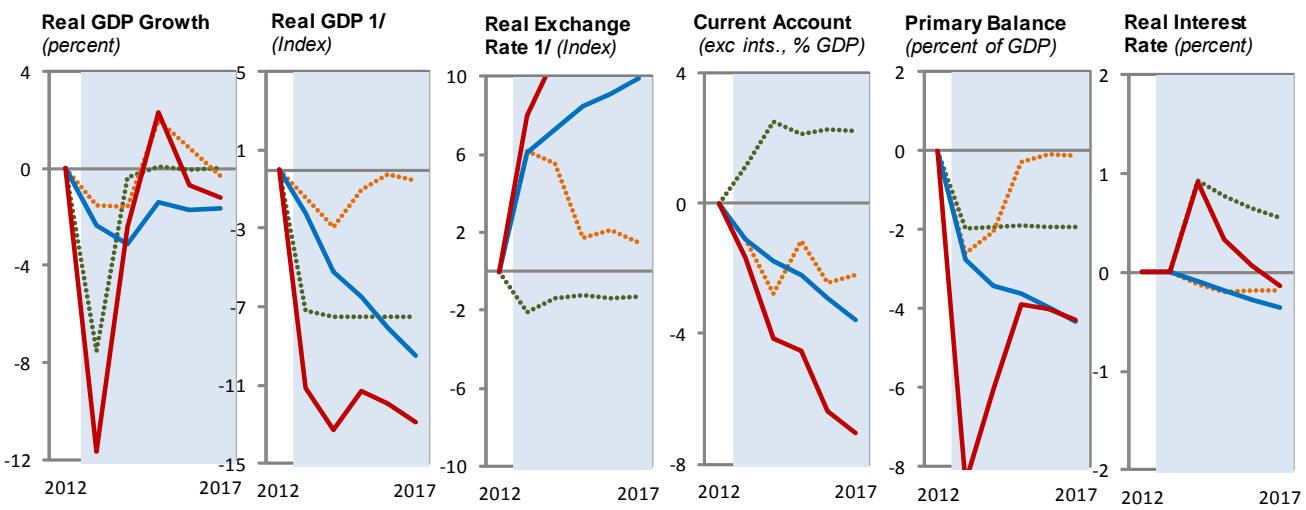

Sovereign Spread percent)

1/Deviation in percent of baseline. 
Table A1. VAR Estimation Results

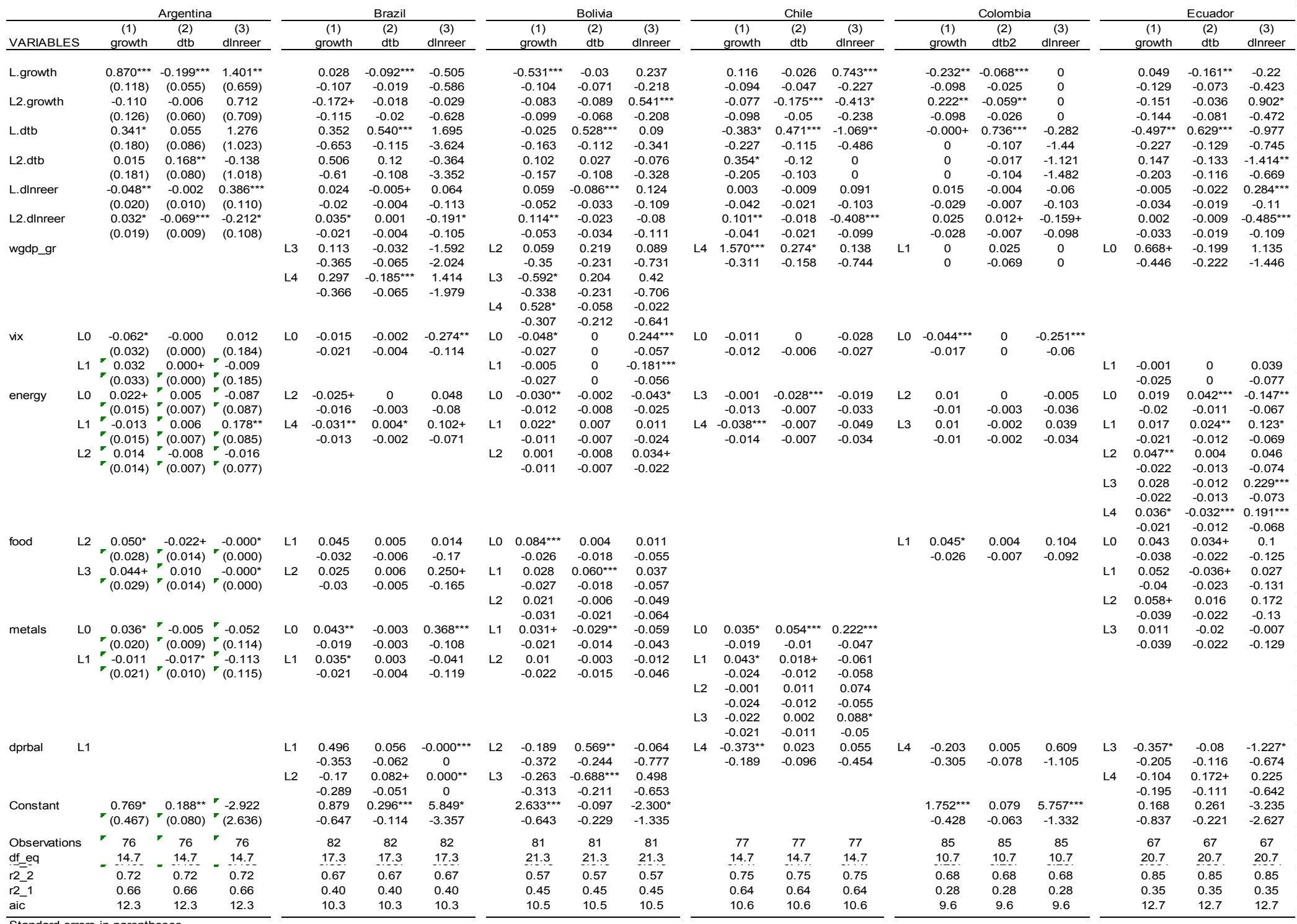

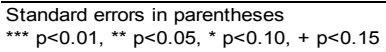


Table A1. VAR Estimation Results (cont.)

\begin{tabular}{|c|c|c|c|c|c|c|c|c|c|c|c|c|c|c|c|c|c|c|c|c|}
\hline \multirow{2}{*}{\multicolumn{2}{|c|}{ VARIABIFS }} & \multicolumn{3}{|c|}{ Mexico } & \multicolumn{4}{|c|}{ Paraguay } & \multicolumn{4}{|c|}{ Peru } & \multicolumn{4}{|c|}{ Uruguay } & \multicolumn{4}{|c|}{ Venezuela } \\
\hline & & $\begin{array}{c}(1) \\
\text { growth }\end{array}$ & $\begin{array}{l}(2) \\
\mathrm{dtb}\end{array}$ & $\begin{array}{c}(3) \\
\text { dlnreer }\end{array}$ & & $\begin{array}{c}(1) \\
\text { growth }\end{array}$ & $\begin{array}{c}(2) \\
\mathrm{dtb2} \\
\end{array}$ & $\begin{array}{c}\text { (3) } \\
\text { dlnreer }\end{array}$ & & $\begin{array}{c}(1) \\
\text { growth }\end{array}$ & $\begin{array}{l}(2) \\
\mathrm{dtb}\end{array}$ & $\begin{array}{c}\text { (3) } \\
\text { dlnreer }\end{array}$ & & $\begin{array}{c}(1) \\
\text { growth }\end{array}$ & $\begin{array}{l}(2) \\
\mathrm{dtb} \\
\end{array}$ & $\begin{array}{c}(3) \\
\text { dlnreer }\end{array}$ & & $\begin{array}{c}(1) \\
\text { growth }\end{array}$ & $\begin{array}{l}(2) \\
d t b \\
\end{array}$ & $\begin{array}{c}(3) \\
\text { dlnreer }\end{array}$ \\
\hline \multirow{2}{*}{\multicolumn{2}{|c|}{ L.growth }} & -0.079 & $-0.073^{* *}$ & $-1.074+$ & & $-0.273^{* *}$ & $-0.166^{*}$ & 0.193 & & $0.234^{\star \star}$ & $-0.109^{* * *}$ & $0.607^{* * *}$ & & $0.221+$ & -0.009 & 0 & & -0.135 & $-0.119^{* \star *}$ & 0.289 \\
\hline & & -0.127 & -0.029 & -0.733 & & -0.123 & -0.089 & -0.181 & & -0.101 & -0.031 & -0.171 & & -0.148 & -0.064 & 0 & & -0.102 & -0.034 & -0.226 \\
\hline \multirow{2}{*}{\multicolumn{2}{|c|}{ L2. growth }} & 0.015 & $-0.122^{* * *}$ & 0.728 & & -0.147 & -0.067 & -0.208 & & -0.093 & -0.01 & -0.178 & & 0.106 & 0.02 & 0 & & $-0.332^{* * *}$ & -0.045 & 0.33 \\
\hline & & -0.104 & -0.024 & -0.571 & & -0.127 & -0.092 & -0.187 & & -0.11 & -0.034 & -0.187 & & -0.128 & -0.056 & 0 & & -0.109 & -0.037 & -0.247 \\
\hline \multirow{2}{*}{\multicolumn{2}{|c|}{ L.dtb }} & 0.16 & $0.621^{\star \star \star}$ & 0 & & -0.249 & $0.465^{\star \star \star}$ & -0.262 & & -0.511 & $0.704^{\text {***}}$ & 0.032 & & 0 & $0.309^{* *}$ & -0.299 & & $-1.025^{\star \star \star *}$ & $0.762^{* \star *}$ & 0.135 \\
\hline $2 \pi+b$ & & -0.376 & -0.095 & 0 & & -0.19 & -0.13 & -0.28 & & -0.392 & -0.122 & -0.665 & & 0 & -0.139 & -1.141 & & -0.356 & -0.12 & -0.794 \\
\hline & 0.195 & -0.113 & 0 & & 0.147 & $0.180+$ & 0.046 & & 0.213 & $-0.258^{* *}$ & 0.048 & & $-0.000^{*}$ & $0.225^{*}$ & -0.961 & & $0.967^{* * *}$ & $-0.239^{\star *}$ & 0.626 \\
\hline & & -0.338 & -0.086 & 0 & & -0.172 & -0.125 & -0.254 & & -0.355 & -0.108 & -0.602 & & 0 & -0.126 & -0.932 & & -0.324 & -0.109 & -0.719 \\
\hline L.dlnreer & & $0.102^{* \star *}$ & -0.006 & 0.099 & & -0.035 & -0.005 & $0.287^{\star *}$ & & -0.019 & -0.001 & $0.223^{\star *}$ & & -0.002 & $-0.042^{* *}$ & 0.097 & & -0.034 & $-0.033^{*}$ & 0.017 \\
\hline & & -0.021 & -0.005 & -0.126 & & -0.085 & -0.061 & -0.126 & & -0.066 & -0.02 & -0.111 & & -0.058 & -0.021 & -0.152 & & -0.054 & -0.018 & -0.121 \\
\hline L2.dlnreer & & 0.027 & 0.002 & -0.057 & & 0.004 & 0.07 & $-0.181+$ & & 0.029 & -0.025 & $-0.181^{*}$ & & -0.021 & 0.023 & 0.077 & & 0.071 & -0.021 & 0.097 \\
\hline & & -0.023 & -0.005 & -0.134 & & -0.081 & -0.058 & -0.119 & & -0.056 & -0.017 & -0.094 & & -0.055 & -0.02 & -0.153 & & -0.055 & -0.019 & -0.124 \\
\hline wgdp_gr & LO & $0.975^{\star \star \star}$ & -0.022 & $2.524+$ & LO & 0.842 & -0.257 & 1.527 & LO & 0.151 & $0.221^{*}$ & $-1.587^{\star *}$ & LO & $1.672^{\star \star \star}$ & $0.382+$ & 0 & L1 & 0.882 & 0.163 & 0.812 \\
\hline (3) & & -0.288 & -0.062 & -1.729 & & -0.786 & -0.518 & -1.159 & & -0.423 & -0.126 & -0.717 & & -0.612 & -0.235 & 0 & & -1.201 & -0.385 & -2.54 \\
\hline & L1 & $0.833^{* *}$ & 0.046 & -1.353 & L1 & 0.855 & 0.371 & -1.1 & & & & & L1 & -0.645 & $-0.623^{* *}$ & 0 & L2 & -0.195 & 0.34 & -2.636 \\
\hline & & -0.331 & -0.076 & -1.976 & & -0.845 & -0.591 & -1.244 & & & & & & -0.635 & -0.26 & 0 & & -1.142 & -0.384 & -2.539 \\
\hline & L2 & -0.103 & $0.216^{\star * *}$ & -1.143 & L2 & -0.521 & 0.259 & 0.602 & & & & & & & & & & & & \\
\hline & & -0.36 & -0.083 & -2.113 & & -0.839 & -0.599 & -1.235 & & & & & & & & & & & & \\
\hline & & & & & L3 & 0.74 & -0.328 & 0.106 & & & & & & & & & & & & \\
\hline & & & & & & -0.726 & -0.52 & -1.069 & & & & & & & & & & & & \\
\hline vix & LO & 0.007 & 0 & $-0.139+$ & L1 & -0.024 & 0 & -0.045 & L1 & $-0.043^{*}$ & 0 & -0.018 & LO & -0.024 & $0.000^{* *}$ & -0.106 & LO & $-0.116^{*}$ & 0 & 0 \\
\hline & & -0.015 & 0 & -0.092 & & -0.053 & 0 & -0.078 & & -0.024 & 0 & -0.039 & & -0.039 & 0 & -0.11 & & -0.061 & 0 & 0 \\
\hline energy & LO & 0.001 & $0.008^{\star \star *}$ & 0.036 & L2 & 0.004 & -0.007 & -0.025 & L1 & $0.031^{* *}$ & -0.001 & -0.017 & LO & $-0.049^{*}$ & -0.01 & $0.131+$ & L1 & $0.089^{*}$ & 0.019 & -0.072 \\
\hline & & -0.01 & -0.002 & -0.057 & & -0.032 & -0.023 & -0.046 & & -0.015 & -0.005 & -0.026 & & -0.028 & -0.01 & -0.084 & & -0.049 & -0.017 & -0.11 \\
\hline & L1 & $0.015+$ & $-0.003+$ & 0.056 & L3 & -0.037 & $-0.037+$ & 0.065 & & & & & L1 & $0.062^{\star *}$ & 0.009 & $-0.133^{*}$ & L2 & 0.066 & -0.008 & $0.186^{*}$ \\
\hline & & -0.009 & -0.002 & -0.054 & & -0.032 & -0.023 & -0.047 & & & & & & -0.029 & -0.011 & -0.076 & & -0.05 & -0.017 & -0.11 \\
\hline & L2 & -0.01 & $0.005^{\star \star}$ & 0.027 & L4 & $-0.055^{*}$ & 0.021 & -0.058 & & & & & L2 & -0.034 & $-0.018+$ & 0.06 & L3 & -0.015 & 0.01 & 0.026 \\
\hline & & -0.01 & -0.002 & -0.057 & & -0.029 & -0.021 & -0.043 & & & & & & -0.03 & -0.011 & -0.078 & & -0.049 & -0.017 & -0.11 \\
\hline & & & & & & & & & & & & & & & & & L4 & $0.102^{\star *}$ & $-0.025^{*}$ & 0.034 \\
\hline & & & & & & & & & & & & & & & & & & -0.043 & -0.015 & -0.097 \\
\hline food & & & & & LO & 0.018 & 0.024 & 0.098 & & & & & L3 & 0.074 & -0.005 & $0.267+$ & LO & $0.140+$ & $0.047+$ & $-0.576^{* * *}$ \\
\hline & & & & & & -0.058 & -0.042 & -0.086 & & & & & & -0.06 & -0.022 & -0.18 & & -0.091 & -0.031 & -0.203 \\
\hline & & & & & L1 & 0.076 & 0.03 & $0.246^{* * *}$ & & & & & L4 & 0.006 & 0.023 & $-0.267+$ & L1 & -0.115 & -0.009 & $-0.313+$ \\
\hline & & & & & & -0.058 & -0.042 & -0.086 & & & & & & -0.055 & -0.02 & -0.171 & & $-0 . c$ & -0.032 & -0.213 \\
\hline & & & & & L2 & 0.008 & $-0.071+$ & 0.079 & & & & & & & & & L2 & -0.018 & 0.046 & -0.264 \\
\hline & & & & & $2<$ & -0.067 & -0.047 & -0.098 & & & & & & & & & 26 & -0.095 & -0.033 & -0.215 \\
\hline & & & & & L3 & $0.103^{*}$ & 0.023 & $0.143+$ & & & & & & & & & L3 & 0.089 & $-0.062^{*}$ & -0.045 \\
\hline & & & & & & -0.062 & -0.045 & -0.091 & & & & & & & & & & -0.094 & -0.032 & -0.211 \\
\hline & & & & & L4 & 0.08 & 0.014 & -0.042 & & & & & & & & & & & & \\
\hline & & & & & & -0.064 & -0.046 & -0.094 & & & & & & & & & & & & \\
\hline metals & & & & & & & & & LO & $\begin{array}{c}0.055^{* *} \\
-0.023\end{array}$ & $\begin{array}{l}0.016^{* *} \\
-0.007\end{array}$ & $\begin{array}{l}0.070^{*} \\
-0.039\end{array}$ & & & & & & & & \\
\hline dprbal & L2 & $-1.470^{* *}$ & $-0.272+$ & -3.194 & L4 & -0.874 & 0.036 & -0.518 & L2 & -0.175 & -0.004 & 0.193 & L2 & -0.51 & $-0.000^{* * *}$ & $0.000^{* *}$ & L3 & -0.206 & 0.147 & -0.972 \\
\hline & & -0.723 & -0.166 & -4.294 & & -0.666 & -0.46 & -0.982 & & -0.367 & -0.112 & -0.623 & & -0.927 & 0 & 0 & & -0.324 & -0.11 & -0.726 \\
\hline Constant & & $-0.806+$ & -0.076 & 2.832 & & 0.126 & 0.179 & 0.1 & & $1.812^{\star \star}$ & 0.015 & 0.929 & & 0.421 & 0.223 & 2.365 & & 2.343 & -0.175 & 1.739 \\
\hline & & -0.55 & -0.069 & -3.352 & & -1.914 & -0.515 & -2.842 & & -0.734 & -0.114 & -1.211 & & -1.222 & -0.175 & -2.652 & & -2.023 & -0.319 & -2.108 \\
\hline Observatior & & 88 & 88 & 88 & & 6 & 69 & 69 & & 7 & 77 & 77 & & 42 & 42 & 42 & & 73 & 73 & 73 \\
\hline df_E & & & & 14 & & $2 C$ & & & & 11 & 11 & 11 & & 13 & 13.0 & 13 & & 18 & 18.3 & 18.3 \\
\hline r2_-3 & & 0.16 & 0.16 & 0.16 & & 0.40 & 0.40 & 0.40 & & 0.29 & 0.29 & 0.2 & & 0.23 & 0.23 & 0.2 & & 0.28 & 0.28 & 0.28 \\
\hline r2_2 & & 0.73 & 0.73 & 0.73 & & 0.44 & 0.44 & 0.44 & & 0.64 & 0.64 & 0.6 & & 0.51 & 0.51 & 0.51 & & 0.74 & 0.74 & 0.74 \\
\hline$r 2-1$ & & 0.57 & 0.57 & 0.57 & & 0.2 & 0.2 & 0.2 & & 0.30 & 0.30 & 0.30 & & 0.35 & 0.35 & 0.35 & & 0.37 & 0.37 & 0.37 \\
\hline aic & & 9.3 & 9.3 & 9.3 & & 14.9 & 14.9 & 14.9 & & 9.7 & 9.7 & 9.7 & & 13.2 & 13.2 & 13.2 & & 16.7 & 16.7 & 16.7 \\
\hline
\end{tabular}

\section{CInternational Monetary Fund. Not for Redistribution}


Table A2.

Estimation of Country Sovereign Spreads - OLS

\begin{tabular}{|c|c|c|c|c|c|c|c|}
\hline & (1) & (2) & (3) & (4) & (5) & (6) & (7) \\
\hline VARIABLES & & & dembispread & & & & \\
\hline L.dca & $\begin{array}{r}-11.097 \\
(9.024)\end{array}$ & & & & & & \\
\hline L.ded & $\begin{array}{c}1.262 \\
(5.966)\end{array}$ & $\begin{array}{c}0.155 \\
(5.895)\end{array}$ & & & & & \\
\hline L.dpb & $\begin{array}{c}-3.679 \\
(11.681)\end{array}$ & $\begin{array}{c}-4.580 \\
(12.038)\end{array}$ & $\begin{array}{c}-4.586 \\
(11.976)\end{array}$ & & & & \\
\hline L.dpd & $\begin{array}{c}18.846^{*} \\
(10.588)\end{array}$ & $\begin{array}{c}18.623^{\star} \\
(10.579)\end{array}$ & $\begin{array}{l}18.721^{*} \\
(9.753)\end{array}$ & $\begin{array}{l}18.737^{*} \\
(9.749)\end{array}$ & $\begin{array}{c}19.655^{\star \star} \\
(9.720)\end{array}$ & $\begin{array}{c}11.780 \\
(19.503)\end{array}$ & $\begin{array}{c}14.275 \\
(19.194)\end{array}$ \\
\hline L.dfxresy & $\begin{array}{c}-8.522^{\star \star \star} \\
(3.190)\end{array}$ & $\begin{array}{c}-8.633^{\star \star *} \\
(3.178)\end{array}$ & $\begin{array}{c}-8.625^{\star \star *} \\
(3.052)\end{array}$ & $\begin{array}{c}-8.807^{\star \star *} \\
(3.012)\end{array}$ & & $\begin{array}{c}-9.024^{* * *} \\
(3.163)\end{array}$ & \\
\hline dlnreer & $\begin{array}{c}-6.596^{* *} \\
(2.628)\end{array}$ & $\begin{array}{c}-6.592^{\star *} \\
(2.627)\end{array}$ & $\begin{array}{l}-6.591^{\star *} \\
(2.609)\end{array}$ & $\begin{array}{c}-6.587^{\star *} \\
(2.607)\end{array}$ & $\begin{array}{c}-6.620^{\star *} \\
(2.627)\end{array}$ & $\begin{array}{c}-6.677^{\star *} \\
(2.601)\end{array}$ & $\begin{array}{c}-6.691^{\star *} \\
(2.619)\end{array}$ \\
\hline dvix & $\begin{array}{l}5.187^{\star \star} \\
(2.415)\end{array}$ & $\begin{array}{l}5.108^{\star *} \\
(2.318)\end{array}$ & $\begin{array}{l}5.111^{\star *} \\
(2.317)\end{array}$ & $\begin{array}{l}5.159^{\star *} \\
(2.323)\end{array}$ & $\begin{array}{l}4.867^{\star \star} \\
(2.391)\end{array}$ & $\begin{array}{l}5.165^{\star \star} \\
(2.334)\end{array}$ & $\begin{array}{l}4.866^{\star \star} \\
(2.398)\end{array}$ \\
\hline _lifsXdvi_213 & $\begin{array}{c}12.907^{* *} \\
(5.332)\end{array}$ & $\begin{array}{c}12.960^{\star *} \\
(5.289)\end{array}$ & $\begin{array}{c}12.955^{\star *} \\
(5.257)\end{array}$ & $\begin{array}{c}12.907^{\star *} \\
(5.261)\end{array}$ & $\begin{array}{c}13.229^{* *} \\
(5.289)\end{array}$ & $\begin{array}{c}12.840^{* *} \\
(5.214)\end{array}$ & $\begin{array}{c}13.183^{* *} \\
(5.248)\end{array}$ \\
\hline _lifsXdvi_223 & $\begin{array}{c}3.706 \\
(3.405)\end{array}$ & $\begin{array}{c}3.832 \\
(3.340)\end{array}$ & $\begin{array}{c}3.831 \\
(3.343)\end{array}$ & $\begin{array}{c}3.772 \\
(3.332)\end{array}$ & $\begin{array}{c}3.935 \\
(3.356)\end{array}$ & $\begin{array}{c}3.727 \\
(3.343)\end{array}$ & $\begin{array}{c}3.903 \\
(3.364)\end{array}$ \\
\hline _lifsXdvi228 & $\begin{array}{l}-3.484 \\
(2.443)\end{array}$ & $\begin{array}{l}-3.280 \\
(2.360)\end{array}$ & $\begin{array}{l}-3.282 \\
(2.364)\end{array}$ & $\begin{array}{l}-3.444+ \\
(2.333)\end{array}$ & $\begin{array}{l}-3.295 \\
(2.391)\end{array}$ & $\begin{array}{r}-3.455+ \\
(2.344)\end{array}$ & $\begin{array}{l}-3.301 \\
(2.399)\end{array}$ \\
\hline _lifsXdvi_233 & $\begin{array}{c}2.559 \\
(2.702)\end{array}$ & $\begin{array}{c}2.632 \\
(2.618)\end{array}$ & $\begin{array}{c}2.630 \\
(2.619)\end{array}$ & $\begin{array}{c}2.607 \\
(2.623)\end{array}$ & $\begin{array}{c}2.885 \\
(2.680)\end{array}$ & $\begin{array}{c}2.555 \\
(2.634)\end{array}$ & $\begin{array}{c}2.850 \\
(2.687)\end{array}$ \\
\hline _lifsXdvi_243 & $\begin{array}{l}7.957^{*} \\
(4.662)\end{array}$ & $\begin{array}{l}8.141^{*} \\
(4.620)\end{array}$ & $\begin{array}{l}8.139^{*} \\
(4.618)\end{array}$ & $\begin{array}{l}8.094^{*} \\
(4.630)\end{array}$ & $\begin{array}{l}8.330 * \\
(4.698)\end{array}$ & $\begin{array}{l}8.063^{*} \\
(4.650)\end{array}$ & $\begin{array}{l}8.311^{*} \\
(4.713)\end{array}$ \\
\hline _lifsXdvi_248 & $\begin{array}{c}18.641^{* * *} \\
(6.207)\end{array}$ & $\begin{array}{c}18.657^{\star * \star} \\
(6.215)\end{array}$ & $\begin{array}{c}18.654^{\star * \star} \\
(6.212)\end{array}$ & $\begin{array}{c}18.602^{\star * *} \\
(6.197)\end{array}$ & $\begin{array}{c}18.697^{\star \star \star} \\
(6.249)\end{array}$ & $\begin{array}{c}18.615^{\star * *} \\
(6.189)\end{array}$ & $\begin{array}{c}18.708^{\star * *} \\
(6.243)\end{array}$ \\
\hline _lifsXdvi_273 & $\begin{array}{l}-0.738 \\
(2.601)\end{array}$ & $\begin{array}{l}-0.630 \\
(2.510)\end{array}$ & $\begin{array}{l}-0.633 \\
(2.515)\end{array}$ & $\begin{array}{l}-0.680 \\
(2.513)\end{array}$ & $\begin{array}{l}-0.419 \\
(2.572)\end{array}$ & $\begin{array}{l}-0.699 \\
(2.521)\end{array}$ & $\begin{array}{l}-0.428 \\
(2.578)\end{array}$ \\
\hline _lifsXdvi_293 & $\begin{array}{c}2.649 \\
(2.616)\end{array}$ & $\begin{array}{c}2.818 \\
(2.537)\end{array}$ & $\begin{array}{c}2.817 \\
(2.537)\end{array}$ & $\begin{array}{c}2.731 \\
(2.543)\end{array}$ & $\begin{array}{c}3.095 \\
(2.611)\end{array}$ & $\begin{array}{c}2.689 \\
(2.555)\end{array}$ & $\begin{array}{c}3.069 \\
(2.619)\end{array}$ \\
\hline _lifsXdvi_298 & $\begin{array}{c}2.627 \\
(2.674)\end{array}$ & $\begin{array}{c}2.750 \\
(2.588)\end{array}$ & $\begin{array}{c}2.745 \\
(2.582)\end{array}$ & $\begin{array}{c}2.704 \\
(2.588)\end{array}$ & $\begin{array}{c}3.048 \\
(2.664)\end{array}$ & $\begin{array}{c}2.696 \\
(2.600)\end{array}$ & $\begin{array}{c}3.048 \\
(2.674)\end{array}$ \\
\hline _lifsXdvi_299 & $\begin{array}{c}10.880^{* *} \\
(4.334)\end{array}$ & $\begin{array}{c}10.694^{\star *} \\
(4.272)\end{array}$ & $\begin{array}{c}10.692^{\star *} \\
(4.270)\end{array}$ & $\begin{array}{c}10.633^{\star *} \\
(4.273)\end{array}$ & $\begin{array}{c}11.039^{\star *} \\
(4.291)\end{array}$ & $\begin{array}{c}10.595^{\star \star} \\
(4.279)\end{array}$ & $\begin{array}{c}11.017^{* *} \\
(4.294)\end{array}$ \\
\hline L.dpd_sq & & & & & & $\begin{array}{c}0.039 \\
(0.103)\end{array}$ & $\begin{array}{c}0.030 \\
(0.102)\end{array}$ \\
\hline Observations & 2,990 & 2,990 & 2,990 & 2,990 & 2,990 & 2,990 & 2,990 \\
\hline R-squared & 0.148 & 0.147 & 0.147 & 0.147 & 0.145 & 0.147 & 0.145 \\
\hline $\mathrm{N}$ & 2990 & 2990 & 2990 & 2990 & 2990 & 2990 & 2990 \\
\hline r2_o & . & . & . & . & . & . & . \\
\hline r2_w & . & . & . & . & . & . & . \\
\hline r2_b & . & . & . & . & . & . & . \\
\hline $\mathrm{F}$ & 24.88 & 25.43 & 26.30 & 27.34 & 29.29 & 26.33 & 28.08 \\
\hline
\end{tabular}

